\title{
Interventions for treating tuberculous pericarditis (Review)
}

Wiysonge CS, Ntsekhe M, Thabane L, Volmink J, Majombozi D, Gumedze F, Pandie S, Mayosi BM

Wiysonge CS, Ntsekhe M, Thabane L, Volmink J, Majombozi D, Gumedze F, Pandie S, Mayosi BM. Interventions for treating tuberculous pericarditis.

Cochrane Database of Systematic Reviews 2017, Issue 9. Art. No.: CD000526.

DOI: 10.1002/14651858.CD000526.pub2.

www.cochranelibrary.com 
TABLE OF CONTENTS

HEADER

ABSTRACT

PLAIN LANGUAGE SUMMARY

SUMMARY OF FINDINGS

2

BACKGROUND

OBJECTIVES

METHODS

RESULTS

Figure 1.

Figure 2.

Figure 3.

DISCUSSION

AUTHORS' CONCLUSIONS

ACKNOWLEDGEMENTS

REFERENCES

CHARACTERISTICS OF STUDIES

DATA AND ANALYSES

Analysis 1.1. Comparison 1 Steroids versus placebo in HIV-negative people, Outcome 1 Deaths from all causes.

Analysis 1.2. Comparison 1 Steroids versus placebo in HIV-negative people, Outcome 2 Deaths from pericarditis.

Analysis 1.3. Comparison 1 Steroids versus placebo in HIV-negative people, Outcome 3 Constrictive pericarditis.

Analysis 1.4. Comparison 1 Steroids versus placebo in HIV-negative people, Outcome 4 Repeat pericardiocentesis.

Analysis 1.5. Comparison 1 Steroids versus placebo in HIV-negative people, Outcome 5 Cancer.

Analysis 1.6. Comparison 1 Steroids versus placebo in HIV-negative people, Outcome 6 Hospitalization.

Analysis 1.7. Comparison 1 Steroids versus placebo in HIV-negative people, Outcome 7 Pericardiectomy.

Analysis 1.8. Comparison 1 Steroids versus placebo in HIV-negative people, Outcome 8 Opportunistic infections.

Analysis 2.1. Comparison 2 Steroids versus placebo in HIV-positive people, Outcome 1 Deaths from all causes.

Analysis 2.2. Comparison 2 Steroids versus placebo in HIV-positive people, Outcome 2 Deaths from pericarditis.

Analysis 2.3. Comparison 2 Steroids versus placebo in HIV-positive people, Outcome 3 Constrictive pericarditis.

Analysis 2.4. Comparison 2 Steroids versus placebo in HIV-positive people, Outcome 4 Repeat pericardiocentesis.

Analysis 2.5. Comparison 2 Steroids versus placebo in HIV-positive people, Outcome 5 Cancer.

Analysis 2.6. Comparison 2 Steroids versus placebo in HIV-positive people, Outcome 6 Hospitalization.

Analysis 2.7. Comparison 2 Steroids versus placebo in HIV-positive people, Outcome 7 Pericardiectomy.

Analysis 2.8. Comparison 2 Steroids versus placebo in HIV-positive people, Outcome 8 Opportunistic infections.

Analysis 3.1. Comparison 3 Colchicine versus placebo in HIV-positive people, Outcome 1 Death from all causes.

Analysis 3.2. Comparison 3 Colchicine versus placebo in HIV-positive people, Outcome 2 Constrictive pericarditis. .................

Analysis 4.1. Comparison $4 \mathrm{M}$. indicus pranii versus placebo in HIV-negative people, Outcome 1 Deaths from all causes. ........

Analysis 4.2. Comparison $4 \mathrm{M}$. indicus pranii versus placebo in HIV-negative people, Outcome 2 Deaths from pericarditis. .......

Analysis 4.3. Comparison $4 \mathrm{M}$. indicus pranii versus placebo in HIV-negative people, Outcome 3 Constrictive pericarditis. .......

Analysis 4.4. Comparison $4 \mathrm{M}$. indicus pranii versus placebo in HIV-negative people, Outcome 4 Repeat pericardiocentesis. ....

Analysis 4.5. Comparison $4 \mathrm{M}$. indicus pranii versus placebo in HIV-negative people, Outcome 5 Cancer.

Analysis 4.6. Comparison $4 \mathrm{M}$. indicus pranii versus placebo in HIV-negative people, Outcome 6 Hospitalization. ....................

Analysis 4.7. Comparison $4 \mathrm{M}$. indicus pranii versus placebo in HIV-negative people, Outcome 7 Opportunistic infections. .......

Analysis 5.1. Comparison $5 \mathrm{M}$. indicus pranii versus placebo in HIV-positive people, Outcome 1 Deaths from all causes. .........

Analysis 5.2. Comparison 5 M. indicus pranii versus placebo in HIV-positive people, Outcome 2 Deaths from pericarditis. ........

Analysis 5.3. Comparison $5 \mathrm{M}$. indicus pranii versus placebo in HIV-positive people, Outcome 3 Constrictive pericarditis. .......

Analysis 5.4. Comparison $5 \mathrm{M}$. indicus pranii versus placebo in HIV-positive people, Outcome 4 Repeat pericardiocentesis. .....

Analysis 5.5. Comparison $5 \mathrm{M}$. indicus pranii versus placebo in HIV-positive people, Outcome 5 Cancer.

Analysis 5.6. Comparison $5 \mathrm{M}$. indicus pranii versus placebo in HIV-positive people, Outcome 6 Hospitalization.

4 
Analysis 6.2. Comparison 6 Surgical drainage versus no intervention in HIV-negative people, Outcome 2 Death from pericarditis.

Analysis 6.3. Comparison 6 Surgical drainage versus no intervention in HIV-negative people, Outcome 3 Repeat pericardiocentesis.

Analysis 6.4. Comparison 6 Surgical drainage versus no intervention in HIV-negative people, Outcome 4 Pericardiectomy. ...... 
[Intervention Review]

\section{Interventions for treating tuberculous pericarditis}

Charles S Wiysonge1,2, Mpiko Ntsekhe², Lehana Thabane ${ }^{4}$, Jimmy Volmink², Dumisani Majombozi², Freedom Gumedze ${ }^{5}$, Shaheen Pandie6, Bongani M Mayosi6

${ }^{1}$ Cochrane South Africa, South African Medical Research Council, Cape Town, South Africa. ${ }^{2}$ Centre for Evidence-based Health Care, Faculty of Medicine and Health Sciences, Stellenbosch University, Cape Town, South Africa. ${ }^{3}$ Division of Cardiology, Groote Schuur Hospital, Cape Town, South Africa. ${ }^{4}$ Department of Clinical Epidemiology and Biostatistics, McMaster University, Hamilton, Canada. ${ }^{5}$ Department of Statistical Sciences, University of Cape Town, Cape Town, South Africa. ${ }^{6}$ Department of Medicine, University of Cape Town, Cape Town, South Africa

Contact address: Bongani M Mayosi, Department of Medicine, University of Cape Town, Cape Town, South Africa. bongani.mayosi@uct.ac.za.

Editorial group: Cochrane Infectious Diseases Group.

Publication status and date: Unchanged, published in Issue 9, 2017.

Citation: Wiysonge CS, Ntsekhe M, Thabane L, Volmink J, Majombozi D, Gumedze F, Pandie S, Mayosi BM. Interventions for treating tuberculous pericarditis. Cochrane Database of Systematic Reviews 2017, Issue 9. Art. No.: CD000526. DOI: 10.1002/14651858.CD000526.pub2.

Copyright $\odot 2017$ The Authors. Cochrane Database of Systematic Reviews published by John Wiley \& Sons, Ltd. on behalf of The Cochrane Collaboration. This is an open access article under the terms of the Creative Commons Attribution-Non-Commercial Licence, which permits use, distribution and reproduction in any medium, provided the original work is properly cited and is not used for commercial purposes.

\section{A B S T R A C T}

\section{Background}

Tuberculous pericarditis can impair the heart's function and cause death; long term, it can cause the membrane to fibrose and constrict causing heart failure. In addition to antituberculous chemotherapy, treatments include corticosteroids, drainage, and surgery.

\section{Objectives}

To assess the effects of treatments for tuberculous pericarditis.

\section{Search methods}

We searched the Cochrane Infectious Diseases Group Specialized Register (27 March 2017); the Cochrane Central Register of Controlled Trials (CENTRAL), published in the Cochrane Library (2017, Issue 2); MEDLINE (1966 to 27 March 2017); Embase (1974 to 27 March 2017 ); and LILACS (1982 to 27 March 2017). In addition we searched the metaRegister of Controlled Trials (mRCT) and the World Health Organization (WHO) International Clinical Trials Registry Platform (ICTRP) search portal using 'tuberculosis' and 'pericard*' as search terms on 27 March 2017. We searched ClinicalTrials.gov and contacted researchers in the field of tuberculous pericarditis. This is a new version of the original 2002 review.

\section{Selection criteria}

We included randomized controlled trials (RCTs) and quasi-RCTs.

\section{Data collection and analysis}

Two review authors independently screened search outputs, evaluated study eligibility, assessed risk of bias, and extracted data; and we resolved any discrepancies by discussion and consensus. One trial assessed the effects of both corticosteroid and Mycobacterium indicus pranii treatment in a two-by-two factorial design; we excluded data from the group that received both interventions. We conducted fixedeffect meta-analysis and assessed the certainty of the evidence using the GRADE approach. 


\section{Main results}

Seven trials met the inclusion criteria; all were from sub-Saharan Africa and included 1959 participants, with 1051/1959 (54\%) HIV-positive. All trials evaluated corticosteroids and one each evaluated colchicine, $M$. indicus pranii immunotherapy, and open surgical drainage. Four trials (1841 participants) were at low risk of bias, and three trials (118 participants) were at high risk of bias.

In people who are not infected with HIV, corticosteroids may reduce deaths from all causes (risk ratio (RR) $0.80,95 \%$ confidence interval (CI) 0.59 to $1.09 ; 660$ participants, 4 trials, low certainty evidence) and the need for repeat pericardiocentesis (RR $0.85,95 \% \mathrm{Cl} 0.70$ to $1.04 ; 492$ participants, 2 trials, low certainty evidence). Corticosteroids probably reduce deaths from pericarditis (RR $0.39,95 \% \mathrm{Cl} 0.19$ to $0.80 ; 660$ participants, 4 trials, moderate certainty evidence). However, we do not know whether or not corticosteroids have an effect on constriction or cancer among HIV-negative people (very low certainty evidence).

In people living with HIV, only $19.9 \%$ (203/1959) were on antiretroviral drugs. Corticosteroids may reduce constriction (RR 0.55 , 0.26 to 1.16 ; 575 participants, 3 trials, low certainty evidence). It is uncertain whether corticosteroids have an effect on all-cause death or cancer (very low certainty evidence); and may have little or no effect on repeat pericardiocentesis (RR 1.02, 0.89 to 1.18; 517 participants, 2 trials, low certainty evidence).

For colchicine among people living with HIV, we found one small trial (33 participants) which had insufficient data to make any conclusions about any effects on death or constrictive pericarditis.

Irrespective of HIV status, due to very low certainty evidence from one trial, it is uncertain whether adding $M$. indicus pranii immunotherapy to antituberculous drugs has an effect on any outcome.

Open surgical drainage for effusion may reduce repeat pericardiocentesis In HIV-negative people (RR $0.23,95 \% \mathrm{Cl} 0.07$ to $0.76 ; 122$ participants, 1 trial, low certainty evidence) but may make little or no difference to other outcomes. We did not find an eligible trial that assessed the effects of open surgical drainage in people living with HIV.

The review authors found no eligible trials that examined the length of antituberculous treatment needed nor the effects of other adjunctive treatments for tuberculous pericarditis.

\section{Authors' conclusions}

For HIV-negative patients, corticosteroids may reduce death. For HIV-positive patients not on antiretroviral drugs, corticosteroids may reduce constriction. For HIV-positive patients with good antiretroviral drug viral suppression, clinicians may consider the results from HIVnegative patients more relevant.

Further research may help evaluate percutaneous drainage of the pericardium under local anaesthesia, the timing of pericardiectomy in tuberculous constrictive pericarditis, and new antibiotic regimens.

2 April 2019

Up to date

All studies incorporated from most recent search

All eligible published studies found in the last search (27 Mar, 2017) were included and one ongoing study was identified (see 'Characteristics of ongoing studies' section)

\section{PLAIN LANGUAGE SUMMARY}

\section{Treatment for tuberculosis infection of the membrane around the heart}

\section{What is the issue?}

Tuberculosis infection of the pericardium surrounding the heart is uncommon but life-threatening.

\section{What is the aim of this review?}

The aim of this Cochrane Review was to assess the effects of treatments for people with tuberculous pericarditis.

\section{What is this important?}

Doctors prescribe antituberculous drugs for six months, drain fluid from the pericardium if the patient has heart failure, and sometimes remove the pericardium if it is thick and making the patient ill and sometimes give corticosteroids to reduce the effects of the inflammation.

\section{What are the main results of the review?}


Cochrane researchers collected and examined all potentially relevant studies and found seven trials, all conducted in sub-Saharan Africa. Six trials evaluated corticosteroids. Other treatments evaluated included Mycobacterium indicus pranii immunotherapy, colchicine, and surgical removal of fluid under general anaesthesia. This review is a new edition of the 2002 review.

In people not infected with HIV, six trials found that additional steroids may reduce deaths overall (low certainty evidence) and probably reduce deaths caused by pericarditis (moderate certainty evidence). Steroids may prevent reaccumulation of fluid in the pericardial space (low certainty evidence). However, we do not know whether or not corticosteroids have an effect on constriction or cancer among HIVnegative people (very low certainty evidence).

In people living with HIV, most people evaluated in the included trials were not on antiretroviral drugs. For these patients, corticosteroids may reduce constrictive pericarditis (low certainty evidence), but we do not know if this translates into a reduction in the number of deaths or cancer (very low certainty evidence). Corticosteroids may have little or no effect on reaccumulation of fluid in the pericardial space (low certainty evidence).

Colchicine was evaluated in one trial of 33 people, with insufficient data to make any conclusions about an effect.

Based on one trial, it is uncertain whether adding M. indicus pranii immunotherapy to antituberculous drugs has an effect on any outcome in people with tuberculous pericarditis regardless of their HIV status (very low certainty evidence).

Open surgical drainage of the fluid accumulating between the heart and the membrane using general anaesthesia may be associated with less life-threatening reaccumulation of fluid in people who are not infected with HIV, but conclusions are not possible as the number of participants studied was too small. We did not find an eligible trial that assessed the effects of open surgical drainage in people living with HIV.

The review authors found no eligible trials that examined the length of antituberculous treatment needed nor the effects of other adjunctive treatments for tuberculous pericarditis.

\section{How up-to-date is this review?}

The review authors searched for trials published up to 27 March 2017. 


\section{SUMMARY OF FINDINGS}

\section{Summary of findings for the main comparison. Corticosteroids for tuberculous pericarditis in HIV-negative people}

Population: HIV-negative people with tuberculous pericarditis

Settings: any setting

Intervention: corticosteroids

Comaprison: placebo

\begin{tabular}{|c|c|c|c|c|c|c|}
\hline \multirow[t]{2}{*}{ Outcomes } & \multicolumn{2}{|c|}{$\begin{array}{l}\text { Illustrative comparative risks } \\
(95 \% \mathrm{Cl})\end{array}$} & \multirow[t]{2}{*}{$\begin{array}{l}\text { Relative effect } \\
(95 \% \mathrm{CI})\end{array}$} & \multirow{2}{*}{$\begin{array}{l}\text { Number of par- } \\
\text { ticipants } \\
\text { (trials) }\end{array}$} & \multirow{2}{*}{$\begin{array}{l}\text { Certainty of } \\
\text { the evidence } \\
\text { (GRADE) }\end{array}$} & \multirow[t]{2}{*}{ Comments } \\
\hline & Placebo & Steroids & & & & \\
\hline $\begin{array}{l}\text { Death from all } \\
\text { causes }\end{array}$ & 22 per 100 & $\begin{array}{l}18 \text { per } 100 \\
(13 \text { to } 24)\end{array}$ & $\begin{array}{l}\text { RR } 0.80 \\
\text { (0.59 to } 1.09)\end{array}$ & $\begin{array}{l}660 \\
(4 \text { trials })\end{array}$ & $\begin{array}{l}\oplus \oplus \ominus \ominus \\
l o w 1,2\end{array}$ & $\begin{array}{l}\text { Steroids may reduce the risk of deaths from all causes } \\
\text { among HIV-negative people. }\end{array}$ \\
\hline $\begin{array}{l}\text { Death from } \\
\text { pericarditis }\end{array}$ & 8 per 100 & $\begin{array}{l}3 \text { per } 100 \\
(1 \text { to } 6)\end{array}$ & $\begin{array}{l}\text { RR } 0.39 \\
(0.19 \text { to } 0.80)\end{array}$ & $\begin{array}{l}660 \\
(4 \text { trials })\end{array}$ & $\begin{array}{l}\oplus \oplus \oplus \ominus \\
\text { moderate } 2\end{array}$ & $\begin{array}{l}\text { Steroids probably reduce the risk of deaths from peri- } \\
\text { carditis among HIV-negative people. }\end{array}$ \\
\hline $\begin{array}{l}\text { Constrictive } \\
\text { pericarditis }\end{array}$ & 10 per 100 & $\begin{array}{l}7 \text { per } 100 \\
(3 \text { to } 15)\end{array}$ & $\begin{array}{l}\text { RR } 0.72 \\
\text { (0.34 to } 1.55)\end{array}$ & $\begin{array}{l}281 \\
(2 \text { trials })\end{array}$ & $\begin{array}{l}\oplus \ominus \ominus \ominus \\
\text { very low } 2,3,4\end{array}$ & $\begin{array}{l}\text { It is uncertain whether steroids have an effect on the } \\
\text { risk of constriction among HIV-negative people. }\end{array}$ \\
\hline $\begin{array}{l}\text { Repeat pericar- } \\
\text { diocentesis }\end{array}$ & 40 per 100 & $\begin{array}{l}34 \text { per } 100 \\
(28 \text { to } 41)\end{array}$ & $\begin{array}{l}\text { RR } 0.85 \\
\text { (0.70 to } 1.04)\end{array}$ & $\begin{array}{l}492 \\
(2 \text { trials })\end{array}$ & $\begin{array}{l}\oplus \oplus \ominus \ominus \\
l o w^{1,4}\end{array}$ & $\begin{array}{l}\text { Steroids may reduce the risk of repeat drainage of the } \\
\text { pericardium among HIV-negative people. }\end{array}$ \\
\hline Cancer & 1 per 100 & $\begin{array}{l}1 \text { per } 100 \\
(0 \text { to } 12)\end{array}$ & $\begin{array}{l}\text { RR } 0.85 \\
(0.05 \text { to } 13.80)\end{array}$ & $\begin{array}{l}256 \\
(1 \text { trial })\end{array}$ & $\begin{array}{l}\oplus \ominus \ominus \ominus \\
\text { very low } 3,5\end{array}$ & $\begin{array}{l}\text { It is uncertain whether steroids have an effect on the } \\
\text { risk of cancer among HIV-negative people. }\end{array}$ \\
\hline
\end{tabular}

Abbreviations: $\mathrm{Cl}$ : confidence interval; RR: risk ratio.

\section{GRADE Working Group grades of evidence}

High certainty: further research is very unlikely to change our confidence in the estimate of effect.

Moderate certainty: further research is likely to have an important impact on our confidence in the estimate of effect and may change the estimate.

Low certainty: further research is very likely to have an important impact on our confidence in the estimate of effect and is likely to change the estimate.

Very low certainty: we are very uncertain about the estimate.

1We downgraded by 1 for imprecision: the $\mathrm{Cl}$ ranges from a large clinical benefit to a small increase in harm

2 We downgraded by 1 for study limitations: one trial was at high risk of bias.

3We downgraded by 2 for imprecision: the $\mathrm{Cl}$ ranges from clinically important benefits to a large increase in harm.

4 We downgraded by 1 for selective reporting: data were only reported by 2 of the 4 trials that recruited HIV-negative people.

5 We downgraded by 1 for selective reporting: data were only reported by 1 of the 4 trials that recruited HIV-negative people. 


\section{Summary of findings 2. Corticosteroids for tuberculous pericarditis in HIV-positive people}

Population: HIV-positive people with tuberculous pericarditis. Most patients (80\%) not on antiretroviral drugs Settings: any setting

intervention: corticosteroids

Comparison: placebo

\begin{tabular}{|c|c|c|c|c|c|c|}
\hline \multirow[t]{2}{*}{ Outcomes } & \multicolumn{2}{|c|}{$\begin{array}{l}\text { Illustrative comparative risks } \\
(95 \% \mathrm{Cl})\end{array}$} & \multirow[t]{2}{*}{$\begin{array}{l}\text { Relative effect } \\
(95 \% \mathrm{CI})\end{array}$} & \multirow{2}{*}{$\begin{array}{l}\text { Number of par- } \\
\text { ticipants } \\
\text { (trials) }\end{array}$} & \multirow{2}{*}{$\begin{array}{l}\text { Certainty of } \\
\text { the evidence } \\
\text { (GRADE) }\end{array}$} & \multirow[t]{2}{*}{ Comments } \\
\hline & Placebo & $\begin{array}{l}\text { Corticos- } \\
\text { teroids }\end{array}$ & & & & \\
\hline $\begin{array}{l}\text { Death from all } \\
\text { causes }\end{array}$ & 17 per 100 & $\begin{array}{l}15 \text { per } 100 \\
(6 \text { to } 40)\end{array}$ & $\begin{array}{l}\text { RR } 0.91 \\
\text { (0.34 to } 2.42 \text { ) }\end{array}$ & $\begin{array}{l}575 \\
\text { (3 trials) }\end{array}$ & $\begin{array}{l}\oplus \ominus \odot \odot \\
\text { very low } 1,2\end{array}$ & $\begin{array}{l}\text { It is uncertain whether steroids have an effect on the } \\
\text { risk of deaths from all causes among people living with } \\
\text { HIV. }\end{array}$ \\
\hline $\begin{array}{l}\text { Death from } \\
\text { pericarditis }\end{array}$ & 4 per 100 & $\begin{array}{l}4 \text { per } 100 \\
(2 \text { to } 10)\end{array}$ & $\begin{array}{l}\text { RR } 1.07 \\
\text { (0.46 to } 2.54)\end{array}$ & $\begin{array}{l}517 \\
(2 \text { trials })\end{array}$ & $\begin{array}{l}\oplus \ominus \ominus \ominus \\
\text { very low } 1,3\end{array}$ & $\begin{array}{l}\text { It is uncertain whether steroids have an effect on the } \\
\text { risk of deaths from pericarditis among people living with } \\
\text { HIV. }\end{array}$ \\
\hline $\begin{array}{l}\text { Constrictive } \\
\text { pericarditis }\end{array}$ & 6 per 100 & $\begin{array}{l}4 \text { per } 100 \\
(2 \text { to } 7)\end{array}$ & $\begin{array}{l}\text { RR } 0.55 \\
(0.26 \text { to } 1.16)\end{array}$ & $\begin{array}{l}575 \\
(3 \text { trials })\end{array}$ & $\begin{array}{l}\oplus \oplus \ominus \ominus \\
\text { low } 1\end{array}$ & $\begin{array}{l}\text { Steroids may reduce the risk of developing constriction } \\
\text { among people living with HIV. }\end{array}$ \\
\hline $\begin{array}{l}\text { Repeat pericar- } \\
\text { diocentesis }\end{array}$ & 60 per 100 & $\begin{array}{l}61 \text { per } 100 \\
\text { (53 to } 71)\end{array}$ & $\begin{array}{l}\text { RR } 1.02 \\
\text { (0.89 to } 1.18)\end{array}$ & $\begin{array}{l}517 \\
(2 \text { trials })\end{array}$ & $\begin{array}{l}\oplus \oplus \ominus \ominus \\
l o w^{3}, 5\end{array}$ & $\begin{array}{l}\text { Steroids may have little or no effect on the risk of repeat } \\
\text { pericardiocentesis among people living with HIV. }\end{array}$ \\
\hline Cancer & 1 per 100 & $\begin{array}{l}1 \text { per } 100 \\
(0 \text { to } 8)\end{array}$ & $\begin{array}{l}\text { RR } 1.62 \\
\text { (0.27 to } 9.77)\end{array}$ & $\begin{array}{l}502 \\
(1 \text { trial })\end{array}$ & $\begin{array}{l}\oplus \ominus \ominus \ominus \\
\text { very low } 1,3\end{array}$ & $\begin{array}{l}\text { It is uncertain whether steroids have an effect on the } \\
\text { risk of cancer among people living with HIV. }\end{array}$ \\
\hline
\end{tabular}

Abbreviations: $\mathrm{Cl}$ : confidence interval; $\mathrm{RR}$ : risk ratio.

\section{GRADE Working Group grades of evidence}

High certainty: further research is very unlikely to change our confidence in the estimate of effect.

Moderate certainty: further research is likely to have an important impact on our confidence in the estimate of effect and may change the estimate.

Low certainty: further research is very likely to have an important impact on our confidence in the estimate of effect and is likely to change the estimate.

Very low certainty: we are very uncertain about the estimate.

1We downgraded by 2 for imprecision: the $\mathrm{Cl}$ ranges from substantial clinical benefits to substantial harm

2We downgraded by 1 for unexplained heterogeneity $\left(\mathrm{Chi}^{2}=3.82, \mathrm{df}=1(\mathrm{P}=0.05) ; \mathrm{I}^{2}\right.$ statistic $\left.=74 \%\right)$.

3 We downgraded by 1 for selective reporting: only 2 of the 3 studies that recruited HIV-positive people reported data. 
We downgraded by 1 for study limitations: 1 study had a high risk of bias.

5 We downgraded by 1 for imprecision: the $\mathrm{Cl}$ ranges from a small beneficial effect to clinically important harms.

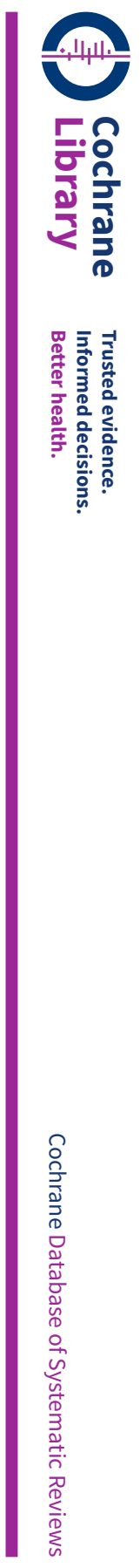




\section{B A C K G R O U N D}

\section{Description of the condition}

Tuberculous pericarditis refers to an infection of the membrane that covers the heart (pericardium) by the bacterium Mycobacterium tuberculosis. Infection of the pericardium can result in fluid accumulation around the heart, which constrains the heart's pumping action (tamponade), and is life-threatening. Sometimes the infection causes a thickening of the pericardium without an effusion (constrictive pericarditis), and this can also constrain the pumping action (Mayosi 2005; Ntsekhe 2012). Tuberculous pericarditis manifests with fatigue, shortness of breath, swelling of the body, and can cause death

Healthcare practitioners in low- and middle-income countries, where tuberculosis is common, are familiar with the condition (Gelfand 1957; Strang 1984). In high-income countries, the condition occurs in less than $5 \%$ of all people with tuberculosis (Lorell 1997; Imazio 2015). The human immunodeficiency virus (HIV) epidemic has resulted in more cases of tuberculosis in Africa and other resource-constrained regions, with a consequent rise in tuberculous pericarditis (Cegielski 1990; Mayosi 2006; Mayosi 2008). Post-mortem examinations conducted before the HIV era indicate that the pericardium is involved in $1 \%$ of people infected with tuberculosis (Fowler 1991). However, identical studies in people who died with advanced HIV reveal that extrapulmonary disease with multiple organ involvement is more frequent (Lucas 1993; Rana 1997). In people living with HIV who have pericardial effusion, tuberculosis is the cause in over four-fifths of cases (Ntsekhe 2005). In addition, the burden of tuberculous pericarditis experienced a rapid increase in regions of the world where tuberculosis-HIV coinfection is common (Ntsekhe 2013). This could be explained in part by the fact that the lifetime risk of tuberculosis in immunecompetent people without HIV infection is 10\% (Lawn 2011), which increases to a yearly risk of $10 \%$ early in HIV infection and up to a $30 \%$ yearly risk in people with advanced immunosuppression (Maartens 2007).

In the pre-antibiotic era, mortality of people with tuberculous pericarditis was $80 \%$ to $90 \%$ (Harvey 1937), but the advent of effective antituberculous chemotherapy in the 1940 s resulted in a decrease in case fatality rate to about $35 \%$ by 1970 (Rooney 1970). However, even with antituberculous drug regimens that contain rifampicin and isoniazid, the mortality rate remains high and is estimated to be between $8 \%$ and $17 \%$ in people without HIV infection (Desai 1979; Bhan 1980). In addition, HIV infection has an adverse effect on mortality rate (Mayosi 2005; Ntsekhe 2008; Wiysonge 2008). In one study, 185 participants with tuberculous pericarditis were consecutively enrolled in 15 referral hospitals in three African countries (Cameroon, Nigeria, and South Africa) between March 2004 and October 2004; and followed up during the six-month course of antituberculous treatment (Mayosi 2006). The mortality rate in this study was $17 \%$ in people without clinical evidence of HIV infection and $40 \%$ in people with clinical features of HIV infection (Mayosi 2008). HIV-associated tuberculous pericarditis more often occurs as part of a disseminated process with a greater amount of heart muscle involvement, and patients have larger fluid accumulation in the pericardium (Ntsekhe 2013).

\section{Description of the intervention}

Doctors currently prescribe rifampicin, isoniazid, pyrazinamide, and ethambutol for six months; remove fluid from the pericardium if the patient is very sick; and remove the membrane if it is thick and making the patient ill (Mayosi 2002). However, the number of complications and deaths due to the disease remain high (Mayosi 2008; Ntsekhe 2013). It has been proposed that adding corticosteroids to antituberculous antibiotics would lead to further decreases in the aggressiveness of the disease and deaths. Some study authors recommend the routine use of corticosteroids in all cases of tuberculous pericarditis (Alzeer 1993; Senderovitz 1994; Strang 1997). In contrast, other experts advise that corticosteroids should be reserved for people who are critically ill with recurrent large effusion and who do not respond to pericardial drainage and antituberculous drugs alone (Lorell 1997).

In addition to the corticosteroid controversy, there is no consensus regarding the optimal use of other therapeutic interventions (Ntsekhe 2013). Removal of fluid can be percutaneous under local anaesthesia or surgical under general anaesthesia. Furthermore, doctors can differ in the way they manage this condition in terms of duration of antituberculous drugs and when to operate. Other potential treatments for tuberculous pericarditis may include intrapericardial fibrinolysis (Augustin 2011), cellular therapy, use of repurposed drugs, cytokine therapy (Zumla 2015), and surgical removal of the thickened membrane (that is pericardiectomy) (Schrire 1967; Quayle 1987).

\section{How the intervention might work}

\section{Length of treatment}

Various specialists recommend different antibiotic treatment regimens of different lengths, from six months to 12 months (Sagristà-Sauleda 1988; Fowler 1991; Koh 1994; Strang 2004a; Strang 2004b). It is uncertain whether longer treatment leads to better outcomes (Mayosi 2002).

\section{Corticosteroids}

The inflammatory response to tuberculous bacilli penetrating the pericardium is responsible for the morbidity and mortality associated with tuberculous pericarditis (Mayosi 2005). Corticosteroids are anti-inflammatory drugs that may attenuate the inflammatory response and improve outcomes by reducing the accumulation of fluid or development of adhesions in the pericardium (Wiysonge 2008). In people living with HIV, active tuberculosis increases immune activation and accelerates progression to the acquired immunodeficiency syndrome; which results in early death. Corticosteroids may improve survival in HIVpositive people that have tuberculous pericarditis by modulating this immunological response (Wiysonge 2008). However, there is concern that corticosteroids may increase the risk of opportunistic infections and cancer in people living with HIV (Mayosi 2014).

\section{Immunomodulators}

As a result of advancements in the understanding of the immunopathogenesis of tuberculosis, there has been an increasing interest in immunotherapies as adjunctive treatments to standard antituberculous drug regimens. Mycobacterium indicus pranii is a non-pathogenic, saprophytic, rapidly growing atypical Mycobacterium species that has immunomodulating properties (Saini 2009). When administered as an intradermal heat-killed 
vaccine, $M$. indicus pranii stimulates a Th1 cellular immune response against shared epitopes for $M$. tuberculosis, which leads to an improved cell-mediated immune response, and therefore less severe disease (Ganju 1990; Singh 1992). A systematic review suggested that $M$. indicus pranii administration may reduce the time to cure of pulmonary tuberculosis, while acknowledging the need for further large trials (Pandie 2014).

\section{Surgical options}

\section{Early drainage}

Complete drainage of the pericardial fluid is sometimes performed as an open surgical procedure under general anaesthesia (Strang 2004b), or percutaneously under local anaesthesia with ultrasound or fluoroscopic guidance. The requirement and optimal method for drainage is not known (Strang 2004b).

\section{Removal of the pericardium}

In tuberculous constrictive pericarditis, some specialists advise an early conservative approach with surgery applied to patients who do not respond after an initial period of antituberculous medication (Schrire 1967). Others advise early surgery in all affected cases (Quayle 1987).

\section{Why it is important to do this review}

This is an update of a Cochrane Review first published in 2000 (Mayosi 2000), and previously updated in 2002 (Mayosi 2002). The previous version included four trials of corticosteroids (Schrire 1959; Hakim 2000; Strang 2004a; Strang 2004b). Early publications of small trials conducted in the pre-HIV era reported fewer deaths with corticosteroids compared to placebo, but the confidence interval $(\mathrm{Cl})$ ranged from a substantial reduction to a clinically important increase in deaths (risk ratio $0.65,95 \% \mathrm{Cl} 0.36$ to $1.16 ; 350$ participants, 2 trials) (Strang 2004a; Strang 2004b). Similar results were obtained among people living with HIV (risk ratio $0.50,95 \% \mathrm{Cl}$ 0.19 to $1.28 ; 58$ participants, 1 trial) (Hakim 2000). One trial showed that complete drainage of the pericardial fluid may relieve cardiac tamponade (Strang 2004b). However, two previously included trials have reported additional data (Strang 2004a; Strang 2004b), and various potentially eligible trials have been published since 2002 (Strang 2004a; Strang 2004b; Cui 2005; Reuter 2006; Mayosi 2014; Liebenberg 2016).

\section{O B J E C T IVES}

To assess the effects of treatments for tuberculous pericarditis.

\section{METHODS}

\section{Criteria for considering studies for this review}

\section{Types of studies}

Randomized controlled trials (RCTs) and quasi-RCTs.

\section{Types of participants}

People of all ages that required treatment for clinically diagnosed tuberculous pericarditis (effusive, constrictive, or effusive-constrictive), whether HIV-negative or HIV-positive.

\section{Types of interventions}

- Long versus shorter durations of antituberculous chemotherapy.

- Corticosteroids versus no corticosteroids.

- Immunomodulators versus no immunomodulators.

- Surgical procedures versus conservative management.

- Other treatments for tuberculous pericarditis.

\section{Types of outcome measures}

\section{Primary outcomes}

- Deaths from all causes.

\section{Secondary outcomes}

- Death from pericarditis.

- Constrictive pericarditis.

- Repeat pericardiocentesis.

- Cancer.

- Hospitalization.

- Pericardiectomy.

- Opportunistic infections.

\section{Search methods for identification of studies}

\section{Electronic searches}

We attempted to identify all relevant trials regardless of language or publication status (published, unpublished, in press, and in progress).

We searched the following databases using the strategy described in Appendix 1: the Cochrane Infectious Diseases Group Specialized Register (27 March 2017); the Cochrane Central Register of Controlled Trials (CENTRAL), published in the Cochrane Library (2017, Issue 2); MEDLINE (1966 to 27 March 2017); Embase (1974 to 27 March 2017); and LILACS (1982 to 27 March 2017).

\section{Searching other resources}

We searched the metaRegister of Controlled Trials (mRCT) and the WHO International Clinical Trials Registry Platform (ICTRP) search portal using 'tuberculosis' and 'pericard ${ }^{* 1}$ as search terms on 27 March 2017.

We also searched ClinicalTrials.gov and contacted researchers in the field of tuberculous pericarditis in March 2017.

In addition, we examined existing reviews of tuberculous pericarditis for relevant citations (Schrire 1967; Bhan 1980; Fowler 1991; Fowler 1992; Alzeer 1993; Senderovitz 1994; Fowler 1995; Cisneros 1996; Dooley 1997; Strang 1997; Mayosi 2002; Ntsekhe 2003; Mayosi 2005; Syed 2007; Imazio 2015; Zumla 2015).

\section{Data collection and analysis}

We conducted screening of search outputs, assessment of potentially eligible studies, assessment of risk of bias, and data extraction for this review in line with the Cochrane policy on trial authors who are also review authors (Kliner 2014). In addition, two Cochrane Infectious Disease Group (CIDG) Editors (Paul Garner and David Sinclair) provided oversight for data collection and analysis. 


\section{Selection of studies}

Three review authors, Charles Wiysonge (CSW), Dumo Majombozi (DM), and Bongani M Mayosi (BMM), independently screened abstracts identified by the search strategy for potentially eligible studies. The three review authors obtained the full-text articles of any potentially relevant articles and then assessed these studies using the prespecified trial inclusion criteria, respecting the Cochrane policy on trial authors who are also review authors (Kliner 2014). We resolved any disagreements by discussion and consensus.

Six review authors, Mpiko Ntsekhe (MN), Lehana Thabane (LT), Jimmy Volmink (JV), Freedom Gumedze (FG), Shaheen Pandie $(\mathrm{SP})$, and $\mathrm{BMM}$, were involved in one trial that met the inclusion criteria of this review (Mayosi 2014). Two review authors who were not involved with this trial, namely CSW and DM, independently performed the application of the inclusion criteria, 'Risk of bias' assessments, and data extraction for this trial. We excluded one potentially eligible study that did not meet the inclusion criteria and documented the reason for exclusion in the 'Characteristics of excluded studies' table. Four review authors, CSW, MN, FG, JV, and BMM, are the authors of an excluded study (Wiysonge 2008). In order to conform to existing Cochrane policies (Higgins 2011; Kliner 2014), a review author who was not involved in this study (DM) made the initial assessment of the eligibility of this study. We have included a study that is awaiting assessment in the 'Characteristics of studies awaiting classification' table (Cui 2005).

\section{Data extraction and management}

Two review authors (either CSW and BMM, or CSW and DM) independently extracted information from the included trials on methods used, participant characteristics, interventions, and outcomes. For all outcomes, we extracted the number of participants randomized and the number of participants analysed. The trials identified and included in this review all randomized individual participants and reported dichotomous outcomes. For each trial, we extracted the number of participants randomized to each intervention, as well as the number of participants with an outcome of interest and the number included in the analysis by the trial authors.

The published article from the Mayosi 2014 trial did not provide data by HIV status, but we requested and obtained these data from the study statistician (FG). CSW entered the data into Review Manager (RevMan) (RevMan 2014), and the study statistician FG verified the entered data for accuracy.

Multiple publications from the same data constituted one included trial, and we marked the publication that provided the most data to the analyses as the primary reference (Hakim 2000; Strang 2004a; Strang 2004b; Mayosi 2014). If data were available on prespecified outcomes at two or more periods, we took the more complete or later one into account (Strang 2004a; Strang 2004b).

\section{Assessment of risk of bias in included studies}

One review author (CSW) assessed the risk of bias in each included trial using Cochrane's 'Risk of bias' assessment tool for assessing the risk of bias in intervention studies (Higgins 2011), and two review authors (BMM and DM) verified this assessment; in line with the Cochrane policy on trial authors who are also review authors (Kliner 2014). We assessed whether adequate steps were taken to reduce the risk of bias across seven specific domains, namely, random sequence generation; allocation concealment; blinding of participants and personnel; blinding of outcome assessment; completeness of outcome data; selective outcome reporting; and other issues. For each included trial, we described what the trial authors reported that they did for each domain and decided the risk of bias for that domain by assigning a judgement of 'low', 'high', or 'unclear risk' of bias.

We categorized each included study into one of two levels of bias: low or high risk of bias. Studies with a high risk of selection bias (from inadequate random sequence generation and/or allocation concealment), detection bias (from lack of blinding of outcome assessment), or attrition bias (from incomplete outcome data) were categorized as having high risk of bias. We considered all other included trials to have a low risk of bias. We compared the results of independent 'Risk of bias' assessments and resolved disagreements by consensus.

\section{Measures of treatment effect}

All of the included trials reported dichotomous data, so we expressed the results as risk ratios (RR) with $95 \% \mathrm{Cls}$ for each outcome.

\section{Unit of analysis issues}

We did not encounter any unit of analysis issues in this review, as all included trials were individually RCTs.

\section{Dealing with missing data}

We stratified analyses by HIV status. However, data on HIV status were unavailable in three trials that were conducted (or started recruitment) in South Africa before the onset of the HIV epidemic in the country. We have assumed that the participants in these studies did not have HIV infection (Schrire 1959; Strang 2004a; Strang 2004b). One trial only enrolled HIV-positive people (Hakim 2000), and two recruited both HIV-positive and HIV-negative people (Reuter 2006; Mayosi 2014). The published paper from one of the two trials did not disaggregate results by HIV status (Mayosi 2014). We requested and obtained the disaggregated outcome data from the trial statistician (FG).

\section{Assessment of heterogeneity}

We assessed whether there was heterogeneity of study participants, interventions, and outcomes in order to make a qualitative assessment of the extent to which the included studies were similar to each other. We then included clinically homogeneous studies in meta-analyses and assessed heterogeneity of study results by visually inspecting the forest plots to check for overlapping $\mathrm{Cls}$. In addition, we assessed heterogeneity of effects using the $\mathrm{Chi}^{2}$ test of homogeneity; with statistical significance defined at the $10 \%$ alpha level (that is, $P=0.10$ ). We also used the $\mathrm{I}^{2}$ statistic to quantify the proportion of observed variation of effects across studies, which reflected variation in true effect sizes rather than sampling error (Higgins 2011).

\section{Assessment of reporting biases}

There were too few included studies to examine publication bias using a funnel plot (Higgins 2011). 


\section{Data synthesis}

Using both unpublished (Mayosi 2014), and published data (Schrire 1959; Hakim 2000; Strang 2004a; Strang 2004b; Reuter 2006; Mayosi 2014), we analysed trial participants in groups to which they were randomized; regardless of how much of the intended intervention they actually received. One included study used a $2 \times 2$ factorial design, in which participants received prednisolone plus $M$. indicus pranii, prednisolone plus placebo, $M$. indicus pranii plus placebo, or double placebo. There was a suggestion of clinical interaction between prednisolone and $M$. indicus pranii on cancer incidence (Mayosi 2014). Ten of the 14 cases of cancer $(71.4 \%)$ occurred in the group that took prednisolone plus $M$. indicus pranii. Therefore, in the analysis of intervention effects, we considered data from the group that took only one active intervention (that is, prednisolone or M. indicus pranii, as the case may be); and excluded data from the group that received both interventions.

We used meta-analysis with a fixed-effect model to calculate the summary statistics. We stratified analyses according to HIV status and the type of treatment and control intervention, for example, adjunctive corticosteroids versus placebo or no treatment in HIVnegative people, adjunctive corticosteroids versus placebo or no treatment in people living with HIV.

In addition, we used the GRADE (Grading of Recommendations Assessment, Development and Evaluation) approach to assess the certainty of the evidence for each outcome (Guyatt 2008). We have summarized the certainty of the evidence for corticosteroids in the 'Summary of findings' tables (Summary of findings for the main comparison; Summary of findings 2), which we constructed using GRADEpro Guideline Development Tool software (GRADEpro GDT 2014).

\section{Subgroup analysis and investigation of heterogeneity}

We only conducted meta-analyses for studies with homogeneous participants, interventions, and outcomes. If we had at least 10 studies in any meta-analysis that showed significant statistical heterogeneity (that is, $\mathrm{P}<0.10$ ), we would have explored possible sources of heterogeneity by performing subgroup analyses; with subgroups defined by clinical syndromes of tuberculous pericarditis (that is, pericardial effusion versus constriction) and risk of bias (that is, low versus high).

\section{RES ULTS}

\section{Description of studies}

\section{Results of the search}

We have presented a PRISMA diagram that illustrates the study selection process in Figure 1. 


\section{Figure 1. Study flow diagram}

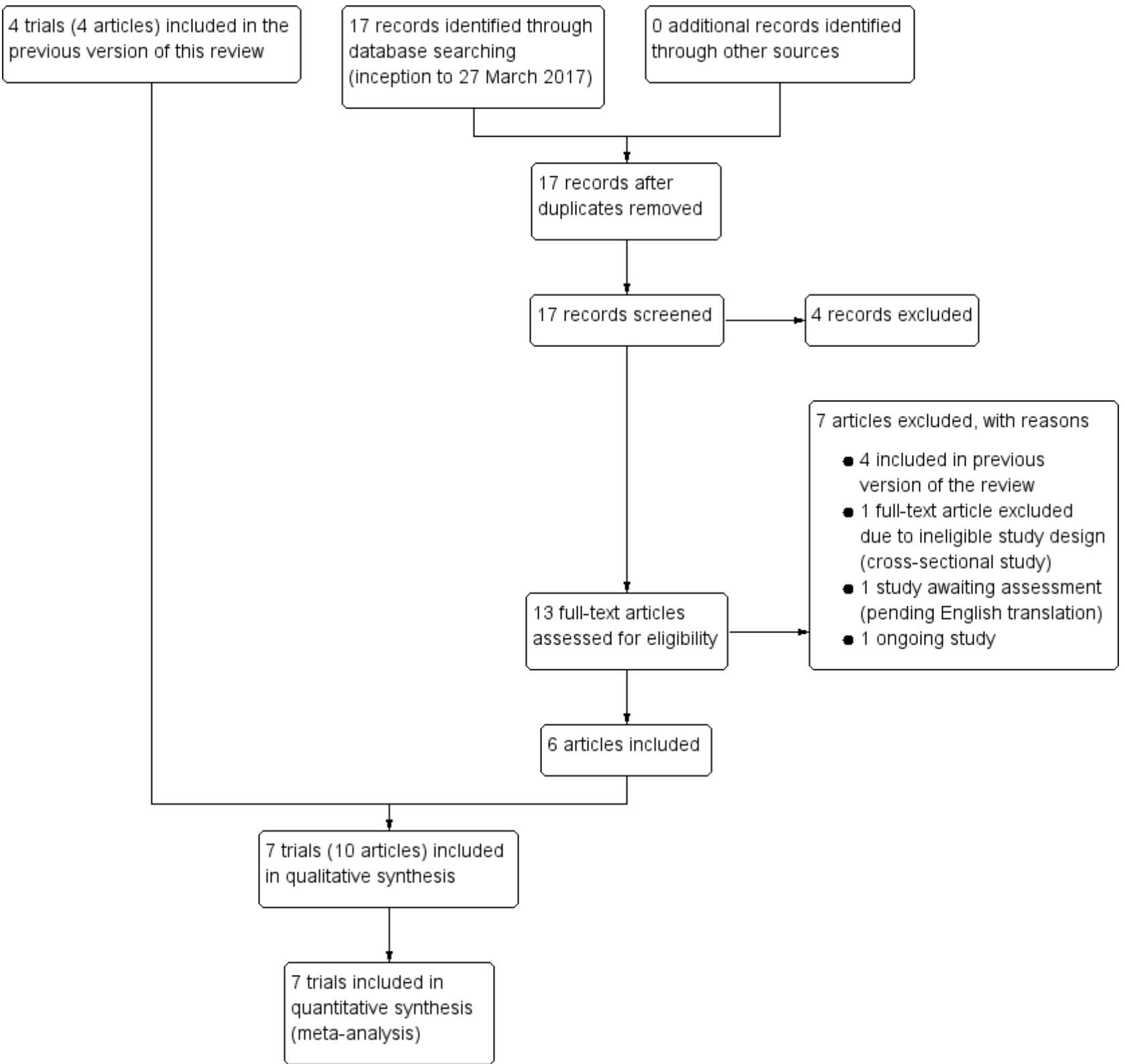

For this Cochrane Review update, we performed a literature search up to 27 March 2017 covering all years; including the years covered by the previous version of the review (Mayosi 2002). This literature search yielded 17 publications. We judged four of the publications to be clearly irrelevant to the review and excluded them. We obtained the full-text articles of the 13 potentially eligible publications and assessed them for eligibility. Four articles, which contain data from four distinct studies (Schrire 1959; Hakim 2000; Strang 2004a; Strang 2004b), were already included in the previous published version of the review (Mayosi 2002). We excluded one article due to ineligible study design (Wiysonge 2008), and another one is awaiting assessment (Cui 2005). One study has not yet published outcome data and we classified it as ongoing (NCT02673879). The remaining six publications, which contain data from six distinct studies, met our inclusion criteria (Hakim 2000; Strang 2004a; Strang 2004b; Reuter 2006; Mayosi 2014; Liebenberg
2016). The most recent follow-up data for two included trials were published as one article (Strang 2004a; Strang 2004b).

\section{Included studies}

The seven eligible trials consisted of six single-country studies conducted in South Africa (Schrire 1959; Strang 2004a; Strang 2004b; Reuter 2006; Liebenberg 2016) and Zimbabwe (Hakim 2000), as well as a multicountry study conducted in Kenya, Malawi, Mozambique, Nigeria, Sierra Leone, South Africa, Uganda, and Zimbabwe (Mayosi 2014). The interventions evaluated were as follows.

- Corticosteroids (Schrire 1959; Hakim 2000; Strang 2004a; Strang 2004b; Reuter 2006; Mayosi 2014).

- Colchicine (Liebenberg 2016).

- M. indicus pranii immunotherapy (Mayosi 2014). 
- Open surgical drainage on admission in participants with tuberculous pericardial effusion (Strang 2004b).

We have provided details of the included studies in the 'Characteristics of included studies' tables.

\section{Optimum duration of treatment}

We did not find any eligible studies that assessed different durations of antituberculosis drug regimens.

\section{Corticosteroids}

We have provided key characteristics of the six included corticosteroid trials in Table 1.

The six trials enrolled a total of 1926 participants. Over half of the participants (1018/1926; 52.9\%) were confirmed HIV-positive. Only one study gave antiretroviral drugs to participants, with 203 (22\%) of these HIV-positive participants on antiretroviral drugs, and thus overall only $19.9 \%$ of participants in the meta-analysis on antiretroviral therapy at enrolment. Five trials enrolled people with pericardial effusion (Schrire 1959; Hakim 2000; Strang 2004b; Reuter 2006; Mayosi 2014), and one enrolled those with pericardial constriction (Strang 2004a).

The corticosteroids assessed were cortisone (Schrire 1959), prednisone and triamcinolone hexacetonide (Reuter 2006), and prednisolone (Schrire 1959; Hakim 2000; Strang 2004a; Strang 2004b; Mayosi 2014). Schrire 1959 did not specify the length of follow-up and Reuter 2006 reported it as one year; Hakim 2000 as 18 months; Mayosi 2014 as two years; and Strang 2004a and Strang $2004 \mathrm{~b}$ as 10 years.

\section{Colchicine}

One trial tested the effects of colchicine among 33 people with a definite or probable diagnosis of tuberculous pericarditis in Kimberley, South Africa (Liebenberg 2016). All 33 participants were HIV-positive and had pericardial effusion at enrolment. Participants in the intervention arm received colchicine $1.0 \mathrm{mg}$ per day for six weeks. The control arm received identical placebo for six weeks as well. The length of follow-up was 16 weeks (Liebenberg 2016).

\section{M. indicus pranii immunotherapy}

One trial evaluated the effects of an immunomodulator, $M$. indicus pranii, among 1250 people aged 18 years or older in subSaharan Africa (Mayosi 2014). Two thirds (840/1250; 67.2\%) of the participants were confirmed to be HIV-positive; with 172 (20.5\%) on antiretroviral therapy at enrolment. All participants had pericardial effusion at enrolment. The $M$. indicus pranii preparation was given in five doses; at the time of enrolment and at 2 weeks, 4 weeks, 6 weeks, and 3 months. The control arm received identical placebo following the same schedule, and the length of follow-up was two years. This trial also assessed the effects of corticosteroids (Mayosi 2014).

\section{Surgical drainage}

One trial assessed the effects of routine open surgical drainage on admission compared to no open surgical drainage in 122 participants with tuberculous pericardial effusion in Umtata, South Africa (Strang 2004b). This trial was conducted before the onset of the HIV epidemic in the country. This study reported data at two years and at 10 years of follow-up. This trial also assessed the effects of corticosteroids (Strang 2004b).

\section{Intrapericardial fibrinolysis}

We found an ongoing trial that is assessing the effects of complete percutaneous pericardial drainage using intrapericardial alteplase compared to conventional pericardiocentesis in Cape Town, South Africa. The study started in 2016 and plans to recruit 2176 people with large pericardial effusion due to tuberculous and non-tuberculous pericarditis. The trial started with a pilot phase involving 218 people. This will confirm the feasibility of conducting a large-scale multicentre clinical trial of intrapericardial fibrinolysis in people with large pericardial effusions (NCT02673879).

\section{Other treatments}

We did not find eligible studies that assessed other potential treatments for tuberculous pericarditis such as pericardiectomy, percutaneous drainage of the pericardium under local anaesthesia, cellular therapy, use of repurposed drugs, or cytokine therapy.

\section{Excluded studies}

The excluded study is a cross-sectional analysis of the contemporary use of adjunctive corticosteroids in the management of patients with tuberculous pericarditis in Africa (Wiysonge 2008). Despite being observational in nature, this study is indexed in electronic databases as a controlled trial. We have provided furthermore details on this study in the 'Characteristics of excluded studies' table.

\section{Studies awaiting assessment}

One study is awaiting assessment, because the full-text article is in Chinese and we do not yet have an English translation (Cui 2005). In the study, consecutively recruited participants were "randomly" assigned to intervention or control arms, but the study authors did not provide any details about random sequence generation and allocation concealment in the study abstract. We have provided available details on this study in the 'Characteristics of studies awaiting classification' table.

\section{Risk of bias in included studies}

We have summarized our 'Risk of bias' judgements for each included trial in Figure 2 and Figure 3. 
Figure 2. 'Risk of bias' graph: review authors' judgements about each 'Risk of bias' item presented as percentages across all included studies

Random sequence generation (selection bias)

Allocation concealment (selection bias)

Blinding of participants and personnel (performance bias)

Blinding of outcome assessment (detection bias)

Incomplete outcome data (attrition bias)

Selective reporting (reporting bias)

Other bias

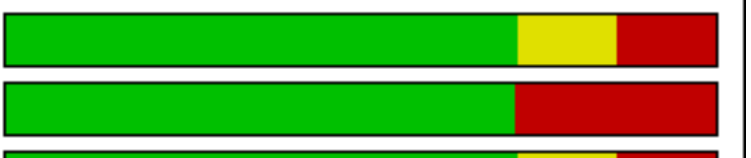

L
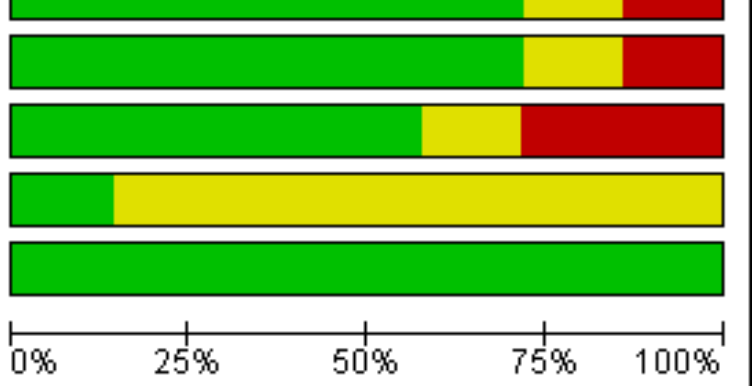

Low risk of bias

Unclear risk of bias

High risk of bias 
Figure 3. 'Risk of bias' summary: review authors' judgements about each 'Risk of bias' item for each included study

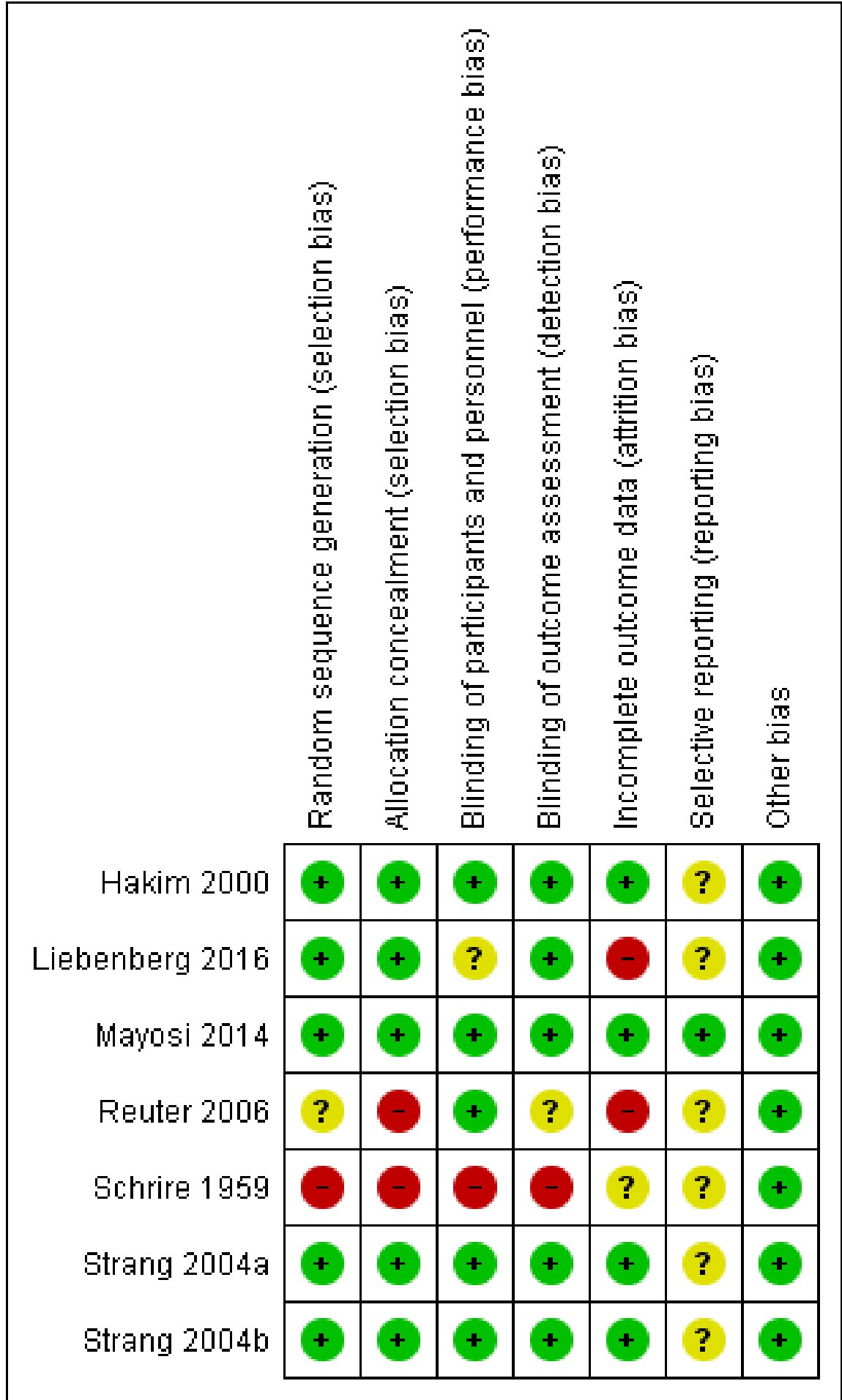

\section{Allocation}

Five trials adequately generated the randomization sequence by either a computer (Hakim 2000; Mayosi 2014; Liebenberg 2016), or a random number list (Strang 2004a; Strang 2004b). The adequacy of the generation of the randomization sequence was unclear in one trial (Reuter 2006), and inadequate in the other trial (Schrire 1959). The concealment of allocation to treatment arms was adequate in five trials (Hakim 2000; Strang 2004a; Strang 2004b; Mayosi 2014; Liebenberg 2016), and inadequate in two trials (Schrire 1959; Reuter 2006).

\section{Blinding}

Participants, care providers, and outcome assessors were blinded to treatment allocation in four trials (Hakim 2000; Strang 2004a; 
Strang 2004b; Mayosi 2014). One study did not use blinding (Schrire 1959). One study reported that "upon completion of the research period, the blinding was unveiled", but does not provide details on how the blinding was done (Liebenberg 2016). In the sixth study there was blinding of participants and care providers, but it is unclear if outcome assessors were blind to treatment allocation (Reuter 2006).

\section{Incomplete outcome data}

Loss to follow-up was minimal (0\% to $5 \%)$ and non-differential in four included trials (Hakim 2000; Strang 2004a; Strang 2004b; Mayosi 2014). One trial did not adequately report losses to followup (Schrire 1959), but losses to follow-up were high (15\% to 16\%) in two trials (Reuter 2006; Liebenberg 2016).

\section{Selective reporting}

One trial was free of reporting bias as the planned outcomes (as indicated in the prospective trial registration [ClinicalTrials.gov registration; NCT100810849] and published protocol) were reported in the trial report (Mayosi 2014). It was unclear to us if the remaining six studies (Schrire 1959; Hakim 2000; Strang 2004a; Strang 2004b; Reuter 2006; Liebenberg 2016) were free from reporting bias; since none of the study protocols were available and none of the trials were prospectively registered.

\section{Other potential sources of bias}

There is no evidence that the included studies had a high risk of other sources of bias; apart from those described above.

\section{Overall 'Risk of bias' assessment}

Based on the results of the 'Risk of bias' assessments for the seven domains above, we classified each included trial as either at low risk of bias or high risk of bias. Four trials had a low risk of bias (Hakim 2000; Strang 2004a; Strang 2004b; Mayosi 2014). The other three included trials were each at high risk of bias (Schrire 1959; Reuter 2006; Liebenberg 2016).

\section{Effects of interventions}

See: Summary of findings for the main comparison Corticosteroids for tuberculous pericarditis in HIV-negative people; Summary of findings 2 Corticosteroids for tuberculous pericarditis in HIV-positive people

\section{Corticosteroids versus no corticosteroids in HIV-negative people}

\subsection{Deaths from all causes}

Four trials showed that corticosteroids may reduce deaths from all causes in HIV-negative people (Strang 2004a; Strang 2004b; Reuter 2006; Mayosi 2014), but the $95 \% \mathrm{Cl}$ includes the possibility of both a large beneficial effect and a small increase in harm: risk ratio (RR) $0.80,95 \% \mathrm{Cl} 0.59$ to 1.09 ; 660 participants, 4 trials; Analysis 1.1). We rated the certainty of the evidence as low (Summary of findings for the main comparison).

\subsection{Deaths from pericarditis}

Four trials provided data on deaths from pericarditis in people without HIV infection (Strang 2004a; Strang 2004b; Reuter 2006; Mayosi 2014). Pooling these data shows that corticosteroids probably reduce deaths from pericarditis: RR $0.39,95 \% \mathrm{Cl} 0.19$ to
$0.80 ; 660$ participants, 4 trials; Analysis 1.2 . We rated the certainty of the evidence as moderate (Summary of findings for the main comparison).

\subsection{Constrictive pericarditis}

Based on two included trials, Reuter 2006 and Mayosi 2014, we are uncertain whether corticosteroids reduce the risk of constrictive pericarditis in people without HIV infection: RR $0.72,95 \% \mathrm{Cl} 0.34$ to $1.55 ; 281$ participants, 2 trials; Analysis 1.3). This evidence is of very low certainty (Summary of findings for the main comparison).

\subsection{Repeat pericardiocentesis}

Based on two included trials, Strang 2004b and Mayosi 2014, corticosteroids may reduce the reaccumulation of fluid requiring repeat drainage of the pericardium among HIV-negative people, but the $\mathrm{Cls}$ include the possibility of both large beneficial effects and a small increase in harm: RR $0.85,95 \% \mathrm{Cl} 0.70$ to $1.04 ; 492$ participants, 2 trials; Analysis 1.4. We rated the certainty of the evidence as low (Summary of findings for the main comparison).

\subsection{Cancer}

From the limited data on cancer reported by one trial (Mayosi 2014), we are uncertain about the effect of corticosteroids on the risk of cancer (RR 0.85, 95\% Cl 0.05 to 13.80; 256 participants (Analysis 1.5) in HIV-negative people, as the evidence is of very low certainty (Summary of findings for the main comparison).

\subsection{Hospitalization}

Only one trial reported on this outcome (Mayosi 2014). We are uncertain whether corticosteroids reduce the risk of hospitalization in HIV-negative people (RR $0.98,95 \% \mathrm{Cl} 0.57$ to 1.70; 256 participants, 1 trial; Analysis 1.6), as the currently available evidence is of very low certainty. We downgraded the evidence by two for imprecision, as the $\mathrm{Cl}$ ranges from clinically important benefits to a large increase in harm. In addition, we downgraded by one for selective reporting, given that data were only reported by one of four trials that recruited HIV-negative people.

\subsection{Pericardiectomy}

Based on data from four trials (Schrire 1959; Strang 2004a; Strang 2004b; Reuter 2006), we are uncertain about the effects of corticosteroids on the risk of pericardiectomy in HIV-negative people: RR $0.91,95 \% \mathrm{Cl} 0.58$ to $1.41 ; 432$ participants, 4 trials; Analysis 1.7). We rated the evidence to be of very low certainty. We downgraded the evidence by two for imprecision, as the $\mathrm{Cl}$ ranges from large benefits to clinically important harms. We further downgraded by one for study limitations, given that two of the four trials were at high risk of bias.

\subsection{Opportunistic infections}

We do not know whether corticosteroids have an effect on opportunistic infections as the certainty of the evidence was assessed as very low (RR $1.71,95 \% \mathrm{Cl} 0.44$ to $6.69 ; 256$ participants, 1 trial; Analysis 1.8). We downgraded the evidence by two for imprecision, as the $\mathrm{Cl}$ ranges from clinically important benefits to a large increase in harm. In addition, we downgraded by one for selective reporting, given that data were only reported by one of four trials that recruited HIV-negative people. 


\section{Corticosteroids versus no corticosteroids in people living with HIV infection}

\subsection{Deaths from all causes}

Three included trials reported on this outcome (Hakim 2000; Reuter 2006; Mayosi 2014). It is uncertain whether corticosteroids have an effect on the risk of deaths from any cause among people living with HIV (RR 0.91, $95 \% \mathrm{Cl} 0.34$ to 2.42; 575 participants, 3 trials; Analysis 2.1). This evidence is of very low certainty (Summary of findings 2 ).

\subsection{Deaths from pericarditis}

Two trials provided data on the effects of corticosteroids on deaths from pericarditis among 517 people living with HIV (Reuter 2006; Mayosi 2014). From these data, we are uncertain whether corticosteroids have an effect on the risk of deaths from pericarditis in HIV-positive people (RR $1.07,95 \% \mathrm{Cl} 0.46$ to 2.54 517 participants, 2 trials; Analysis 2.2; very low certainty evidence; Summary of findings 2 ).

\subsection{Constrictive pericarditis}

Currently available data from three included trials (Hakim 2000; Reuter 2006; Mayosi 2014), show that corticosteroids may reduce the risk of constrictive pericarditis among people living with HIV but the Cls include the possibility of both large beneficial effects and a small increase in harm (RR 0.55, 0.26 to $1.16 ; 575$ participants, 3 trials; Analysis 2.3; low certainty evidence; Summary of findings 2).

\subsection{Repeat pericardiocentesis}

Two trials reported data on the risk of reaccumulation of fluids requiring repeat drainage of the pericardium in HIV-positive people (Reuter 2006; Mayosi 2014). The combined data show that corticosteroids may have little or no effect on this outcome (RR $1.02,95 \% \mathrm{Cl} 0.89$ to 1.18 ; 517 participants, 2 trials; Analysis 2.4; low certainty evidence; Summary of findings 2).

\subsection{Cancer}

Based on currently available data from one included trial, Mayosi 2014, we are uncertain about the effects of corticosteroids on the risk of cancer in people living with HIV (RR 1.62, 95\% $\mathrm{Cl} 0.27$ to 9.77; 502 participants, 1 trial; Analysis 2.5; very low certainty evidence; Summary of findings 2).

\subsection{Hospitalization}

Based on one included trial, Mayosi 2014, corticosteroids may reduce the risk of hospitalization in people living with HIV, but the Cls include the possibility of both large beneficial effects and a small increase in harm (RR $0.80,95 \% \mathrm{Cl} 0.59$ to $1.09 ; 502$ participants, 1 trial; Analysis 2.6). This evidence is of low certainty. We downgraded the evidence by one for imprecision, as the $\mathrm{Cl}$ ranges from clinically important benefits to little or no effect. In addition, we downgraded by one for selective reporting, given that data were only reported by one of three trials that recruited HIVnegative people.

\subsection{Pericardiectomy}

There is insufficient evidence from one included trial, Reuter 2006, to determine whether corticosteroids have an effect on the risk of pericardiectomy in people living with HIV (RR $2.10,95 \% \mathrm{Cl} 0.10$ to 44.40 ; 15 participants, 1 trial; Analysis 2.7 ; very low certainty evidence). We downgraded the evidence by two for imprecision, as the $\mathrm{Cl}$ ranges from substantial benefits to clinically important harms. We further downgraded by one for selective reporting, given that data were only reported by one of three trials that recruited HIV-negative people.

\subsection{Opportunistic infections}

Based on data from two included trials, Reuter 2006 and Mayosi 2014, it is uncertain whether corticosteroids have an effect on the risk of opportunistic infections in HIV-positive people (RR 0.95, 95\% $\mathrm{Cl} 0.61$ to 1.48; 517 participants, 2 trials; Analysis 2.8). We assessed the certainty of this evidence as very low. We downgraded the evidence by two for imprecision, as the $\mathrm{Cl}$ ranges from substantial benefits to clinically important harms. We further downgraded by one for study limitations, given that one of the two trials has a high risk of bias.

\section{Colchicine versus placebo}

From the results of one trial among 33 HIV-positive people (Liebenberg 2016), it is uncertain whether colchicine has an effect on the risk of deaths from all causes (RR $0.74,95 \% \mathrm{Cl} 0.17$ to 3.12; Analysis 3.1) or constrictive pericarditis (RR $1.11,95 \% \mathrm{Cl} 0.21$ to 5.76; Analysis 3.2). We assessed the certainty of the evidence for each outcome as very low. We downgraded the evidence by two for imprecision, as the $\mathrm{Cl}$ ranges from substantial benefits to clinically important harms. We further downgraded by one for study limitations, given that the included trial has a high risk of bias.

\section{M. indicus pranii versus placebo}

One trial evaluated the effects of $M$. indicus pranii immunotherapy in a two-by-two factorial design among 1250 people aged 18 years or older in Zimbabwe, South Africa, Sierra Leone, Uganda, Nigeria, Mozambique, Malawi, and Kenya (Mayosi 2014).

The trial reveals uncertainty about the effects of $M$. indicus pranii on deaths from all causes (RR $1.07,95 \% \mathrm{Cl} 0.56$ to 2.03 ; Analysis 4.1), deaths from pericarditis (RR $1.50,95 \% \mathrm{Cl} 0.44$ to 5.15 ; Analysis 4.2), constrictive pericarditis ( $\mathrm{RR} 1.56,95 \% \mathrm{Cl} 0.71$ to 3.42 ; Analysis 4.3), repeat pericardiocenthesis ( $\mathrm{RR} 1.21,95 \% \mathrm{Cl} 0.96$ to 1.52 ; Analysis 4.4), cancer (RR 3.03, 95\% Cl 0.12 to 75.37; Analysis 4.5), hospitalization (RR $1.22,95 \% \mathrm{Cl} 0.70$ to 2.13 ; Analysis 4.6), and opportunistic infections (RR $0.67,95 \% \mathrm{Cl}$ from 0.11 to 3.90 ; Analysis 4.7) in HIV-negative people. The certainty of the evidence was very low for all the outcomes. We downgraded the evidence by two for imprecision, as the $\mathrm{Cls}$ for all outcomes range from substantial benefits to clinically important harms. We further downgraded by one for possibility of publication bias, as only one trial has so far reported data on this intervention.

Similar to HIV-negative people, among people living with HIV, we are also uncertain whether $M$. indicus pranii has an effect on the risk of deaths from all causes (Analysis 5.1), deaths from pericarditis (Analysis 5.2), constrictive pericarditis (Analysis 5.3), repeat pericardiocenthesis (Analysis 5.4), cancer (Analysis 5.5), hospitalization (Analysis 5.6), or opportunistic infections (Analysis 5.7) as the current evidence is of very low certainty. There were too few HIV-positive patients on antiretroviral treatment to assess the effects of $M$. indicus pranii in this group of participants. We downgraded the evidence by two for imprecision, as the Cls for all outcomes range from clinically important benefits to substantial increases in harms. We further downgraded by one for possibility of 
publication bias, as only one trial has so far reported data on this intervention.

\section{Open surgical drainage for effusion versus no drainage}

One trial, conducted in South Africa, assessed the effects of routine open surgical drainage on admission to hospital compared to no intervention among 122 participants with tuberculous pericardial effusion (Strang 2004b). This trial started before the onset of the HIV epidemic in South Africa and, although no HIV testing was done, we have assumed the participants to be HIV-negative.

The results of the trial show that open surgical drainage may reduce the risk of reaccumulation of fluid requiring repeat pericardiocentesis in people without HIV infection (RR 0.23, 95\% $\mathrm{Cl} 0.07$ to 0.76 ; Analysis 6.3). However, the intervention may make little or no difference to any other outcome measured in the study; including deaths from all causes (Analysis 6.1), deaths from pericarditis (Analysis 6.2), and pericardiectomy (Analysis 6.4). We rated the certainty of the evidence for each of these outcomes as low. We downgraded the evidence by one for imprecision, as the Cls for most outcomes range from clinically important benefits to little or no effect. We further downgraded by one for possibility of publication bias, as only one trial has so far reported data on this intervention.

\section{DISCUSSION}

\section{Summary of main results}

This is an update of a Cochrane Review published in 2002 (Mayosi 2002). Seven randomized controlled trials (RCTs) met the inclusion criteria of this review, and all were conducted in sub-Saharan Africa. The 2002 review included four trials (Schrire 1959; Strang 2004a; Strang 2004b; Hakim 2000). In addition to updated outcome data from two previously included trials (Strang 2004a; Strang 2004b), we have included three new trials in this update (Reuter 2006; Mayosi 2014; Liebenberg 2016). Four studies are at low risk of bias (Hakim 2000; Strang 2004a; Strang 2004b; Mayosi 2014), and three are at high risk of bias (Schrire 1959; Reuter 2006; Liebenberg 2016). The included trials enrolled 1959 participants (54\% of them HIVpositive). Six trials evaluated corticosteroids (Schrire 1959; Hakim 2000; Strang 2004a; Strang 2004b; Reuter 2006; Mayosi 2014), and one each evaluated colchicine (Liebenberg 2016), M. indicus pranii immunotherapy (Mayosi 2014), and open surgical drainage of pericardial effusion (Strang 2004b).

The key findings from these studies are as follows.

- In people without HIV infection, corticosteroids probably reduce deaths from pericarditis (moderate certainty evidence) and may reduce deaths from all causes and the need for repeat pericardiocentesis (low certainty evidence). However, it is uncertain whether corticosteroids have an effect on any other outcome among HIV-negative people (very low certainty evidence) (Summary of findings for the main comparison).

- In people living with HIV and not on antiretroviral drugs, corticosteroids may reduce constrictive pericarditis and hospitalization (low certainty evidence). However, corticosteroids may make little or no difference to the need for repeat pericardiocentesis (low certainty evidence) and it is uncertain whether the intervention has an effect on deaths or any other outcome in HIV-positive people (very low certainty evidence) (Summary of findings 2).
- It is uncertain whether colchicine has an effect on any outcome among HIV-positive people (very low certainty evidence). All participants were on antiretroviral treatment.

- It is uncertain whether $M$. indicus pranii has an effect on the risk of deaths or any other outcome, regardless of HIV status (very low certainty evidence).

- In people without HIV infection, routine open surgical drainage for effusion may reduce the need for repeat pericardiocentesis, but may make little or no difference to any other outcome (low certainty evidence).

\section{Overall completeness and applicability of evidence}

We found that adjunctive corticosteroids may lead to a modest relative reduction of about $20 \%$ on the risk of all-cause mortality among HIV-negative people. Before the biggest trial on the subject was published (Mayosi 2014), two small trials, Strang 2004a and Strang 2004b, had previously suggested that adjunctive corticosteroids may reduce mortality by $35 \%$ among HIV-negative patients (Ntsekhe 2003). Regarding people living with HIV, currently available data suggest a relative reduction of $9 \%$ in mortality, but the $\mathrm{Cl}$ ranges very widely from a $66 \%$ relative reduction to a massive $142 \%$ relative increase in mortality. Before the publication of the big trial, Mayosi 2014, data from one small trial suggested that the use of adjunctive corticosteroids among HIV-positive people with tuberculous pericarditis would result in a $50 \%$ relative reduction in mortality (Hakim 2000).

Evidence from small early trials on health interventions is often untrustworthy (Wiysonge 2014). An examination of more than 85,000 binary-outcome forest plots from more than 3000 Cochrane Reviews found that most large treatment effects emerged from small trials and when additional larger trials were performed, the effect sizes typically became much smaller (Pereira 2012).

Apart from corticosteroids, we found only one trial each that assessed the effects of colchicine (Liebenberg 2016), M. indicus pranii immunotherapy (Mayosi 2014), and open surgical drainage (Strang 2004b).

There is unclear evidence regarding the relationship between corticosteroids, $M$. indicus pranii, and increased rates of cancer. This merits further study. One trial found an association between increased rates of cancer among people randomized to receive bothM. indicus pranii and corticosteroids (Mayosi 2014). However, this trial was inadequately powered to determine whether this effect was due to corticosteroids alone, $M$. indicus pranii alone, or a synergistic action between the two interventions.

We aimed to identify the optimal drug combination and treatment duration, but found no eligible trials. This is an important question in the light of the recent demonstration that the concentrations of rifampicin, ethambutol, and pyrazinamide in pericardial fluid based on current treatment regimens were dramatically low and below the minimum inhibitory concentrations of $M$. tuberculosis (Shenje 2015). Furthermore, patients with culture-confirmed tuberculous pericarditis have a high bacillary burden, and this bacterial burden drives mortality (Pasipanodya 2015). Therefore the design of a highly bactericidal regimen for this condition is needed, and testing of its effectiveness in RCTs.

Currently there are no RCTs studying the issue of timing of pericardiectomy in people with a diagnosis of tuberculous 
constrictive pericarditis. The current recommendation of pericardiectomy for persistent signs of constriction after at least six weeks of antituberculous chemotherapy is based on expert opinion (Commerford 1991; Mutyaba 2014).

In addition, we found no eligible completed trials that assessed the effects of percutaneous drainage of the pericardium under local anaesthesia, intrapericardial fibrinolysis (Augustin 2011), nor novel therapies such as cellular therapy, use of repurposed drugs, and cytokine therapy (Zumla 2015).

\section{Quality of the evidence}

We included seven RCTs in this review. In the GRADE system, RCTs without important limitations constitute high certainty evidence. However, the system considers five factors that can lower the certainty of the evidence: study limitations, heterogeneity, indirectness, imprecision, and publication bias (Balshem 2011). Four included studies were well-conducted RCTs (Hakim 2000; Strang 2004a; Strang 2004b; Mayosi 2014), at a low overall risk of bias (Figure 2; Figure 3). Each of the remaining three trials had a high overall risk of bias (Schrire 1959; Reuter 2006; Liebenberg 2016). These study limitations, as well as the imprecision of most effects, had an important impact on our rating of the certainty of the evidence (see the 'Summary of findings' tables: Summary of findings for the main comparison; Summary of findings 2).

\section{Potential biases in the review process}

We minimized potential biases in the review process by adhering to the guidelines of the Cochrane Handbook for Systematic Reviews of Interventions (Higgins 2011). We conducted comprehensive searches of both peer-reviewed and grey literature, without limiting the searches to a specific language. Two review authors independently assessed study eligibility, extracted data, and assessed the risk of bias in each included trial. When a potentially eligible study was conducted by review co-authors, we requested independent researchers (who were not involved in the article under consideration) to assess eligibility and (if eligible for inclusion) extract data (Kliner 2014).

\section{Agreements and disagreements with other studies or reviews}

The previously published version of this Cochrane Review, Mayosi 2002, found that corticosteroids could have important clinical benefits in both HIV-negative and HIV-positive people. However, the three included trials were too small to demonstrate a significant effect (Hakim 2000; Strang 2004a; Strang 2004b). The review authors also included one trial that examined open surgical drainage compared with conservative management, and showed that surgery relieved cardiac tamponade (Strang 2004b). A year later, Ntsekhe and colleagues published a systematic review of the effectiveness of adjunctive corticosteroids in tuberculous pericarditis, in which they concluded that corticosteroids could have large beneficial effects on mortality and morbidity in tuberculous pericarditis but published trials were too small to be conclusive (Ntsekhe 2003). No other systematic review of treatments for tuberculous pericarditis has been published since then.

Imazio 2015 published a systematic review on the causes, diagnosis, therapy, prevention, and prognosis of pericarditis. However, the authors focused the treatment component of the review on interventions for idiopathic and viral pericarditis in North America and Europe.

This Cochrane Review is therefore the most comprehensive review to date on interventions for treating tuberculous pericarditis.The review's findings are slightly different to the largest trial ever completed, authored by some of the authors of this review, which showed no significant difference for corticosteroids on a composite outcome reflecting benefit, and a slight increase in HIV-associated cancer. The finessing of the results and the interpretation is probably due to multiple factors, including combining with other studies; and re-analysing the the original trial data stratified by HIV status.

\section{AUTHORS' CONCLUSIONS}

\section{Implications for practice}

Our review shows that corticosteroids and open surgical drainage have evidence of benefit in people with tuberculous pericarditis.

In HIV-negative people, corticosteroids probably reduce deaths from pericarditis (moderate certainty evidence) and may reduce deaths from all causes (low certainty evidence) and the need for repeat pericardiocentesis (low certainty evidence); while open surgical drainage may reduce the subsequent need for pericardiocentesis (low certainty evidence).

In the treatment of people living with HIV not on antiretroviral drugs, corticosteroids may reduce constrictive pericarditis (low certainty evidence) and hospitalizations (low certainty evidence); with little or no effect on deaths (low certainty evidence).

\section{Implications for research}

The relationship between corticosteroids, immunomodulators, and increased rates of cancer needs to be investigated further. In addition, high-quality randomized trials are needed on percutaneous drainage of the pericardium under local anaesthesia, the timing of pericardiectomy in tuberculous constrictive pericarditis, new antibiotic regimens, cellular therapy, use of repurposed drugs, and cytokine therapy.

We will update this Cochrane Review when the ongoing trial of intrapericardial fibrinolysis is published (NCT02673879).

\section{ACKNOWLEDGEMENTS}

We thank Paul Garner and David Sinclair for guidance in the preparation of this Cochrane Review.

We are also grateful to Patrick Commerford, for contributing to earlier versions of this review.

Charles S Wiysonge's work is supported by the South African Medical Research Council, the National Research Foundation of South Africa (Grant Numbers: 106035 and 108571), and by the Effective Health Care Research Consortium. This Consortium and the CIDG editorial base are funded by UK aid from the UK Government for the benefit of developing countries (Grant: 5242). The views expressed in this publication do not necessarily reflect UK government policy.

The work of BM Mayosi is funded by the South African Medical Research Council, the National Research Foundation of South 
Africa, the Wellcome Trust, and the Lily and Ernst Hausmann Research Trust. 


\section{R E F E R E N C E S}

\section{References to studies included in this review}

Hakim 2000 \{published data only\}

* Hakim J, Ternouth I, Mushangi E, Siziya S, Robertson V, Malin A. Double blind randomised placebo controlled trial of adjuvant prednisolone in the treatment of effusive tuberculous pericarditis in HIV seropositive patients. Heart 2000;84(2):183-8.

Hakim JG, Ternouth I, Mushangi E. Mortality in patients with HIV-related tuberculous pericarditis (TBP) treated with adjunctive prednisolone [abstract]. International Clinical Epidemiology Network. Abstracts of the INCLEN XV Global Meeting, 1998, Queretaro, Mexico. Journal of Clinical Epidemiology 1998;51(Suppl 1):5S.

\section{Liebenberg 2016 \{published data only\}}

Liebenberg JJ, Dold CJ, Olivier LR. A prospective investigation into the effect of colchicine on tuberculous pericarditis. Cardiovascular Journal of Africa 2016;27(6):350-5.

\section{Mayosi 2014 \{published data only\}}

* Mayosi BM, Ntsekhe M, Bosch J, Pandie S, Jung H, Gumedze F, et al. Prednisolone and Mycobacterium indicus pranii in tuberculous pericarditis. New England Journal of Medicine 2014;371(12):1121-30.

Mayosi BM, Ntsekhe M, Bosch J, Pogue J, Gumedze F, Badri M, et al. Rationale and design of the Investigation of the Management of Pericarditis (IMPI) trial: a $2 \times 2$ factorial randomized doubleblind multicenter trial of adjunctive prednisolone and Mycobacterium w immunotherapy in tuberculous pericarditis. American Heart Journal 2013;165(2):109-15.e3.

\section{Reuter 2006 \{published data only\}}

Reuter H, Burgess LJ, Louw VJ, Doubell AF. Experience with adjunctive corticosteroids in managing tuberculous pericarditis. Cardiovascular Journal of South Africa 2006;17(5):233-8.

\section{Schrire 1959 \{published data only\}}

Schrire V. Experience with pericarditis at Groote Schuur Hospital, Cape Town: an analysis of one hundred and sixty cases over a six-year period. South African Medical Journal 1959;33:810-7.

\section{Strang 2004a \{published and unpublished data\}}

* Strang JI, Nunn AJ, Johnson DA, Casbard A, Gibson DG, Girling DJ. Management of tuberculous constrictive pericarditis and tuberculous pericardial effusion in Transkei: results at 10 years follow-up. QJM 2004;97(8):525-35.

Strang JIG, Kakaza HHS, Gibson DG, Girling DJ, Nunn AJ, Fox W. Controlled trial of prednisolone as adjuvant in treatment of tuberculous constrictive pericarditis. Lancet 1987;2(8573):1418-22.

\section{Strang 2004b \{published and unpublished data\}}

* Strang JI, Nunn AJ, Johnson DA, Casbard A, Gibson DG, Girling DJ. Management of tuberculous constrictive pericarditis and tuberculous pericardial effusion in Transkei: results at 10 years follow-up. QJM 2004;97(8):525-35.
Strang JIG, Kakaza HHS, Gibson DG, Allen BW, Mitchison DA, Evans DJ, et al. Controlled clinical trial of complete open surgical drainage and of prednisolone in treatment of tuberculous pericardial effusion in Transkei. Lancet 1988;2(8614):759-64.

\section{References to studies excluded from this review}

Wiysonge 2008 \{published data only\}

Wiysonge CS, Ntsekhe M, Gumedze F, Sliwa K, Blackett KN, Commerford PJ, et al. Contemporary use of adjunctive corticosteroids in tuberculous pericarditis. International Journal of Cardiology 2008;124(3):388-90.

\section{References to studies awaiting assessment}

Cui 2005 \{published data only\}

Cui HB, Chen XY, Cui CC, Shou XL, Liu XH, Yao XW, et al. Prevention of pericardial constriction by transcatheter intrapericardial fibrinolysis with urokinase. Chinese Medical Sciences Journal 2005;20(1):5-10.

\section{References to ongoing studies}

NCT02673879 \{published data only\}

NCT02673879. IMPI 2 - A Trial of Intrapericardial Alteplase in Large Pericardial Effusion (IMPI-2). https://clinicaltrials.gov/ct2/ show/NCT02673879 (first received 1 February 2016).

\section{Additional references}

\section{Alzeer 1993}

Alzeer AH, FitzGerald JM. Corticosteroids and tuberculosis: risks and use as adjunct therapy. Tubercle and Lung Disease 1993;74(1):6-11.

\section{Augustin 2011}

Augustin P, Desmard M, Mordant P, Lasocki S, Maury JM, Heming N, et al. Clinical review: intrapericardial fibrinolysis in management of purulent pericarditis. Critical Care 2011;15(2):220. [DOI: 10.1186/cc10022]

\section{Balshem 2011}

Balshem B, Helfand M, Schünemann HJ, Oxman AD, Kunz R, Brozek J, et al. GRADE guidelines: 3. Rating the quality of evidence. Journal of Clinical Epidemiology 2011;64(4):401-6.

\section{Bhan 1980}

Bhan GL. Tuberculous pericarditis. Journal of Infection 1980;2(4):360-4.

\section{Cegielski 1990}

Cegielski JP, Ramaiya K, Lallinger GJ, Mtulia IA, Mbaga IM. Pericardial disease and human immunodeficiency virus in Dar es Salaam, Tanzania. Lancet 1990;335(8683):209-12. 


\section{Cisneros 1996}

Cisneros JR, Murray KM. Corticosteroids in tuberculosis. Annals of Pharmacotherapy 1996;30(11):1298-303.

\section{Commerford 1991}

Commerford PJ, Strang JIG. Tuberculous pericarditis. In: Coovadia HM, Benatar SR editor(s). A Century of Tuberculosis: South African Perspectives. Cape Town: Oxford University Press, 1991.

\section{Desai 1979}

Desai HN. Tuberculous pericarditis: a review of 100 cases. South African Medical Journal 1979;55(22):877-80

\section{Dooley 1997}

Dooley DP, Carpenter JL, Rademacher S. Adjunctive corticosteroid therapy for tuberculosis: a critical reappraisal of the literature. Clinical Infectious Diseases 1997;25(4):872-87.

\section{Fowler 1991}

Fowler NO. Tuberculous pericarditis. JAMA 1991;266(1):99-103.

\section{Fowler 1992}

Fowler NO. Pericardial disease. Heart Disease \& Stroke 1992;1(2):85-94

\section{Fowler 1995}

Fowler NO. Constrictive pericarditis: its history and current status. Clinical Cardiology 1995;18(6):341-50.

\section{Ganju 1990}

Ganju L, Mukherjee R, Batra HV, Talwar GP. Immuno-blot analysis of antigens of Mycobacterium w: a candidate antileprosy vaccine using monoclonal antibodies and patient sera. Zentralblatt für Bakteriologie 1990;273(3):378-85.

\section{Gelfand 1957}

Gelfand M. The Sick African. The Sick African. 3rd Edition. Cape Town: Juta, 1957:447.

\section{GRADEpro GDT 2014 [Computer program]}

GRADE Working Group, McMaster University. GRADEpro GDT. Version accessed 15 September 2014. Hamilton (ON): GRADE Working Group, McMaster University, 2014.

\section{Guyatt 2008}

Guyatt GH, Oxman AD, Vist GE, Kunz R, Falck-Ytter Y, AlonsoCoello $P$, et al. GRADE: an emerging consensus on rating quality of evidence and strength of recommendations. $B M J$ 2008;336(7650):924-6.

\section{Harvey 1937}

Harvey AM, Whitehill MR. Tuberculous pericarditis. Medicine 1937; 16:45-94

\section{Higgins 2011}

Higgins JP, Green S, editor(s). Cochrane Handbook for Systematic Reviews of Interventions Version 5.1.0 (updated March 2011). The Cochrane Collaboration, 2011. Available from handbook.cochrane.org. The Cochrane Collaboration.

\section{Imazio 2015}

Imazio M, Gaita F, LeWinter M. Evaluation and treatment of pericarditis: a systematic review. JAMA 2015;314(14):1498-506.

\section{Kliner 2014}

Kliner M, Garner P. When trial authors write Cochrane Reviews: competing interests need to be better managed [editorial]. Cochrane Database of Systematic Reviews 2014; Vol. 9:10.1002/14651858.ED000089.

\section{Koh 1994}

Koh KK, Kim EJ, Cho CH, Choi MJ, Cho SK, Kim SS, et al. Adenosine deaminase and carcinoembryonic antigen in pericardial effusion diagnosis, especially in suspected tuberculous pericarditis. Circulation 1994;89(6):2728-35.

\section{Lawn 2011}

Lawn SD, Zumla Al. Tuberculosis. Lancet 2011;378(9785):57-72.

\section{Lefebvre 2011}

Lefebvre C, Manheimer E, Glanville J. Chapter 6: Searching for studies. In: Higgins JP, Green S, editor(s). Cochrane Handbook for Systematic Reviews of Interventions Version 5.1.0 (updated March 2011). The Cochrane Collaboration, 2011. Available from handbook.cochrane.org. The Cochrane Collaboration.

\section{Lorell 1997}

Lorell BH. Pericardial diseases. In: Braunwald E editor(s). Heart disease: a Textbook of Cardiovascular Medicine. Philadelphia: W.B. Saunders, 1997.

\section{Lucas 1993}

Lucas SB, Hounnou A, Peacock C, Beaumel A, Djomand G, N'Gbichi JM, et al. The mortality and pathology of HIV infection in a West African city. AIDS 1993;7(12):1569-79.

\section{Maartens 2007}

Maartens G, Wilkinson RJ. Tuberculosis. Lancet 2007;370(9604):2030-43.

\section{Mayosi 2005}

Mayosi BM, Burgess LJ, Doubell AF. Tuberculous pericarditis. Circulation 2005;112(23):3608-16.

\section{Mayosi 2006}

Mayosi BM, Wiysonge CS, Ntsekhe M, Volmink JA, Gumedze F, Maartens $G$, et al. Clinical characteristics and initial management of patients with tuberculous pericarditis in the HIV era: the Investigation of the Management of Pericarditis in Africa (IMPI Africa) registry. BMC Infectious Diseases 2006;6:2.

\section{Mayosi 2008}

Mayosi BM, Wiysonge CS, Ntsekhe M, Gumedze F, Volmink JA, Maartens $\mathrm{G}$, et al. Mortality in patients treated for tuberculous pericarditis in sub-Saharan Africa. South African Medical Journal 2008;98(1):36-40.

\section{Mutyaba 2014}

Mutyaba AK, Balkaran S, Cloete R, du Plessis N, Badri M, Brink J, et al. Constrictive pericarditis requiring pericardiectomy at Groote Schuur Hospital, Cape Town, South Africa: causes and 
perioperative outcomes in the HIV era (1990-2012). Journal of Thoracic and Cardiovascular Surgery 2014;148(6):3058-65.e1.

\section{Ntsekhe 2003}

Ntsekhe M, Wiysonge C, Volmink JA, Commerford PJ, Mayosi BM. Adjuvant corticosteroids for tuberculous pericarditis: promising, but not proven. QJM 2003;96(8):593-9.

\section{Ntsekhe 2005}

Ntsekhe M, Hakim J. Impact of human immunodeficiency virus infection on cardiovascular disease in Africa. Circulation 2005;112(23):3602-7.

\section{Ntsekhe 2008}

Ntsekhe M, Wiysonge CS, Gumedze F, Maartens G, Commerford PJ, Volmink JA, et al. HIV infection is associated with a lower incidence of constriction in presumed tuberculous pericarditis: a prospective observational study. PLOS ONE 2008;3(6):e2253.

\section{Ntsekhe 2012}

Ntsekhe M, Shey Wiysonge C, Commerford PJ, Mayosi BM. The prevalence and outcome of effusive constrictive pericarditis: a systematic review of the literature. Cardiovascular Journal of Africa 2012;23(5):281-5.

\section{Ntsekhe 2013}

Ntsekhe M, Mayosi BM. Tuberculous pericarditis with and without HIV. Heart Failure Reviews 2013;18(3):367-73.

\section{Pandie 2014}

Pandie S, Engel ME, Kerbelker ZS, Mayosi BM. Mycobacterium w immunotherapy for treating pulmonary tuberculosis - a systematic review. Current Pharmaceutical Design 2014;20(39):6207-14.

\section{Pasipanodya 2015}

Pasipanodya JG, Mubanga M, Ntsekhe M, Pandie S, Magazi BT, Gumedze F, et al. Tuberculous pericarditis is multibacillary and bacterial burden drives high mortality. EBioMedicine 2015;2(11):1634-9.

\section{Pereira 2012}

Pereira TV, Horwitz RI, loannidis JP. Empirical evaluation of very large treatment effects of medical interventions. JAMA 2012;308(16):1676-84.

\section{Quayle 1987}

Quayle JM, Lipschik GY, Heurich AE. Management of tuberculous pericarditis. Annals of Thoracic Surgery 1987;43(6):653-5.

\section{Rana 1997}

Rana F, Hawken MP, Meme HK, Chakaya JM, Githui WA, Odhiambo JA, et al. Autopsy findings in HIV-1-infected adults in Kenya. Journal of Acquired Immune Deficiency Syndromes and Human Retrovirology 1997;14(1):83-5.

\section{RevMan 2014 [Computer program]}

Nordic Cochrane Centre, The Cochrane Collaboration. Review Manager 5 (RevMan 5). Version 5.3. Copenhagen: Nordic Cochrane Centre, The Cochrane Collaboration, 2014.

\section{Rooney 1970}

Rooney JJ, Crocco JA, Lyons HA. Tuberculous pericarditis. Annals of Internal Medicine 1970;72(1):73-8.

\section{Sagristà-Sauleda 1988}

Sagristà-Sauleda J, Permanya-Miralda G, Soler-Soler J. Tuberculous pericarditis: ten year experience with a prospective protocol for diagnosis and treatment. Journal of the American College of Cardiology 1988;11(4):724-8.

\section{Saini 2009}

Saini V, Raghuvanshi S, Talwar GP, Ahmed N, Khurana JP, Hasnain SE, et al. Polyphasic taxonomic analysis establishes Mycobacterium indicus pranii as a distinct species. PLOS ONE 2009;4(7):e6263.

\section{Schrire 1967}

Schrire V. Pericarditis (with particular reference to tuberculous pericarditis). Australian Annals of Medicine 1967;16(1):41-51.

\section{Senderovitz 1994}

Senderovitz T, Viskum K. Corticosteroids and tuberculosis. Respiratory Medicine 1994;88(8):561-5.

\section{Shenje 2015}

Shenje J, Ifeoma Adimora-Nweke F, Ross IL, Ntsekhe M, Wiesner L, Deffur A, et al. Poor penetration of antibiotics into pericardium in pericardial tuberculosis. EBioMedicine 2015;2(11):1640-9.

\section{Singh 1992}

Singh IG, Mukherjee R, Talwar GP, Kaufmann SH. In vitro characterization of $T$ cells from Mycobacterium w-vaccinated mice. Infection and Immunity 1992;60(1):257-63.

\section{Strang 1984}

Strang JIG. Tuberculous pericarditis in Transkei. Clinical Cardiology 1984;7(12):667-70.

\section{Strang 1997}

Strang JIG. Tuberculous pericarditis. Journal of Infection 1997;35(3):215-9.

\section{Syed 2007}

Syed FF, Mayosi BM. A modern approach to tuberculous pericarditis. Progress in Cardiovascular Diseases 2007;50(3):218-36

\section{Wiysonge 2014}

Wiysonge CS. Immunotherapy for tuberculous pericarditis. New England Journal of Medicine 2014;371(26):2533. [DOI: 10.1056/ NEJMc1413185\#SA4] 


\section{Zumla 2015}

Zumla A, Maeurer M, Moll G, Mayosi BM. Host-directed therapies for tuberculous pericarditis. International Journal of Infectious Diseases 2015;32:30-1.

\section{References to other published versions of this review Mayosi 2000}

Mayosi BM, Volmink JA, Commerford PJ. Interventions for treating tuberculous pericarditis. Cochrane

\section{CHARACTERISTICS OF STUDIES}

Characteristics of included studies [ordered by study ID]
Database of Systematic Reviews 2000, Issue 2. [DOI: 10.1002/14651858.CD000526]

\section{Mayosi 2002}

Mayosi BM, Ntsekhe M, Volmink JA, Commerford PJ. Interventions for treating tuberculous pericarditis. Cochrane Database of Systematic Reviews 2002, Issue 4. [DOI: 10.1002/14651858.CD000526]

* Indicates the major publication for the study

Hakim 2000

Methods Computer-generated randomization list

Double blind placebo controlled trial

Participants 58 HIV-positive participants who were on antituberculous chemotherapy for suspected tuberculous pericarditis.

Inclusion criteria: (a) age 18 to 55 years; (b) residence in Harare city to ensure good follow up; (c) HIV seropositive; (d) no diagnosis of tuberculosis within the past two years; (e) large pericardial effusion on echocardiography (>1 cm anteriorly and $>1 \mathrm{~cm}$ posteriorly; and ( $\mathrm{f}$ ) pericardial aspirate with $>50 \%$ lymphocytes and protein content $>30 \mathrm{~g} / \mathrm{L}$.

Exclusion criteria: (a) antituberculous treatment started more than 48 hours before recruitment; (b) corticosteroid treatment within previous one month; (c) presence of Kaposi's sarcoma or any other malignancy; (d) coexisting life threatening disease; (e) bacterial pneumonia; (f) pregnancy; (g) cavitating pulmonary tuberculosis; and $(h)$ other causes of pericardial effusion.

"All patients received a standard short course anti tuberculous regimen in accordance with national guidelines. This included rifampicin, isoniazid, pyrazinamide, and ethambutol for two months, followed by rifampicin and isoniazid for a further four months in standard doses."

Interventions

Intervention

- Prednisolone for the first 6 weeks of antituberculous chemotherapy.

- Dose for adults: $60 \mathrm{mg}$ for the first week, and tapering by $10 \mathrm{mg}$ every week.

\section{Control}

- Placebo.

Outcomes Primary outcomes

- Death.

- Resolution of pericardial effusion.

\section{Secondary outcomes}

- Resolution of pretreatment symptoms and signs, and ECG changes.

- Corticosteroid-related adverse effects. 
Hakim 2000 (Continued)

\begin{tabular}{lll} 
Bias & Authors' judgement & Support for judgement \\
\hline $\begin{array}{l}\text { Random sequence genera- } \\
\text { tion (selection bias) }\end{array}$ & Low risk & $\begin{array}{l}\text { "Randomisation was achieved by the use of a computer generated randomisa- } \\
\text { tion list". }\end{array}$ \\
\hline $\begin{array}{l}\text { Allocation concealment } \\
\text { (selection bias) }\end{array}$ & Low risk & $\begin{array}{l}\text { "Prednisolone/placebo packages were prepared according to the randomisa- } \\
\text { tion list, but labelled with the study number only. A package consisted of six } \\
\text { well labelled bottles each containing the number of tablets required in each of } \\
\text { the six weeks of the intervention. Eligible patients were given a drug package } \\
\text { consecutively working down the randomisation list." }\end{array}$
\end{tabular}

$\begin{aligned} & \text { Blinding of participants } \\ & \text { and personnel (perfor- }\end{aligned}$
"Clinicians and patients were blinded to the identity of the tablets. A randomi-
sation code list was kept sealed and was released at the end of the study".

All outcomes

Blinding of outcome as- Low risk sessment (detection bias)

All outcomes
Two cardiologists with extensive experience of echocardiography in this setting performed all examinations. "Clinicians and patients were blinded to the identity of the tablets. A randomisation code list was kept sealed and was released at the end of the study".

Incomplete outcome data Low risk Follow-up data was available on all 58 enrolled participants.

(attrition bias)

All outcomes

\begin{tabular}{|c|c|c|}
\hline $\begin{array}{l}\text { Selective reporting (re- } \\
\text { porting bias) }\end{array}$ & Unclear risk & $\begin{array}{l}\text { The study protocol was not available and there is no earlier methods paper } \\
\text { listing the prespecified outcomes. }\end{array}$ \\
\hline Other bias & Low risk & $\begin{array}{l}\text { There is no evidence that the study had any additional biases to the ones men- } \\
\text { tioned above. }\end{array}$ \\
\hline
\end{tabular}

Liebenberg 2016

$\begin{array}{ll}\text { Methods } & \text { Participants "were randomised to an intervention and control group using a web-based computer sys- } \\ \text { tem that ensured assignment concealment". } \\ \text { "Upon completion of the research period, the blinding was unveiled and data were presented for statis- } \\ \text { tical analysis". }\end{array}$

Participants
in the Northern Cape of South Africa.
All participants received standard treatment according to the South African National Tuberculosis
Management Guidelines, that is weight-adjusted antituberculosis drugs and oral corticosteroids for 4
weeks. Participants also had pericardial "aspiration until dryness", and antiretroviral therapy.

Interventions

\section{Intervention}

- Colchicine $1.0 \mathrm{mg}$ per day for 6 weeks.

\section{Comparison}

- Placebo for 6 weeks.

Participants were followed up with serial echocardiography for 16 weeks. 
Liebenberg 2016 (Continued)

- Constrictive pericarditis.

Notes Study location: Kimberley, South Africa.

\section{Risk of bias}

\begin{tabular}{lll}
\hline Bias & Authors' judgement & Support for judgement \\
\hline $\begin{array}{l}\text { Random sequence genera- } \\
\text { tion (selection bias) }\end{array}$ & Low risk & $\begin{array}{l}\text { The mention of an internet-based computer system implies use of a comput- } \\
\text { er-generated randomization sequence. }\end{array}$ \\
\hline
\end{tabular}

\begin{tabular}{lll}
\hline $\begin{array}{l}\text { Allocation concealment } \\
\text { (selection bias) }\end{array}$ & Low risk & $\begin{array}{l}\text { Participants "were randomised to an intervention and control group using a } \\
\text { web-based computer system that ensured assignment concealment". }\end{array}$ \\
\hline $\begin{array}{l}\text { Blinding of participants } \\
\begin{array}{l}\text { and personnel (perfor- } \\
\text { mance bias) }\end{array}\end{array}$ & Unclear risk & $\begin{array}{l}\text { The study authors reported that "Upon completion of the research period, the } \\
\text { blinding was unveiled and data were presented for statistical analysis", but did } \\
\text { All outcomes }\end{array}$ \\
\hline
\end{tabular}

\begin{tabular}{|c|c|c|}
\hline $\begin{array}{l}\text { Blinding of outcome as- } \\
\text { sessment (detection bias) }\end{array}$ & Low risk & $\begin{array}{l}\text { The study reported that blinding was unveiled only after completion of the fol- } \\
\text { low-up period, when presenting data to the statistician. }\end{array}$ \\
\hline
\end{tabular}

All outcomes

Incomplete outcome data High risk In this study, 5/33 (15.15\%) participants were lost to follow-up.
(attrition bias)

All outcomes

\begin{tabular}{lll}
\hline $\begin{array}{l}\text { Selective reporting (re- } \\
\text { porting bias) }\end{array}$ & Unclear risk & $\begin{array}{l}\text { We do not have access to the study protocol and are unable to comment on } \\
\text { whether there was selective reporting of outcomes in this study. }\end{array}$ \\
\hline Other bias & Low risk & There was no evidence of other sources of bias in the study. \\
\hline
\end{tabular}

\section{Mayosi 2014}

\begin{tabular}{ll}
\hline Methods & Computer-generated randomization list \\
& Double-blind placebo-controlled $2 \times 2$ factorial study \\
\hline Participants & $\begin{array}{l}1400 \text { participants (two-thirds HIV-positive) } 18 \text { years of age or older, with a pericardial effusion con- } \\
\text { firmed by echocardiography, evidence of definite or probable tuberculous pericarditis, and had begun } \\
\text { antituberculous treatment less than } 1 \text { week before enrolment. } \\
\text { "Trial participants received antimicrobial treatment for tuberculosis and antiretroviral treatment for } \\
\text { HIV according to World Health Organization (WHO) guidelines; management during the course of the } \\
\text { trial was revised as recommended treatment practices evolved". }\end{array}$ \\
\hline
\end{tabular}

- Prednisolone for 6 weeks at a dose of $120 \mathrm{mg}$ per day in the first week, $90 \mathrm{mg}$ per day in the second week, $60 \mathrm{mg}$ per day in the 3rd week, $30 \mathrm{mg}$ per day in the 4th week, $15 \mathrm{mg}$ per day in the 5 th week, and $5 \mathrm{mg}$ per day in the 6th week.

\section{Control 1}

- Identical placebo for 6 weeks at a dose of $120 \mathrm{mg}$ per day in the $1 \mathrm{st}$ week, $90 \mathrm{mg}$ per day in the 2nd week, $60 \mathrm{mg}$ per day in the 3rd week, $30 \mathrm{mg}$ per day in the 4th week, $15 \mathrm{mg}$ per day in the 5 th week, and $5 \mathrm{mg}$ per day in the 6th week. 
Mayosi 2014 (Continued)

\section{Intervention 2}

- M. indicus pranii preparation (CADI-Mw injection, Cadila Pharmaceuticals) in 5 doses: at the time of enrolment and at 2 weeks, 4 weeks, 6 weeks, and 3 months. The 1 st dose was given as 2 injections of $0.1 \mathrm{~mL}$ (containing $0.5 \times 10^{9}$ organisms) in each deltoid region of the upper arm; the 4 subsequent doses were given as a single injection of $0.1 \mathrm{~mL}$.

\section{Control 2}

- Identical placebo in 5 doses: at the time of enrolment and at 2 weeks, 4 weeks, 6 weeks, and 3 months. The 1st dose was given as 2 injections of $0.1 \mathrm{~mL}$ in each deltoid region of the upper arm; the 4 subsequent doses were given as a single injection of $0.1 \mathrm{~mL}$.

Primary outcome
- Composite of death or 1st occurrence of cardiac tamponade requiring pericardiocentesis or constric-
tive pericarditis.

\section{Secondary outcomes}

- Individual components of the primary outcome.

- Hospitalization.

\section{Safety outcomes}

- Opportunistic infections.

- Cancer.

- CD4+ T-lymphocyte cell count (measure of immunosuppression) and immune reconstitution inflammatory syndrome (in HIV-positive).

Notes

Study location: multiple sites in South Africa, Mozambique, Malawi, Uganda, Sierra Leone, Zimbabwe, Kenya, and Nigeria

\section{Risk of bias}

\begin{tabular}{|c|c|c|}
\hline Bias & Authors' judgement & Support for judgement \\
\hline $\begin{array}{l}\text { Random sequence genera- } \\
\text { tion (selection bias) }\end{array}$ & Low risk & Computer-generated randomization list. \\
\hline $\begin{array}{l}\text { Allocation concealment } \\
\text { (selection bias) }\end{array}$ & Low risk & Central allocation, stratified by centre, with random block sizes. \\
\hline $\begin{array}{l}\text { Blinding of participants } \\
\text { and personnel (perfor- } \\
\text { mance bias) } \\
\text { All outcomes }\end{array}$ & Low risk & Both prednisolone and M. indicus pranii preparation had identical placebos. \\
\hline $\begin{array}{l}\text { Blinding of outcome as- } \\
\text { sessment (detection bias) } \\
\text { All outcomes }\end{array}$ & Low risk & $\begin{array}{l}\text { A committee of clinicians blinded to treatment allocation (the Outcomes Adju- } \\
\text { dication Committee) adjudicated all primary and secondary outcomes. }\end{array}$ \\
\hline $\begin{array}{l}\text { Incomplete outcome data } \\
\text { (attrition bias) } \\
\text { All outcomes }\end{array}$ & Low risk & $\begin{array}{l}\text { Participants were analysed in groups to which they were randomized, regard- } \\
\text { less of how much of the intended intervention they actually received. Prima- } \\
\text { ry outcome data were known for } 1371 \text { of } 1400(97.9 \%) \text { participants in the pred- } \\
\text { nisolone-placebo comparison; with no significant differences between pred- } \\
\text { nisolone }(688 / 706 ; .97 .5 \%) \text { and placebo }(683 / 694 ; 98.4 \%) \text { arms. For the } M \text {. in- } \\
\text { dicus pranii - placebo comparison, primary outcome data were available for } \\
1223 \text { of } 1250 \text { participants }(97.8 \%) \text {; with no significant differences between } M \text {. } \\
\text { indicus pranii }(611 / 625 ; 97.8 \%) \text { and placebo }(612 / 625 ; 97.9 \%) \text {. }\end{array}$ \\
\hline
\end{tabular}


Mayosi 2014 (Continued)

Selective reporting (re- Low risk The study authors reported the outcomes planned for in the prospective trial porting bias) registration (ClinicalTrials.gov registration number NCT100810849) and pub-

lished protocol in the trial report.

Other bias Low risk There was no evidence of other biases in the study.

Reuter 2006

$\begin{array}{ll}\text { Methods } & \text { Computer-generated randomization list } \\ \text { Double-blind placebo-controlled study }\end{array}$

Participants 57 participants, aged 17 to 66 years, with large pericardial effusions on echocardiography, pericardial aspirate with protein content $>30 \mathrm{~g} / \mathrm{L}$, and pericardial fluid adenosine deaminase (ADA) activity $>35$ $\mathrm{U} / \mathrm{L} ; 23$ females and 34 males; 40 had microbiological or histological evidence of TB or both, and 17 patients were diagnosed by clinical and supportive laboratory data. 21 (37.0\%) were HIV-positive.

"A standard short-course anti-tuberculous regimen was initiated according to national guidelines, namely a combination of rifampicin, isoniazid, pyrazinamide and ethambutol for two months, followed by rifampicin and isoniazid for a further four months...Patients were discharged on anti-tuberculous therapy and pyridoxine, with or without adjunctive prednisone. HIV-positive patients also received daily oral cotrimoxazole; due to the prevailing national policy at the time of this study, none of these patients received antiretroviral therapy".

\section{Intervention 1}

- $200 \mathrm{mg}(5 \mathrm{~mL})$ intrapericardial triamcinolone hexacetonide. Triamcinolone was injected directly into the pericardium just prior to the removal of the indwelling catheter. Due to limited resources, an oral placebo was not used in conjunction with the intrapericardial triamcinolone. 17 participants were in this arm, 6 (35\%) were HIV-positive.

\section{Intervention 2}

- Oral prednisone plus intrapericardial placebo ( $5 \mathrm{~mL} 0.9 \%$ saline solution). Oral prednisone was started at $60 \mathrm{mg} /$ day for 4 weeks, followed by $30 \mathrm{mg} /$ day for 4 weeks, $15 \mathrm{mg} /$ day for 2 weeks and $5 \mathrm{mg} /$ day for 1 week. There were 16 participants in this arm, 9 (56\%) were HIV-positive.

\section{Control}

- Placebo (5 mL intrapericardial 0.9\% saline). 24 participants were included in this arm, and 6 (25\%) were HIV-positive.

\section{Primary outcome}

- All-cause mortality.

\section{Secondary outcomes}

- Death attributed to pericarditis.

- Disability related to pericardial disease at 1 year (defined as a history of restricted physical activity using New York Heart Association functional classification.

- Effusive constriction.

- Fibrous constrictive pericarditis requiring pericardiectomy.

\section{Notes} Study location: Cape Town, South Africa.

We excluded data from the intrapericardial triamcinolone arm from this review. 
Reuter 2006 (Continued)

Risk of bias

\begin{tabular}{lll}
\hline Bias & Authors' judgement & Support for judgement \\
\hline $\begin{array}{l}\text { Random sequence genera- } \\
\text { tion (selection bias) }\end{array}$ & Unclear risk & $\begin{array}{l}\text { Participants were "randomly assigned as per a predetermined randomisation } \\
\text { schedule for } 100 \text { patients on a 3:3:4 basis. Numbers were drawn from a hat, } \\
\text { stored on a list on a computer and provided to the treating physician with the } \\
\text { assigned treatment by a non-clinical administrator." }\end{array}$
\end{tabular}

\begin{tabular}{lll}
\hline $\begin{array}{l}\text { Allocation concealment } \\
\text { (selection bias) }\end{array}$ & High risk & $\begin{array}{l}\text { An unblinded, independent physician administered one of the three randomly } \\
\text { assigned treatment options. }\end{array}$ \\
\hline $\begin{array}{l}\text { Blinding of participants } \\
\begin{array}{l}\text { and personnel (perfor- } \\
\text { mance bias) }\end{array}\end{array}$ & Low risk & $\begin{array}{l}\text { The randomisation code remained concealed and was not revealed to the in- } \\
\text { vestigators or the study subjects until completion of the study." }\end{array}$ \\
All outcomes &
\end{tabular}

\begin{tabular}{|c|c|c|}
\hline $\begin{array}{l}\text { Blinding of outcome as- } \\
\text { sessment (detection bias) } \\
\text { All outcomes }\end{array}$ & Unclear risk & $\begin{array}{l}\text { The study states that outcomes were assessed using a combination of clini- } \\
\text { cal and echocardiographic features, but there is no mention of blinding of out- } \\
\text { come assessment. }\end{array}$ \\
\hline
\end{tabular}

\begin{tabular}{lll}
\hline $\begin{array}{l}\text { Incomplete outcome data } \\
\text { (attrition bias) }\end{array}$ & High risk \\
$\begin{array}{l}\text { All outcomes } \\
\text { Selective reporting (re- }\end{array} \quad$ Unclear risk & We do not have access to the study protocol and are unable to comment on \\
porting bias) & whether there was selective reporting of outcomes in this study.
\end{tabular}

\begin{tabular}{ll}
\hline Other bias $\quad$ Low risk No evidence of other biases \\
\hline
\end{tabular}

\section{Schrire 1959}

\begin{tabular}{ll}
\hline Methods & Alternate allocation of 28 participants to adjuvant steroids or no steroids \\
\hline Participants & $\begin{array}{l}28 \text { participants who were on antituberculous chemotherapy for suspected tuberculous pericarditis. } \\
\text { The trial authors did not provide the characteristics of the included participants, and did not specify } \\
\text { the antituberculous drugs used. }\end{array}$ \\
\hline
\end{tabular}

Intervention
$\begin{aligned} & \text { Interventions } \\ & \text { Cortisone with a loading dose of } 300 \mathrm{mg} \text { and maintenance dose of } 100 \mathrm{mg} \text { daily for several weeks was } \\ & \text { prescribed for } 14 \text { participants. At a later date, prednisolone } 60 \mathrm{mg} / \text { day with a maintenance dose of } \\ & 20 \mathrm{mg} \text { was substituted. }\end{aligned}$

\section{Control}

- No corticosteroids.

The trial authors did not specify the length of follow-up.

\begin{tabular}{ll}
\hline Outcomes & Constriction requiring pericardiectomy \\
\hline Notes & Study location: Cape Town, South Africa \\
\hline
\end{tabular}

\section{Risk of bias}


Schrire 1959 (Continued)

\begin{tabular}{lll} 
Bias & Authors' judgement & Support for judgement \\
\hline $\begin{array}{l}\text { Random sequence genera- } \\
\text { tion (selection bias) }\end{array}$ & High risk & The trial authors performed randomization by alternation.
\end{tabular}

tion (selection bias)

\begin{tabular}{l}
$\begin{array}{l}\text { Allocation concealment } \\
\text { (selection bias) }\end{array}$ High risk there was no allocation concealment. \\
\hline
\end{tabular}

\begin{tabular}{|c|c|c|}
\hline $\begin{array}{l}\text { Blinding of participants } \\
\text { and personnel (perfor- } \\
\text { mance bias) } \\
\text { All outcomes }\end{array}$ & High risk & The trial did not perform any blinding. \\
\hline $\begin{array}{l}\text { Blinding of outcome as- } \\
\text { sessment (detection bias) } \\
\text { All outcomes }\end{array}$ & High risk & There was no evidence of blinding of outcome assessors. \\
\hline $\begin{array}{l}\text { Incomplete outcome data } \\
\text { (attrition bias) } \\
\text { All outcomes }\end{array}$ & Unclear risk & The trial authors did not adequately report losses to follow-up. \\
\hline $\begin{array}{l}\text { Selective reporting (re- } \\
\text { porting bias) }\end{array}$ & Unclear risk & The study protocol was not available. \\
\hline Other bias & Low risk & There was no evidence of other sources of bias. \\
\hline
\end{tabular}

Strang 2004a

\begin{tabular}{|c|c|}
\hline Methods & $\begin{array}{l}\text { Central randomization } \\
\text { Double blind placebo-controlled study }\end{array}$ \\
\hline Participants & $\begin{array}{l}143 \text { participants with suspected tuberculous constrictive pericarditis aged } 5 \text { years and older. The par- } \\
\text { ticipants in the treatment and control groups were well-matched in terms of clinical characteristics and } \\
\text { completion of antituberculous chemotherapy. }\end{array}$ \\
\hline & $\begin{array}{l}\text { "Those consenting to take part were all prescribed the same } 6 \text {-month standard antituberculosis regi- } \\
\text { men of streptomycin, isoniazid, rifampicin, and pyrazinamide daily for } 14 \text { weeks as an in-patient, fol- } \\
\text { lowed by isoniazid and rifampicin daily up to } 6 \text { months." }\end{array}$ \\
\hline
\end{tabular}

Interventions

\section{Intervention}

- Prednisolone for the first 11 weeks of antituberculous chemotherapy. The dose for children aged 5 to 9 years was $30 \mathrm{mg}$ daily for weeks 1 to $4 ; 15 \mathrm{mg}$ daily for weeks 5 to $8 ; 7.5 \mathrm{mg}$ daily for weeks 9 to 10 ; and $2.5 \mathrm{mg}$ daily for week 11 . Regarding children aged 10 to 14 years, the dose was $45 \mathrm{mg}$ for weeks 1 to $4 ; 22.5 \mathrm{mg}$ for weeks 5 to $8 ; 7.5 \mathrm{mg}$ for weeks 9 to 10 ; and $2.5 \mathrm{mg}$ for week 11 . The dose for adults was $60 \mathrm{mg}$ for the first 4 weeks; $30 \mathrm{mg}$ for weeks 5 to $8 ; 15 \mathrm{mg}$ for weeks 9 to 10 ; and $5 \mathrm{mg}$ for week 1 .

\section{Control}

- Matching placebo.

\begin{tabular}{ll}
\hline Outcomes & Death. \\
- & Death from pericarditis. \\
- Favourable clinical status at 24 months. \\
- Pericardiectomy.
\end{tabular}


Strang 2004a (Continued)

Notes Study location: Umtata, South Africa

\section{Risk of bias}

\begin{tabular}{|c|c|c|}
\hline Bias & Authors' judgement & Support for judgement \\
\hline $\begin{array}{l}\text { Random sequence genera- } \\
\text { tion (selection bias) }\end{array}$ & Low risk & The trial authors used a random number list. \\
\hline $\begin{array}{l}\text { Allocation concealment } \\
\text { (selection bias) }\end{array}$ & Low risk & The trial authors used central randomization. \\
\hline $\begin{array}{l}\text { Blinding of participants } \\
\text { and personnel (perfor- } \\
\text { mance bias) } \\
\text { All outcomes }\end{array}$ & Low risk & Particianpts and care providers were blinded to treatment. \\
\hline $\begin{array}{l}\text { Blinding of outcome as- } \\
\text { sessment (detection bias) } \\
\text { All outcomes }\end{array}$ & Low risk & $\begin{array}{l}\text { Investigators, including outcome assessors, were blinded to treatment alloca- } \\
\text { tion. }\end{array}$ \\
\hline
\end{tabular}

\begin{tabular}{ll}
\hline $\begin{array}{l}\text { Incomplete outcome data } \\
\text { (attrition bias) }\end{array}$ & Low risk \\
All outcomes & During 10 years of follow-up, 1 participant (1.4\%) was lost to follow-up in the \\
prednisolone group and 2 participants (2.7\%) in the placebo group.
\end{tabular}

All outcomes

Selective reporting (re- $\quad$ Unclear risk
porting bias)

porting bias)

Other bias Low risk There was no evidence of other sources of bias.

Strang 2004b

\begin{tabular}{|c|c|}
\hline Methods & $\begin{array}{l}\text { Central randomization } \\
\text { Double blind placebo-controlled study } \\
\text { Factorial design }\end{array}$ \\
\hline Participants & $\begin{array}{l}240 \text { participants aged } 5 \text { years or more diagnosed as having active tuberculous pericardial effusion. The } \\
\text { participants in the treatment and control groups were well-matched in terms of their clinical character- } \\
\text { istics and completion of antituberculous chemotherapy. } \\
\text { "Those consenting to take part were all prescribed the same } 6 \text {-month standard antituberculosis regi- } \\
\text { men of streptomycin, isoniazid, rifampicin, and pyrazinamide daily for } 14 \text { weeks as an in-patient, fol- } \\
\text { lowed by isoniazid and rifampicin daily up to } 6 \text { months." }\end{array}$ \\
\hline
\end{tabular}

Interventions

Intervention 1

- Complete open surgical drainage on admission.

\section{Control 1}

- No open drainage.

\section{Intervention 2}

- Prednisolone for the first 11 weeks of antituberculous chemotherapy. The dose for children aged 5 to 9 years was $30 \mathrm{mg}$ daily for weeks 1 to $4 ; 15 \mathrm{mg}$ daily for weeks 5 to $8 ; 7.5 \mathrm{mg}$ daily for weeks 9 to 10 ; 
Strang 2004b (Continued)

and $2.5 \mathrm{mg}$ daily for week 11. Regarding children aged 10 to 14 years, the dose was $45 \mathrm{mg}$ for weeks 1 to $4 ; 22.5 \mathrm{mg}$ for weeks 5 to $8 ; 7.5 \mathrm{mg}$ for weeks 9 to 10 ; and $2.5 \mathrm{mg}$ for week 11 . The dose for adults was $60 \mathrm{mg}$ for the first 4 weeks; $30 \mathrm{mg}$ for weeks 5 to $8 ; 15 \mathrm{mg}$ for weeks 9 to 10; and $5 \mathrm{mg}$ for week 1 .

\section{Control 2}

- Matching placebo.

\begin{tabular}{ll}
\hline Outcomes & - Death. \\
- Death from pericarditis. \\
- Favourable clinical status at 24 months. \\
- Constriction. \\
- Pericardiectomy.
\end{tabular}

Notes Study location: Umtata, South Africa

\section{Risk of bias}

\begin{tabular}{|c|c|c|}
\hline Bias & Authors' judgement & Support for judgement \\
\hline $\begin{array}{l}\text { Random sequence genera- } \\
\text { tion (selection bias) }\end{array}$ & Low risk & The trial used a random number list to perform random sequence generation. \\
\hline $\begin{array}{l}\text { Allocation concealment } \\
\text { (selection bias) }\end{array}$ & Low risk & The trial authors performed central randomization. \\
\hline $\begin{array}{l}\text { Blinding of participants } \\
\text { and personnel (perfor- } \\
\text { mance bias) } \\
\text { All outcomes }\end{array}$ & Low risk & $\begin{array}{l}\text { The participants and investigators were blinded to the steroid component, but } \\
\text { not to the surgical drainage component. }\end{array}$ \\
\hline $\begin{array}{l}\text { Blinding of outcome as- } \\
\text { sessment (detection bias) } \\
\text { All outcomes }\end{array}$ & Low risk & $\begin{array}{l}\text { "For patients who died, information was obtained on cause of death from hos- } \\
\text { pital records, relatives, or other contacts. All the deaths were reviewed by an } \\
\text { independent assessor without knowledge of the treatment group, and where } \\
\text { possible, he classified the cause." }\end{array}$ \\
\hline $\begin{array}{l}\text { Incomplete outcome data } \\
\text { (attrition bias) } \\
\text { All outcomes }\end{array}$ & Low risk & $\begin{array}{l}\text { 5/117 (4.3\%) participants were lost to follow-up in the prednisolone group } \\
\text { compared to } 7 / 119(5.9 \%) \text { in the placebo group. } \\
2 / 64(3.1 \%) \text { participants were lost to follow-up in the drainage group com- } \\
\text { pared to } 3 / 58(5.2 \%) \text { in the no drainage group. }\end{array}$ \\
\hline $\begin{array}{l}\text { Selective reporting (re- } \\
\text { porting bias) }\end{array}$ & Unclear risk & There was no study protocol available. \\
\hline Other bias & Low risk & There was no evidence of other sources of bias. \\
\hline
\end{tabular}

\section{Characteristics of excluded studies [ordered by study ID]}

\begin{tabular}{ll}
\hline Study & Reason for exclusion \\
\hline Wiysonge 2008 & $\begin{array}{l}\text { Although this study is indexed in electronic databases as a controlled trial, it is actually a cross-sec- } \\
\text { tional study of the contemporary use of adjunctive steroids by physicians treating patients with tu- } \\
\text { berculous pericarditis. We thus excluded it from this review due to ineligible study design. }\end{array}$ \\
\hline
\end{tabular}


Characteristics of studies awaiting assessment [ordered by study ID]

\section{Cui 2005}

Methods $\begin{aligned} & \text { Consecutively recruited participants were "randomly" assigned to intervention or control arms, } \\ & \text { but no further details about random sequence generation and allocation concealment are not pro- } \\ & \text { vided in the abstract. The length of following-up varied from } 8 \text { to } 120 \text { months (mean } 56.8 \pm 29.0 \\ & \text { months). }\end{aligned}$

Participants

Ninety-four participants with infectious exudative pericarditis (34 with purulent pericarditis and 60 with tuberculous pericarditis); disease course less than 1 month; 44 males and 50 females; age 9 to 66 years (mean $45.4 \pm 14.7$ years); consecutively enrolled between 1993 to 2002 in China. The hospital and city are not specified.

$\begin{array}{ll}\text { Interventions } & \begin{array}{l}\text { Intervention arm: intrapericardial urokinase along with conventional treatment in intervention } \\ \text { arm, or conventional treatment alone (including pericardiocentesis and drainage) in the control } \\ \text { arm. The dosage of urokinase ranged from } 200,000 \text { to } 600,000 \mathrm{U} \text { (mean } 320,000 \pm 70,000 \mathrm{U} \text { ). }\end{array}\end{array}$

Outcomes Pericardial constriction, as detected by pericardiography with sterilized air and diatrizoate meglumine as contrast media (in the short-tem) and telephonic survey and echocardiographic examination (in the long-term).

Characteristics of ongoing studies [ordered by study ID]

\section{NCT02673879}

\begin{tabular}{|c|c|}
\hline Trial name or title & The Second Investigation of the Management of Pericarditis (IMPI-2) Trial \\
\hline Methods & $\begin{array}{l}\text { Study design: randomized trial } \\
\text { Intervention model: parallel assignment } \\
\text { Blinding: single blind (outcomes assessor) }\end{array}$ \\
\hline Participants & $\begin{array}{l}\text { The study plans to enrol } 2176 \text { participants. } \\
\text { Inclusion criteria } \\
\text { - Age } \geq 18 \text { years of age. } \\
\text { - Confirmed large pericardial effusion on echocardiography (that is, echo free space } \geq 1 \mathrm{~cm} \text { anterior } \\
\text { to the right ventricle of the heart in diastole). } \\
\text { - Willingness to participate for the full duration of the trial (that is, } 12 \text { months). } \\
\text { - Provision of written informed consent. } \\
\text { Exclusion criteria } \\
\text { - Age }<18 \text { years. } \\
\text { - Uraemic pericarditis (that is, urea }>21.4 \text { mmol } / \mathrm{L} \text { ). } \\
\text { - Thrombocytopenia (that is, }<100,000 \text { platelets } / \mu \mathrm{L} \text { ). } \\
\text { - Presence of a contraindication to the administration of a fibrinolytic agent (major haemorrhage or } \\
\text { major trauma; coincidental stroke; major surgery in the previous } 5 \text { days; blood pressure }>200 / 100 \\
\text { mmHg). }\end{array}$ \\
\hline
\end{tabular}




\section{Comparison: conventional pericardiocentesis.}

Outcomes

\section{Primary outcomes}

- Composite outcome of cardiac tamponade requiring pericardiocentesis or constrictive pericarditis.

\section{Secondary outcomes}

- Major bleeding.

- Clinically relevant non-major bleeding.

- Any bleeding.

- Any other form of bleeding that is not covered by safety outcomes 1-3.

- Other adverse events.

- Any other adverse events.

- Persistent pericardial effusion without cardiac tamponade.

- Recurrent pericardial effusion without cardiac tamponade.

- Hospitalization for any cause; and death from any cause.

- Cardiac tamponade requiring pericardiocentesis.

- Constrictive pericarditis.

- Death from any cause.

- Proportion with proven tuberculosis.

- Time to diagnosis of proven tuberculosis.

- Proportion with proven tuberculosis on novel tests who are not put on treatment.

- Diagnostic accuracy of novel tests of tuberculosis.

- Drug-resistant tuberculosis.

- Specific diagnosis of tuberculous pericarditis.

- Time to diagnosis of specific pericardial disease.

\section{Contacts:}

- Shaheen Pandie: Phone +27823199030; Email: s.pandie@uct.ac.za

- Veronica Francis: Phone+27832449895; Email: veronica.francis@uct.ac.za

\section{DATA AND ANALYSES}

\section{Comparison 1. Steroids versus placebo in HIV-negative people}

\begin{tabular}{lllll}
\hline $\begin{array}{l}\text { Outcome or subgroup ti- } \\
\text { tle }\end{array}$ & No. of studies & $\begin{array}{l}\text { No. of partici- } \\
\text { pants }\end{array}$ & Statistical method & Effect size \\
\hline 1 Deaths from all causes & 4 & 660 & Risk Ratio (M-H, Fixed, 95\% Cl) & $0.80[0.59,1.09]$ \\
\hline
\end{tabular}




\begin{tabular}{|c|c|c|c|c|}
\hline $\begin{array}{l}\text { Outcome or subgroup ti- } \\
\text { tle }\end{array}$ & No. of studies & $\begin{array}{l}\text { No. of partici- } \\
\text { pants }\end{array}$ & Statistical method & Effect size \\
\hline 2 Deaths from pericarditis & 4 & 660 & Risk Ratio (M-H, Fixed, 95\% Cl) & $0.39[0.19,0.80]$ \\
\hline 3 Constrictive pericarditis & 2 & 281 & Risk Ratio (M-H, Fixed, 95\% Cl) & $0.72[0.34,1.55]$ \\
\hline $\begin{array}{l}4 \text { Repeat pericardiocente- } \\
\text { sis }\end{array}$ & 2 & 492 & Risk Ratio (M-H, Fixed, 95\% Cl) & $0.85[0.70,1.04]$ \\
\hline 5 Cancer & 1 & 256 & Odds Ratio (M-H, Fixed, 95\% Cl) & $0.85[0.05,13.80]$ \\
\hline 6 Hospitalization & 1 & 256 & Risk Ratio (M-H, Fixed, 95\% Cl) & $0.98[0.57,1.70]$ \\
\hline 7 Pericardiectomy & 4 & 432 & Risk Ratio (M-H, Fixed, 95\% CI) & $0.91[0.58,1.41]$ \\
\hline 8 Opportunistic infections & 1 & 256 & Risk Ratio (M-H, Fixed, 95\% Cl) & $1.71[0.44,6.69]$ \\
\hline
\end{tabular}

\section{Analysis 1.1. Comparison 1 Steroids versus placebo in HIV-negative people, Outcome 1 Deaths from all causes.}

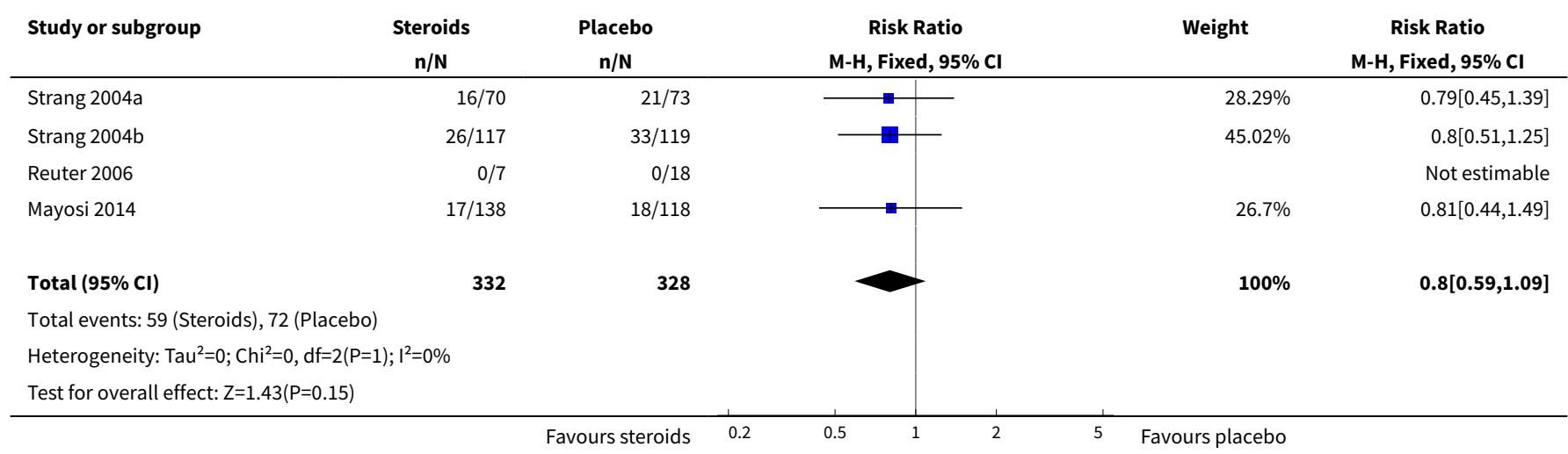

\section{Analysis 1.2. Comparison 1 Steroids versus placebo in HIV-negative people, Outcome 2 Deaths from pericarditis.}

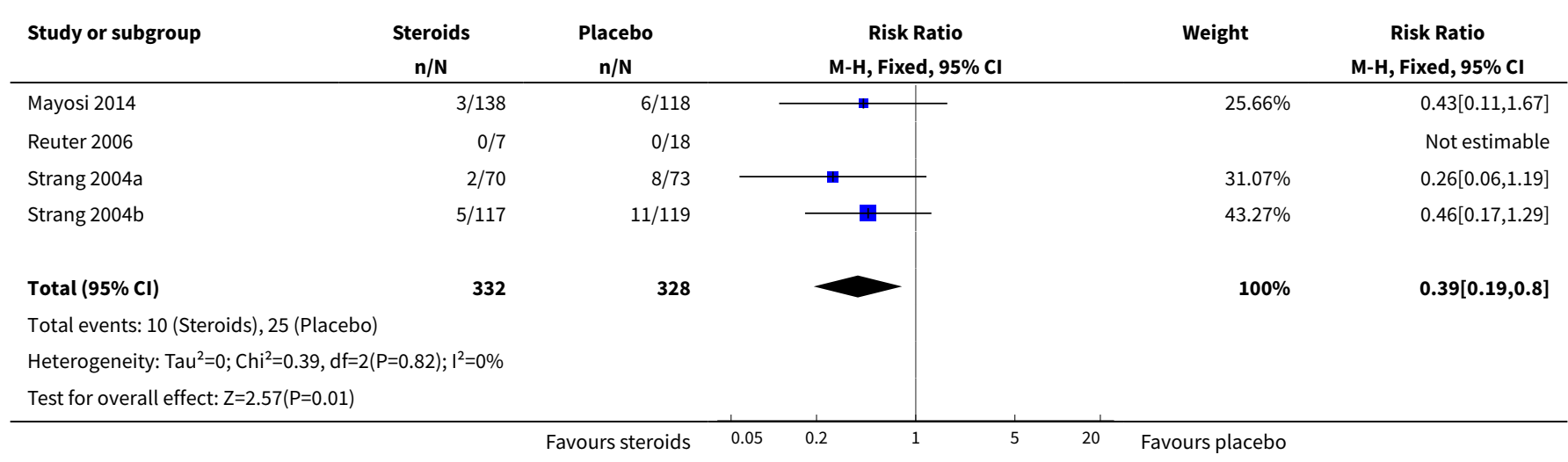


Analysis 1.3. Comparison 1 Steroids versus placebo in HIV-negative people, Outcome 3 Constrictive pericarditis.

\begin{tabular}{|c|c|c|c|c|c|}
\hline Study or subgroup & $\begin{array}{c}\text { Steroids } \\
\mathrm{n} / \mathrm{N}\end{array}$ & $\begin{array}{c}\text { Placebo } \\
\mathbf{n} / \mathbf{N}\end{array}$ & $\begin{array}{c}\text { Risk Ratio } \\
\text { M-H, Fixed, 95\% Cl }\end{array}$ & Weight & $\begin{array}{c}\text { Risk Ratio } \\
\text { M-H, Fixed, 95\% CI }\end{array}$ \\
\hline Mayosi 2014 & $11 / 138$ & $13 / 118$ & - & $100 \%$ & $0.72[0.34,1.55]$ \\
\hline Reuter 2006 & $0 / 7$ & $0 / 18$ & & & Not estimable \\
\hline Total $(95 \% \mathrm{Cl})$ & 145 & 136 & & $100 \%$ & $0.72[0.34,1.55]$ \\
\hline \multicolumn{6}{|c|}{ Total events: 11 (Steroids), 13 (Placebo) } \\
\hline Test for overall effect & & & & & \\
\hline
\end{tabular}

Analysis 1.4. Comparison 1 Steroids versus placebo in HIV-negative people, Outcome 4 Repeat pericardiocentesis.

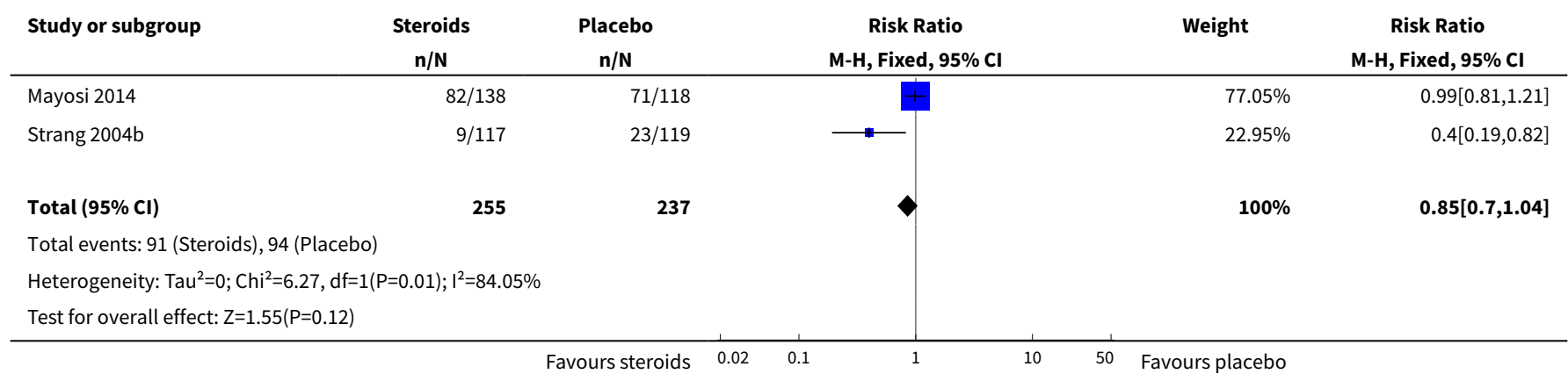

Analysis 1.5. Comparison 1 Steroids versus placebo in HIV-negative people, Outcome 5 Cancer.

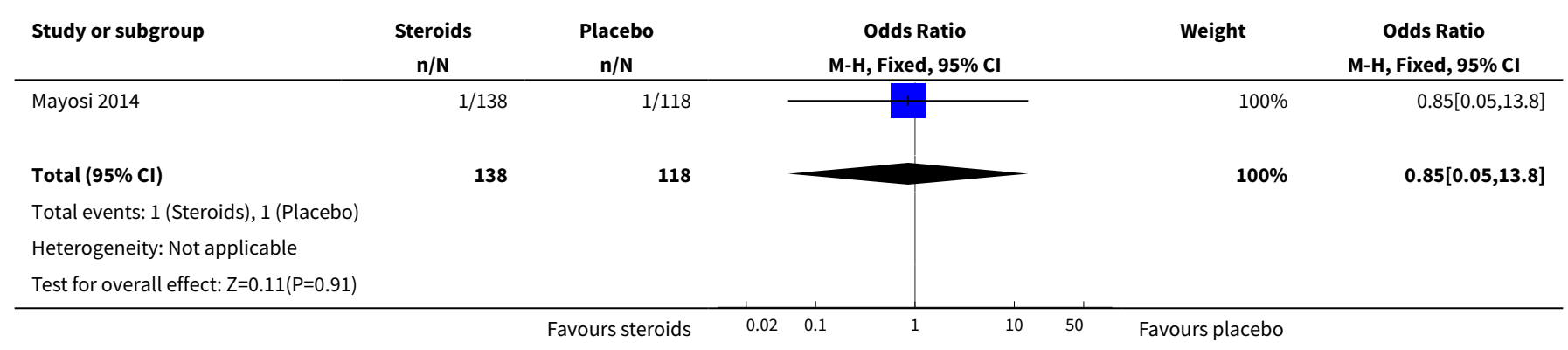

Analysis 1.6. Comparison 1 Steroids versus placebo in HIV-negative people, Outcome 6 Hospitalization.

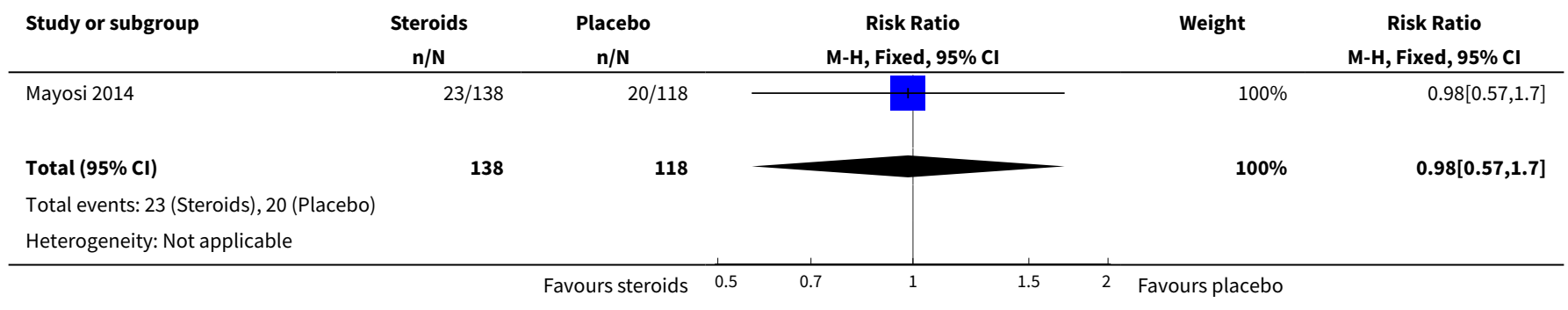




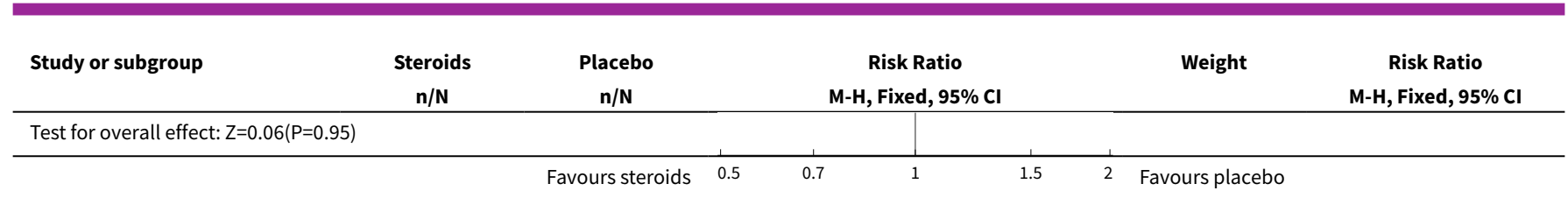

Analysis 1.7. Comparison 1 Steroids versus placebo in HIV-negative people, Outcome 7 Pericardiectomy.

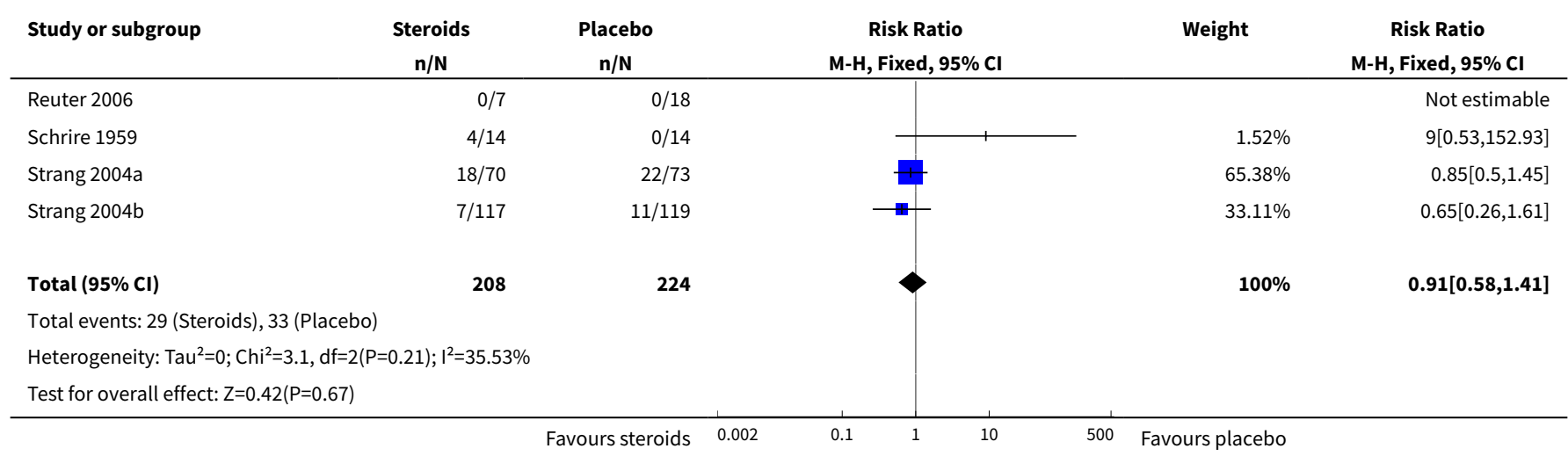

Analysis 1.8. Comparison 1 Steroids versus placebo in HIV-negative people, Outcome 8 Opportunistic infections.

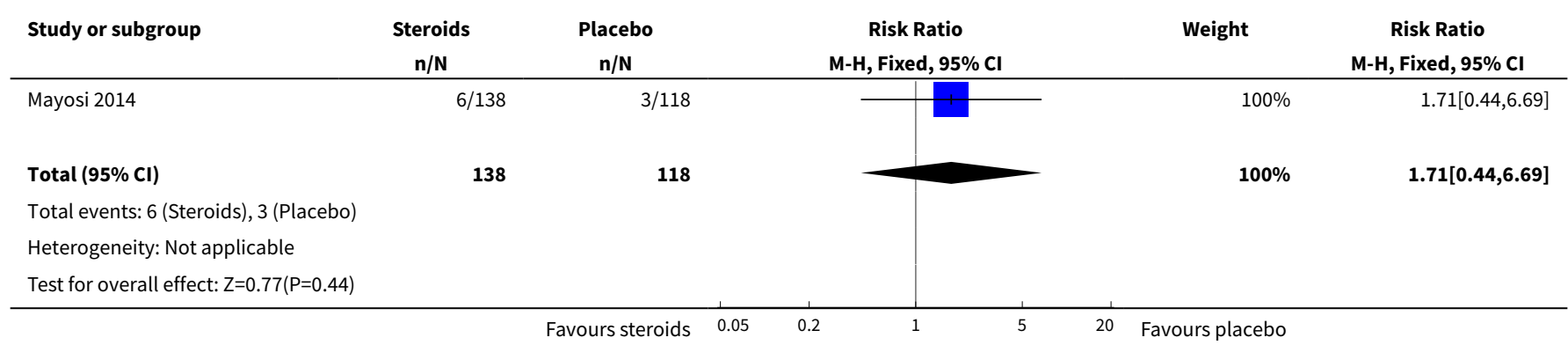

\section{Comparison 2. Steroids versus placebo in HIV-positive people}

\begin{tabular}{lllll}
\hline $\begin{array}{l}\text { Outcome or subgroup ti- } \\
\text { tle }\end{array}$ & No. of studies & $\begin{array}{l}\text { No. of partici- } \\
\text { pants }\end{array}$ & Statistical method & Effect size \\
\hline 1 Deaths from all causes & 3 & 575 & Risk Ratio (M-H, Random, 95\% Cl) & $0.91[0.34,2.42]$ \\
\hline 2 Deaths from pericarditis & 2 & 517 & Risk Ratio (M-H, Fixed, 95\% Cl) & $1.07[0.46,2.54]$ \\
\hline 3 Constrictive pericarditis & 3 & 575 & Risk Ratio (M-H, Fixed, 95\% Cl) & $0.55[0.26,1.16]$ \\
\hline $\begin{array}{l}\text { 4 Repeat pericardiocente- } \\
\text { sis }\end{array}$ & 2 & 517 & Risk Ratio (M-H, Fixed, 95\% Cl) & $1.02[0.89,1.18]$ \\
\hline 5 Cancer & 1 & 502 & Odds Ratio (M-H, Fixed, 95\% Cl) & $1.62[0.27,9.77]$ \\
\hline
\end{tabular}




\begin{tabular}{lllll}
\hline $\begin{array}{l}\text { Outcome or subgroup ti- } \\
\text { tle }\end{array}$ & No. of studies & $\begin{array}{l}\text { No. of partici- } \\
\text { pants }\end{array}$ & Statistical method & Effect size \\
\hline 6 Hospitalization & 1 & 502 & Risk Ratio (M-H, Fixed, 95\% Cl) & $0.80[0.59,1.09]$ \\
\hline 7 Pericardiectomy & 1 & 15 & Risk Ratio (M-H, Fixed, 95\% Cl) & $2.1[0.10,44.40]$ \\
\hline 8 Opportunistic infections & 2 & 517 & Risk Ratio (M-H, Fixed, 95\% Cl) & $0.95[0.61,1.48]$ \\
\hline
\end{tabular}

Analysis 2.1. Comparison 2 Steroids versus placebo in HIV-positive people, Outcome 1 Deaths from all causes.

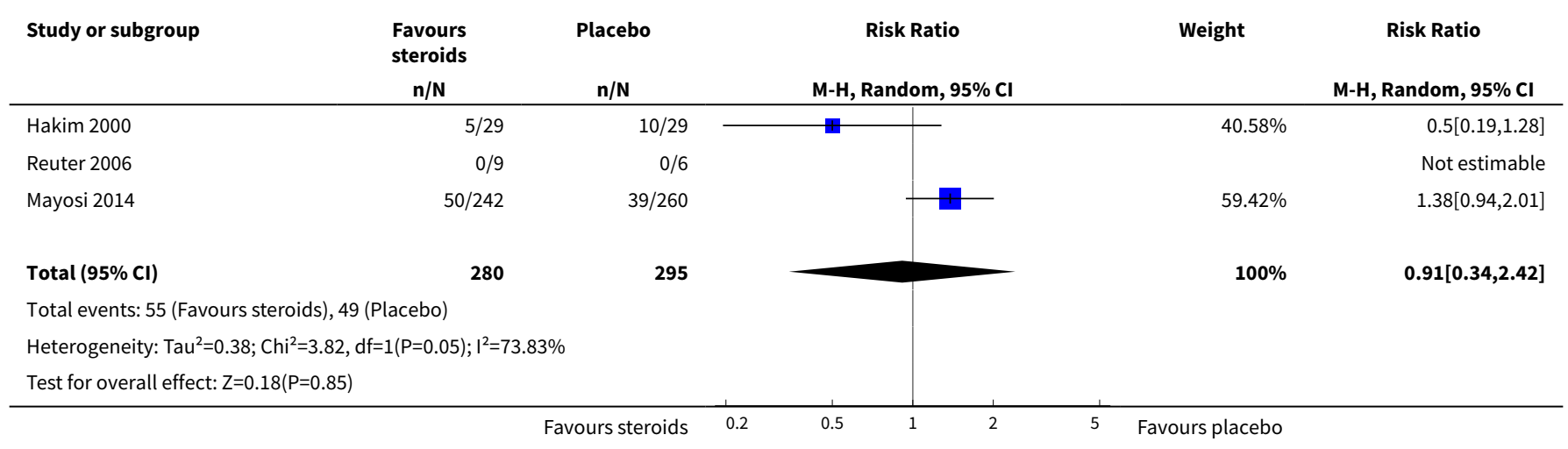

Analysis 2.2. Comparison 2 Steroids versus placebo in HIV-positive people, Outcome 2 Deaths from pericarditis.

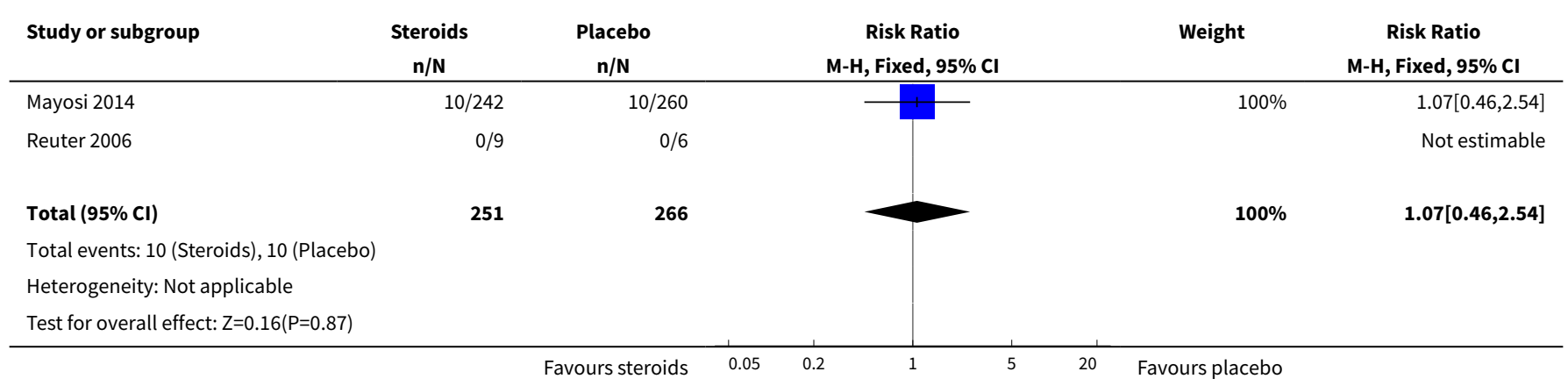

Analysis 2.3. Comparison 2 Steroids versus placebo in HIV-positive people, Outcome 3 Constrictive pericarditis.

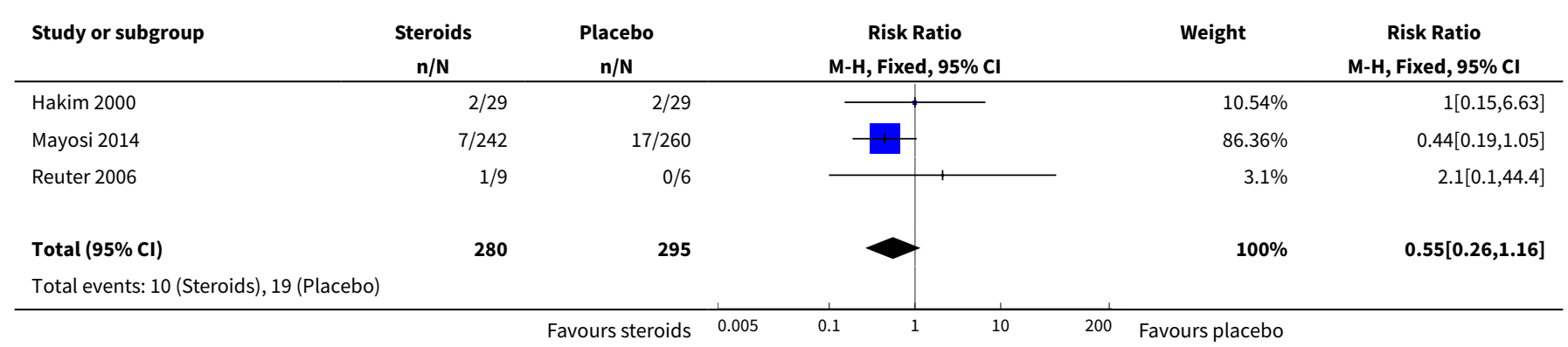




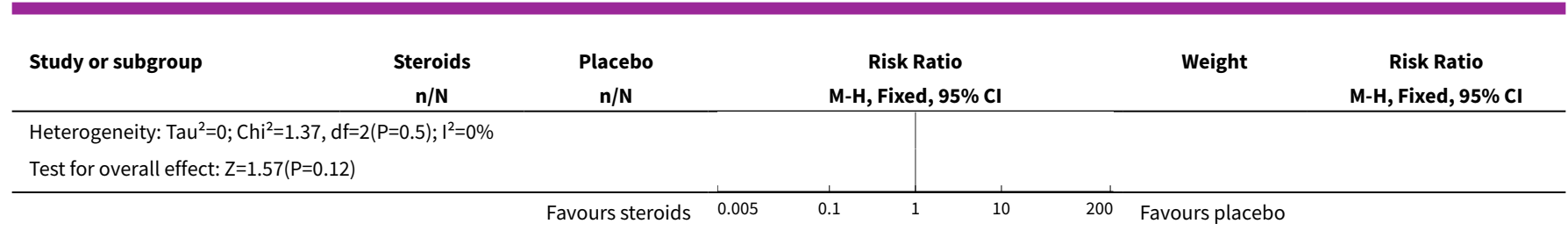

Analysis 2.4. Comparison 2 Steroids versus placebo in HIV-positive people, Outcome 4 Repeat pericardiocentesis.

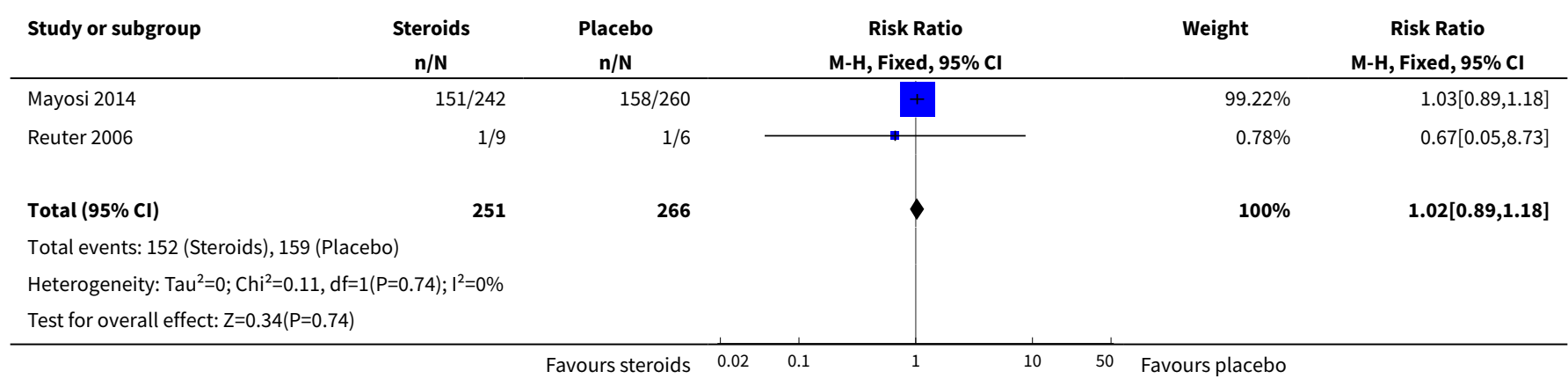

Analysis 2.5. Comparison 2 Steroids versus placebo in HIV-positive people, Outcome 5 Cancer.

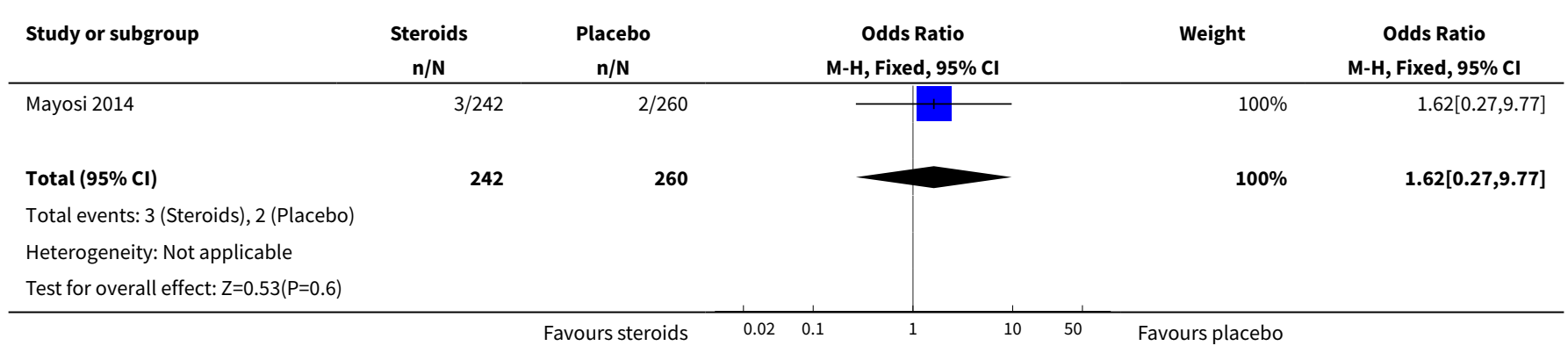

Analysis 2.6. Comparison 2 Steroids versus placebo in HIV-positive people, Outcome 6 Hospitalization.

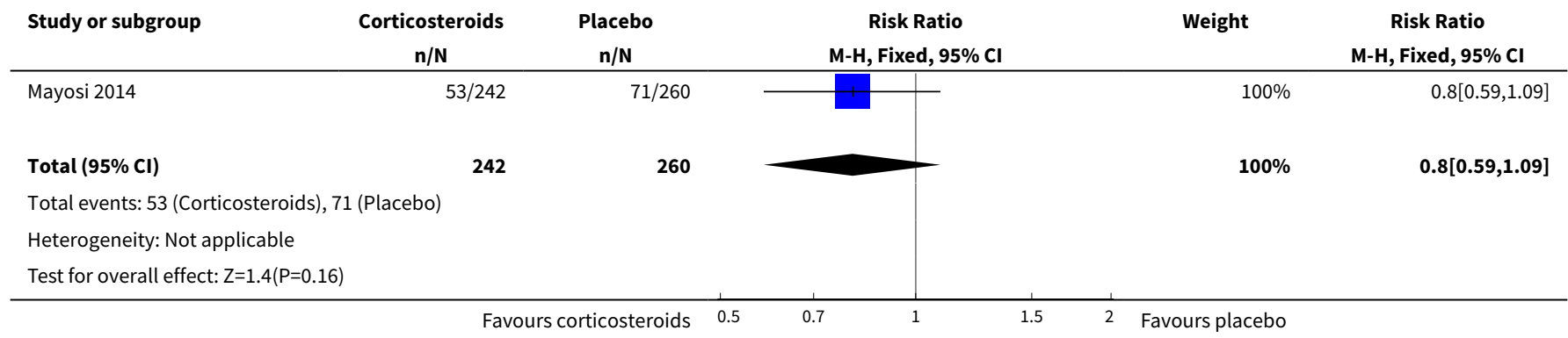


Analysis 2.7. Comparison 2 Steroids versus placebo in HIV-positive people, Outcome 7 Pericardiectomy.

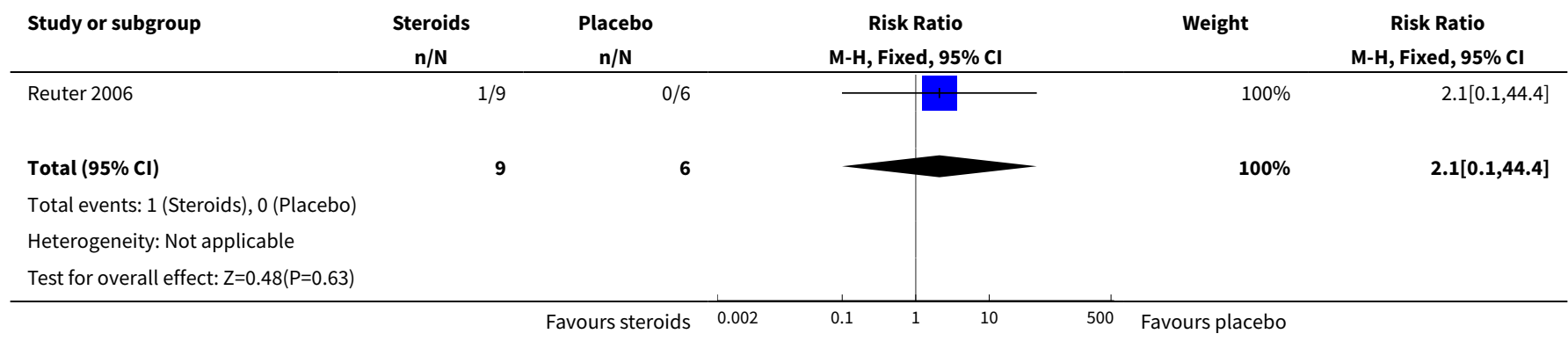

Analysis 2.8. Comparison 2 Steroids versus placebo in HIV-positive people, Outcome 8 Opportunistic infections.

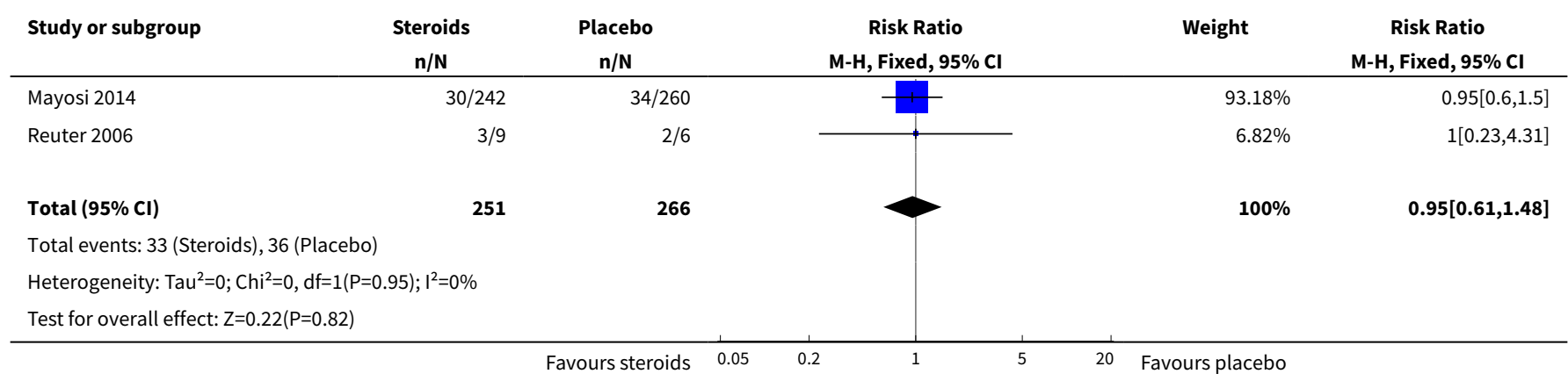

Comparison 3. Colchicine versus placebo in HIV-positive people

\begin{tabular}{lllll}
\hline Outcome or subgroup title & No. of studies & $\begin{array}{l}\text { No. of partici- } \\
\text { pants }\end{array}$ & Statistical method & Effect size \\
\hline 1 Death from all causes & 1 & Risk Ratio (M-H, Fixed, 95\% Cl) & Totals not selected \\
\hline 2 Constrictive pericarditis & 1 & Risk Ratio (M-H, Fixed, 95\% Cl) & Totals not selected \\
\hline
\end{tabular}

Analysis 3.1. Comparison 3 Colchicine versus placebo in HIV-positive people, Outcome 1 Death from all causes.

\begin{tabular}{|c|c|c|c|c|c|c|c|}
\hline & $\begin{array}{c}\text { Colchicine } \\
\mathrm{n} / \mathrm{N}\end{array}$ & $\begin{array}{c}\text { Placebo } \\
\mathrm{n} / \mathrm{N}\end{array}$ & \multicolumn{4}{|c|}{$\begin{array}{c}\text { Risk Ratio } \\
\text { M-H, Fixed, } 95 \% \text { CI }\end{array}$} & \multirow{2}{*}{$\begin{array}{c}\text { Risk Ratio } \\
\text { M-H, Fixed, 95\% Cl } \\
0.74[0.17,3.12]\end{array}$} \\
\hline Liebenberg 2016 & $3 / 19$ & $3 / 14$ & & 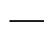 & 1 & - & \\
\hline
\end{tabular}


Analysis 3.2. Comparison 3 Colchicine versus placebo in HIV-positive people, Outcome 2 Constrictive pericarditis.

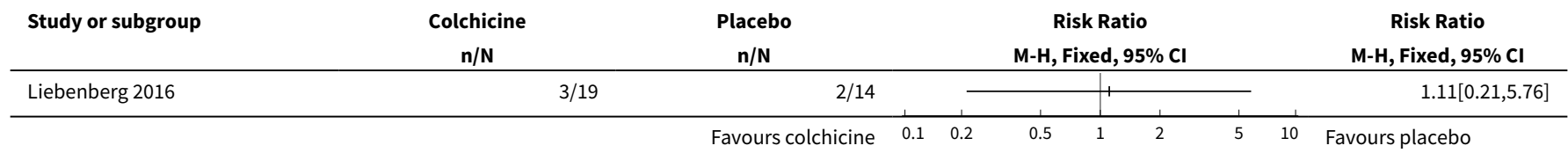

Comparison 4. M. indicus pranii versus placebo in HIV-negative people

\begin{tabular}{lllll}
\hline Outcome or subgroup title & No. of studies & $\begin{array}{l}\text { No. of partici- } \\
\text { pants }\end{array}$ & Statistical method & Effect size \\
\hline 1 Deaths from all causes & 1 & 190 & Risk Ratio (M-H, Fixed, 95\% Cl) & $1.07[0.56,2.03]$ \\
\hline 2 Deaths from pericarditis & 1 & 190 & Risk Ratio (M-H, Fixed, 95\% Cl) & $1.5[0.44,5.15]$ \\
\hline 3 Constrictive pericarditis & 1 & 190 & Risk Ratio (M-H, Fixed, 95\% Cl) & $1.56[0.71,3.42]$ \\
\hline 4 Repeat pericardiocentesis & 1 & 190 & Risk Ratio (M-H, Fixed, 95\% Cl) & $1.21[0.96,1.52]$ \\
\hline 5 Cancer & 1 & 190 & Odds Ratio (M-H, Fixed, 95\% Cl) & $3.03[0.12,75.37]$ \\
\hline 6 Hospitalization & 1 & 190 & Risk Ratio (M-H, Fixed, 95\% Cl) & $1.22[0.70,2.13]$ \\
\hline 7 Opportunistic infections & 1 & 190 & Risk Ratio (M-H, Fixed, 95\% Cl) & $0.67[0.11,3.90]$ \\
\hline
\end{tabular}

Analysis 4.1. Comparison $4 M$. indicus pranii versus placebo in HIV-negative people, Outcome 1 Deaths from all causes.

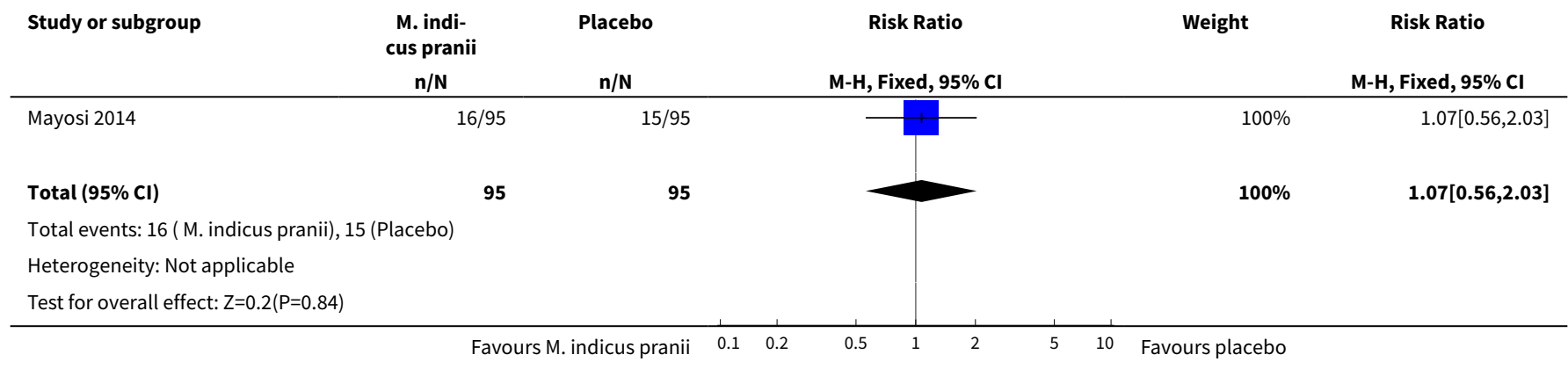

Analysis 4.2. Comparison $4 M$. indicus pranii versus placebo in HIV-negative people, Outcome 2 Deaths from pericarditis.

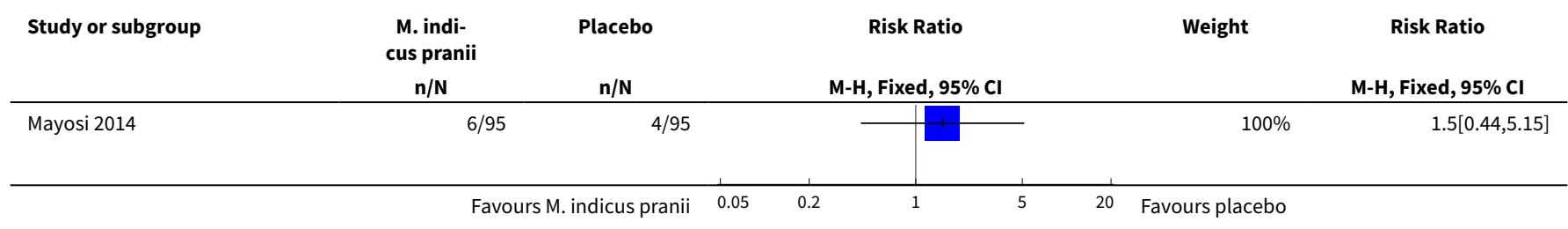




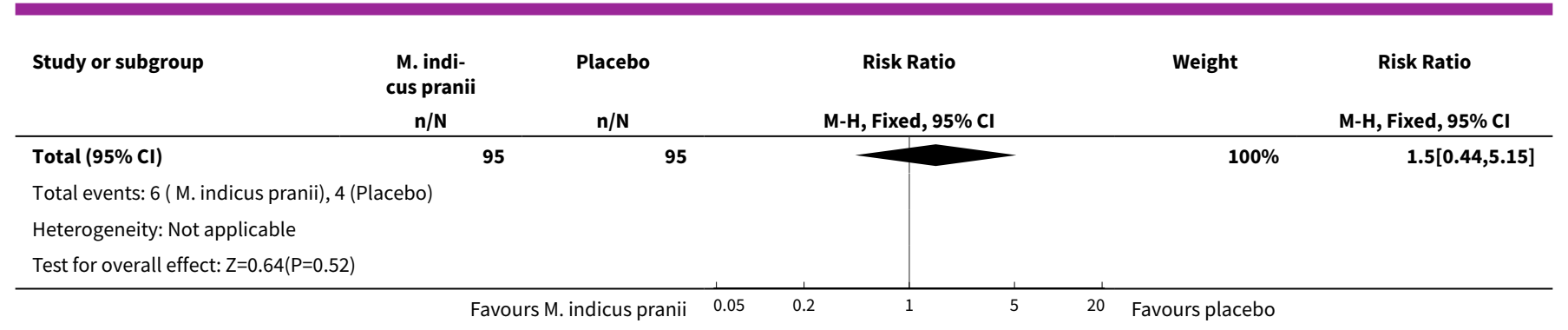

Analysis 4.3. Comparison $4 M$. indicus pranii versus placebo in HIV-negative people, Outcome 3 Constrictive pericarditis.

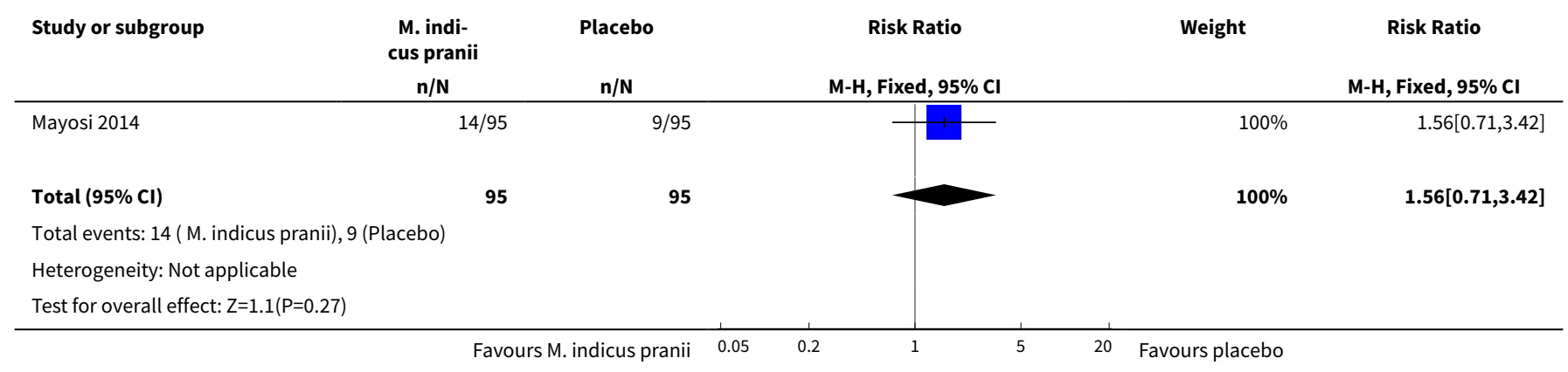

Analysis 4.4. Comparison $4 \mathrm{M}$. indicus pranii versus placebo in HIV-negative people, Outcome 4 Repeat pericardiocentesis.

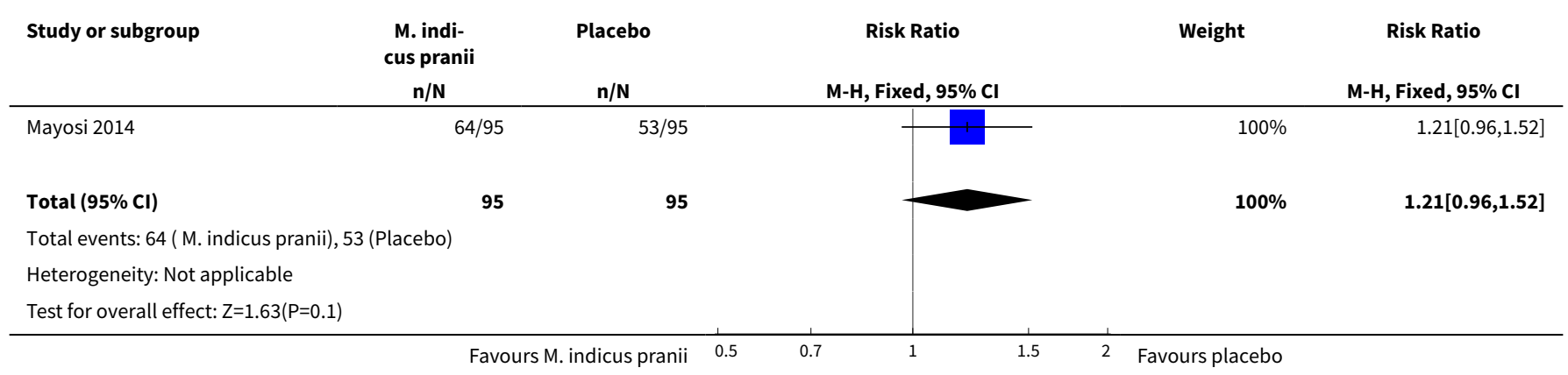

Analysis 4.5. Comparison 4 M. indicus pranii versus placebo in HIV-negative people, Outcome 5 Cancer.

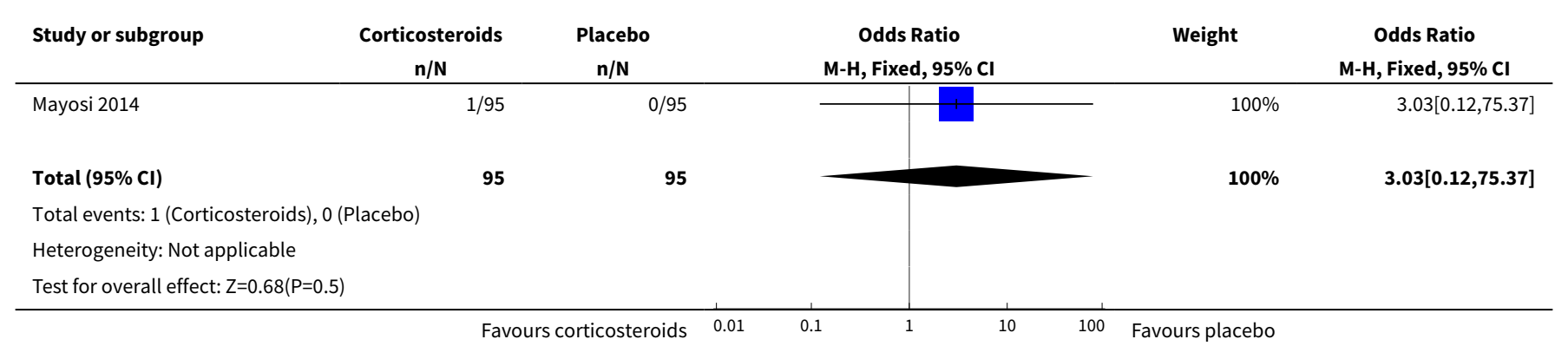




\section{Analysis 4.6. Comparison 4 M. indicus pranii versus placebo in HIV-negative people, Outcome 6 Hospitalization.}

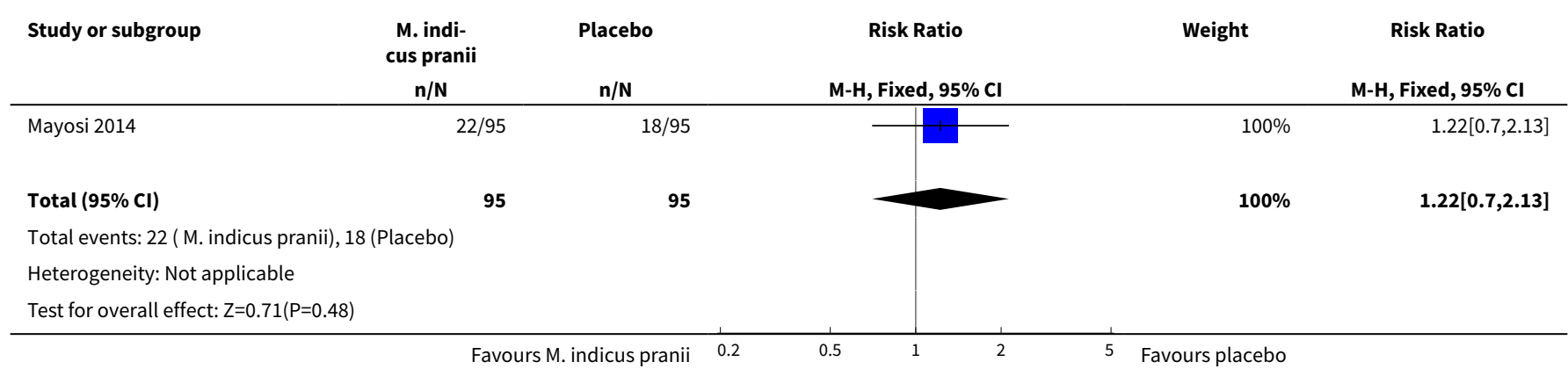

Analysis 4.7. Comparison $4 \mathrm{M}$. indicus pranii versus placebo in HIV-negative people, Outcome 7 Opportunistic infections.

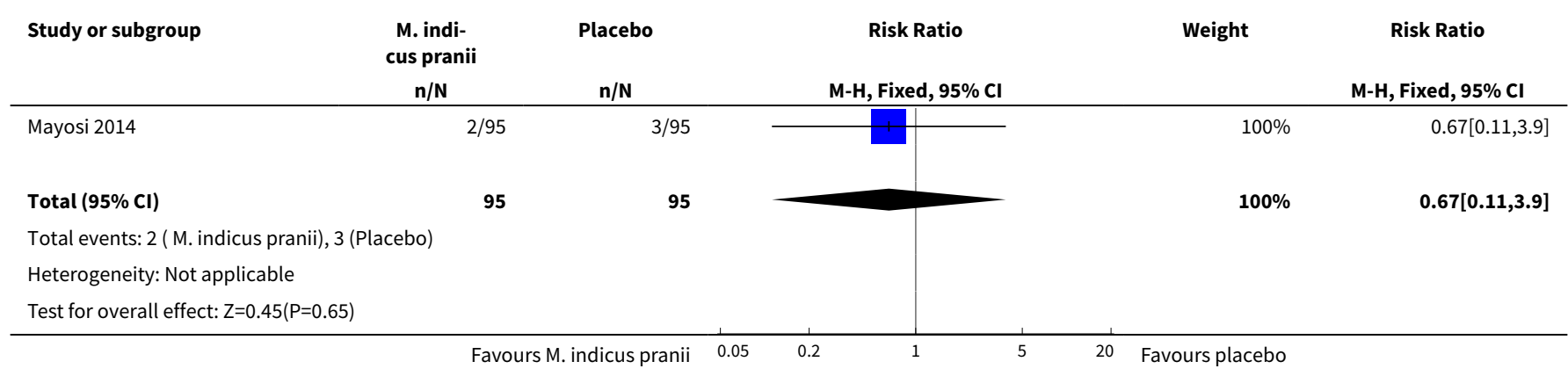

\section{Comparison 5. M. indicus pranii versus placebo in HIV-positive people}

\begin{tabular}{lllll}
\hline Outcome or subgroup title & No. of studies & $\begin{array}{l}\text { No. of partici- } \\
\text { pants }\end{array}$ & Statistical method & Effect size \\
\hline 1 Deaths from all causes & 1 & 414 & Risk Ratio (M-H, Fixed, 95\% Cl) & $1.05[0.69,1.60]$ \\
\hline 2 Deaths from pericarditis & 1 & 414 & Risk Ratio (M-H, Fixed, 95\% Cl) & $0.51[0.16,1.67]$ \\
\hline 3 Constrictive pericarditis & 1 & 414 & Risk Ratio (M-H, Fixed, 95\% Cl) & $0.73[0.33,1.60]$ \\
\hline 4 Repeat pericardiocentesis & 1 & Risk Ratio (M-H, Fixed, 95\% Cl) & $0.94[0.80,1.10]$ \\
\hline 5 Cancer & 1 & Odds Ratio (M-H, Fixed, 95\% Cl) & Totals not selected \\
\hline 6 Hospitalization & 1 & Risk Ratio (M-H, Fixed, 95\% Cl) & Totals not selected \\
\hline 7 Opportunistic infections & 1 & Risk Ratio (M-H, Fixed, 95\% Cl) & Totals not selected \\
\hline
\end{tabular}


Analysis 5.1. Comparison $5 \mathrm{M}$. indicus pranii versus placebo in HIV-positive people, Outcome 1 Deaths from all causes.

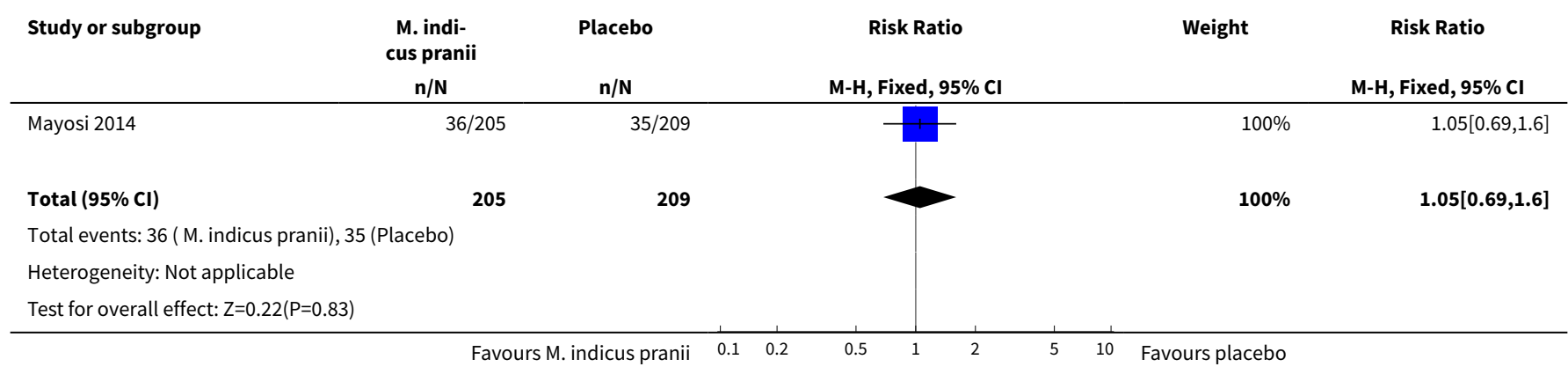

Analysis 5.2. Comparison 5 M. indicus pranii versus placebo in HIV-positive people, Outcome 2 Deaths from pericarditis.

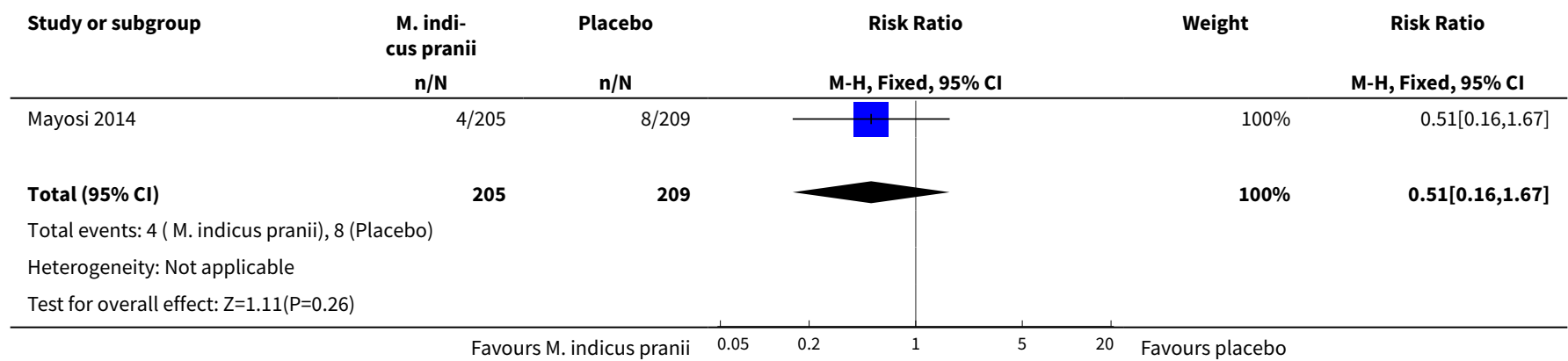

Analysis 5.3. Comparison $5 \mathrm{M}$. indicus pranii versus placebo in HIV-positive people, Outcome 3 Constrictive pericarditis.

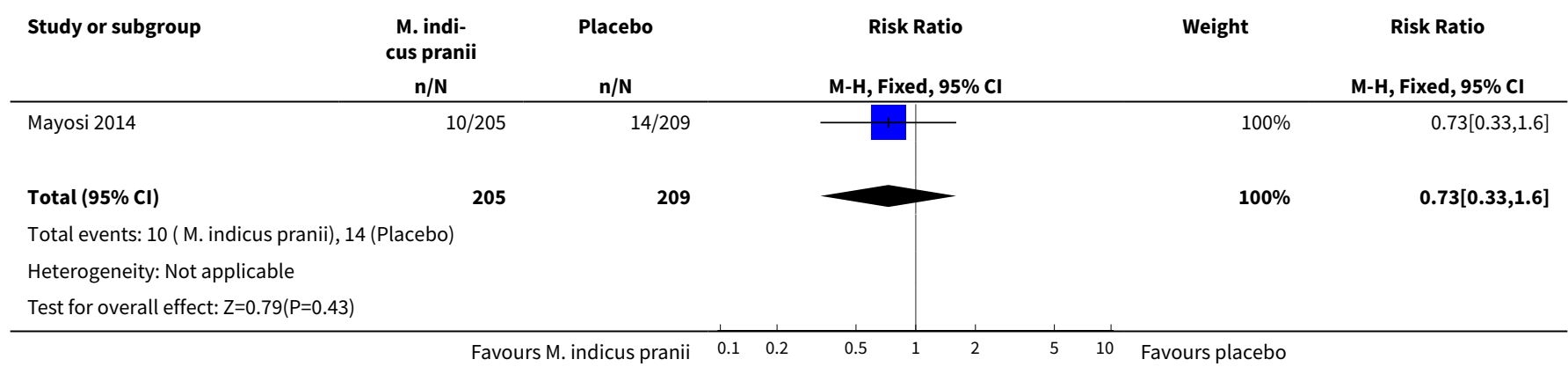


Analysis 5.4. Comparison 5 M. indicus pranii versus placebo in HIV-positive people, Outcome 4 Repeat pericardiocentesis.

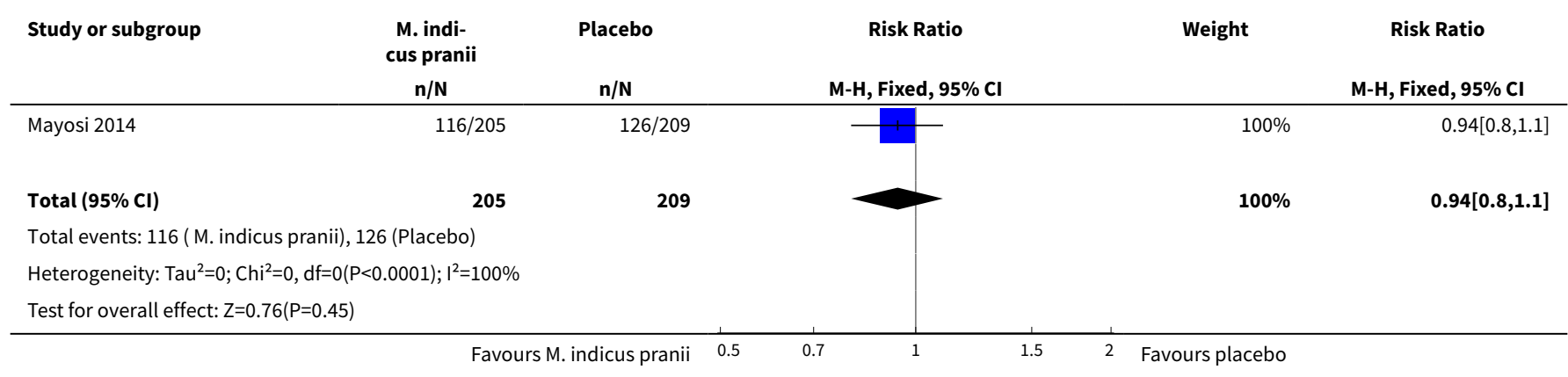

Analysis 5.5. Comparison 5 M. indicus pranii versus placebo in HIV-positive people, Outcome 5 Cancer.

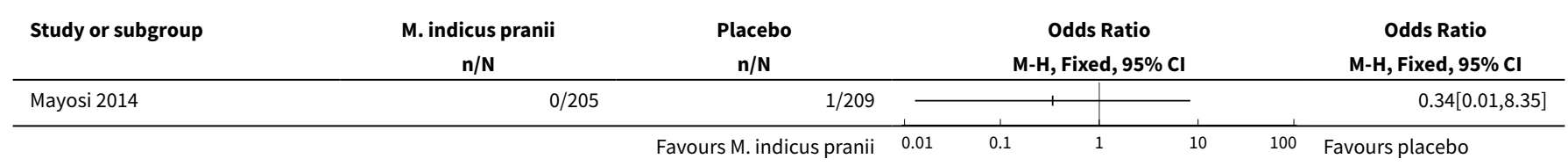

Analysis 5.6. Comparison 5 M. indicus pranii versus placebo in HIV-positive people, Outcome 6 Hospitalization.

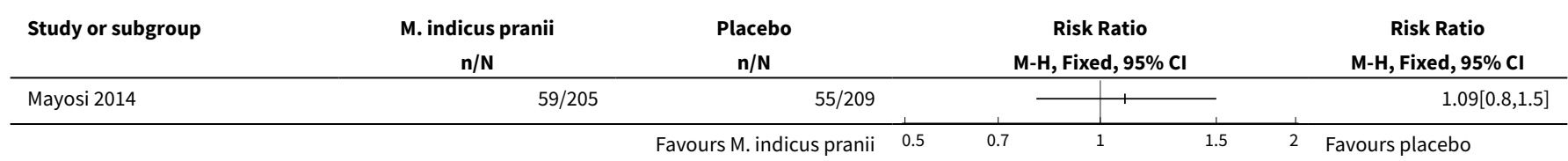

Analysis 5.7. Comparison 5 M. indicus pranii versus placebo in HIV-positive people, Outcome 7 Opportunistic infections.

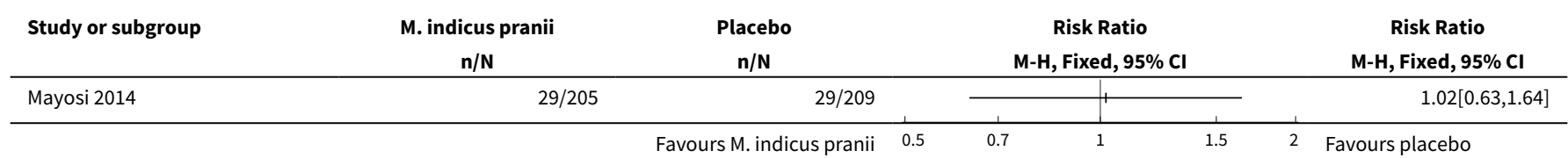

\section{Comparison 6. Surgical drainage versus no intervention in HIV-negative people}

\begin{tabular}{lllll}
\hline Outcome or subgroup title & No. of studies & $\begin{array}{l}\text { No. of partici- } \\
\text { pants }\end{array}$ & Statistical method & Effect size \\
\hline 1 Death from all causes & 1 & 122 & Risk Ratio (M-H, Fixed, 95\% Cl) & $1.07[0.52,2.20]$ \\
\hline 2 Death from pericarditis & 1 & 122 & Risk Ratio (M-H, Fixed, 95\% Cl) & $0.68[0.16,2.91]$ \\
\hline 3 Repeat pericardiocentesis & 1 & 122 & Risk Ratio (M-H, Fixed, 95\% Cl) & $0.23[0.07,0.76]$ \\
\hline \hline
\end{tabular}

Interventions for treating tuberculous pericarditis (Review) 


\begin{tabular}{lllll}
\hline Outcome or subgroup title & No. of studies & $\begin{array}{l}\text { No. of partici- } \\
\text { pants }\end{array}$ & Statistical method & Effect size \\
\hline 4 Pericardiectomy & 1 & 122 & Risk Ratio (M-H, Fixed, 95\% Cl) & $0.54[0.14,2.18]$ \\
\hline
\end{tabular}

Analysis 6.1. Comparison 6 Surgical drainage versus no intervention in HIV-negative people, Outcome 1 Death from all causes.

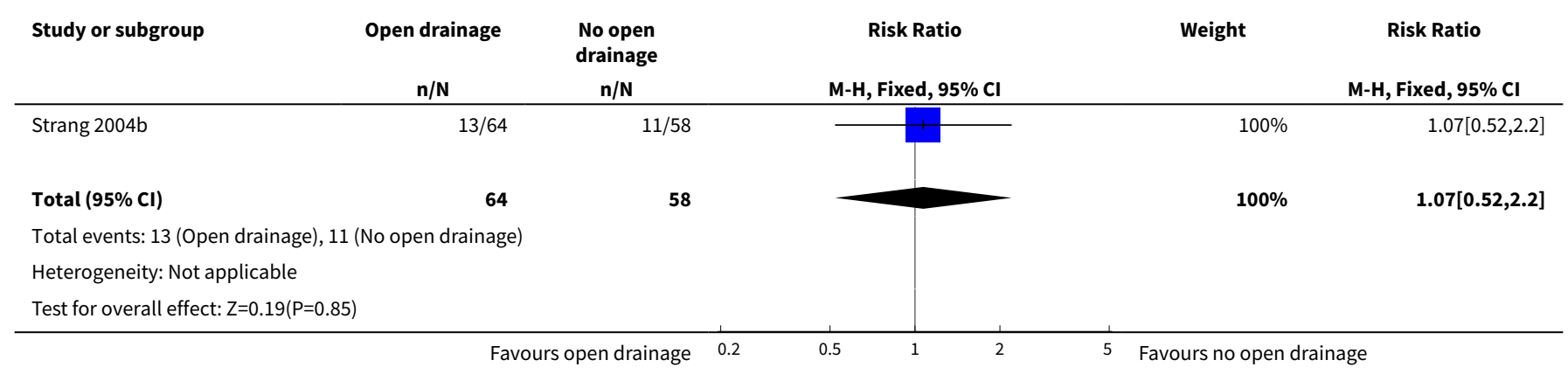

Analysis 6.2. Comparison 6 Surgical drainage versus no intervention in HIV-negative people, Outcome 2 Death from pericarditis.

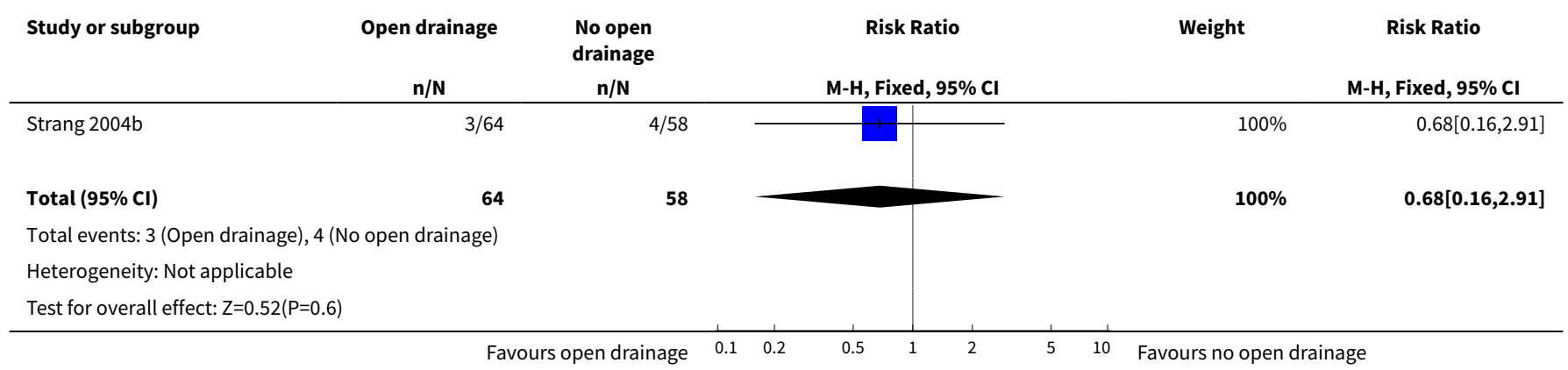

Analysis 6.3. Comparison 6 Surgical drainage versus no intervention in HIV-negative people, Outcome 3 Repeat pericardiocentesis.

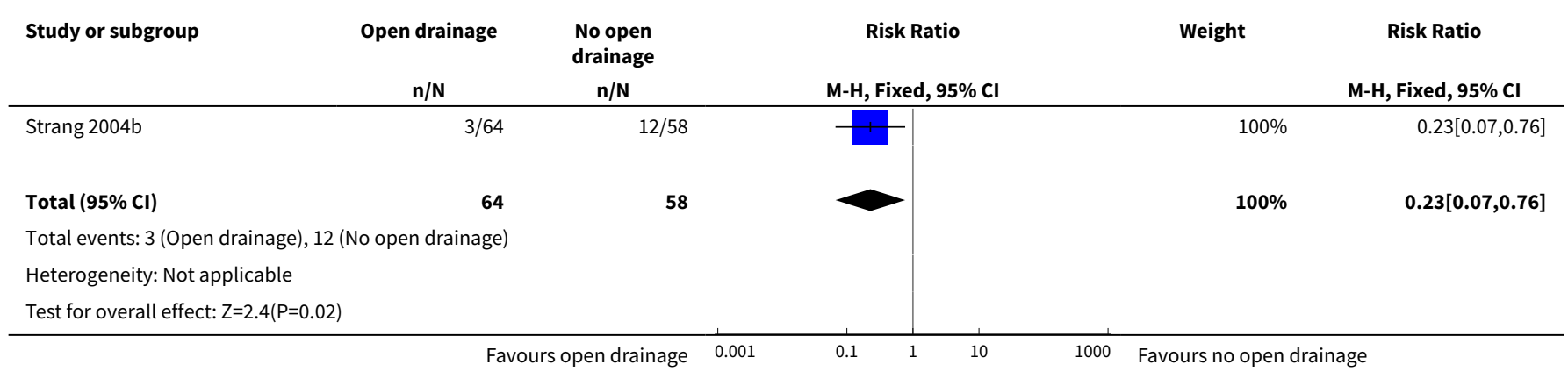


Analysis 6.4. Comparison 6 Surgical drainage versus no intervention in HIV-negative people, Outcome 4 Pericardiectomy.

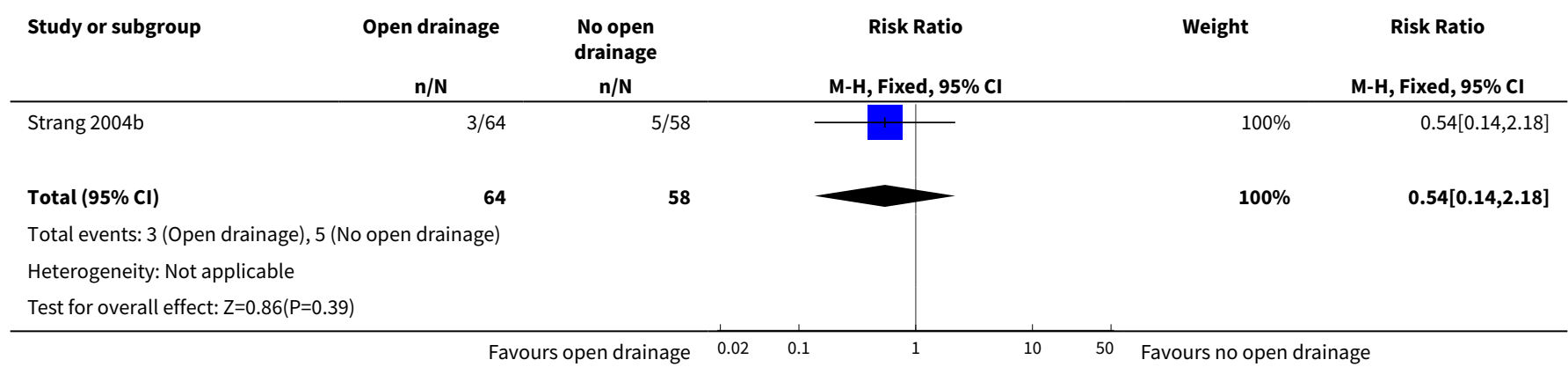




\begin{tabular}{|c|c|c|c|c|c|c|c|c|}
\hline \multirow{3}{*}{ 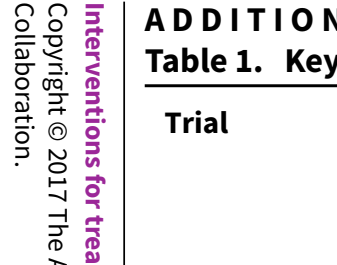 } & \multirow{3}{*}{ Location } & & & & & \multirow{3}{*}{ Intervention } & \multirow{3}{*}{ Outcomes } \\
\hline & & Participants & & & & & & \\
\hline & & Sample size & Age (years) & $\begin{array}{l}\text { HIV-posi- } \\
\text { tive }\end{array}$ & ART & Definite TB & & \\
\hline 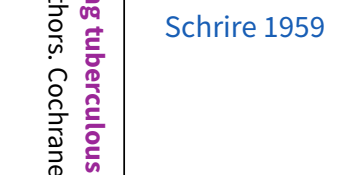 & South Africa & $\begin{array}{l}28 \text { people with } \\
\text { pericardial effu- } \\
\text { sion }\end{array}$ & Adults & None & $\mathrm{N} / \mathrm{A}$ & $\begin{array}{l}\text { Not report- } \\
\text { ed }\end{array}$ & $\begin{array}{l}\text { Cortisone (or pred- } \\
\text { nisolone) for several } \\
\text { weeks versus no corticos- } \\
\text { teroids }^{1}\end{array}$ & Pericardiectomy \\
\hline 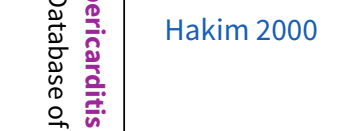 & Zimbabwe & $\begin{array}{l}58 \text { people with } \\
\text { pericardial effu- } \\
\text { sion }\end{array}$ & 18 to 55 & $100 \%$ & $0 \%$ & $38 \%$ & $\begin{array}{l}\text { Prednisolone for } 6 \text { weeks } \\
\text { versus placebo } 3\end{array}$ & $\begin{array}{l}\text { All-cause deaths; constric- } \\
\text { tive pericarditis. }\end{array}$ \\
\hline 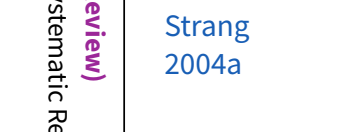 & South Africa & $\begin{array}{l}143 \text { with constric- } \\
\text { tive pericarditis }\end{array}$ & $\geq 5$ & $\begin{array}{l}\text { Assume } \\
\text { none }\end{array}$ & $\mathrm{N} / \mathrm{A}$ & $10 \%$ & $\begin{array}{l}\text { Prednisolone first } 11 \\
\text { weeks versus placebo } 2\end{array}$ & $\begin{array}{l}\text { All-cause deaths; deaths } \\
\text { from pericarditis; peri- } \\
\text { cardiectomy. }\end{array}$ \\
\hline 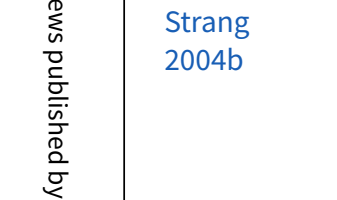 & South Africa & $\begin{array}{l}240 \text { people with } \\
\text { pericardial effu- } \\
\text { sion }\end{array}$ & $\geq 5$ & $\begin{array}{l}\text { Assume } \\
\text { none }\end{array}$ & $\mathrm{N} / \mathrm{A}$ & $60 \%$ & $\begin{array}{l}\text { (1) Prednisolone for } 11 \\
\text { weeks versus placebo } \\
\text { (2) Open surgical drainage } \\
\text { versus no drainage }\end{array}$ & $\begin{array}{l}\text { All-cause deaths; deaths } \\
\text { from pericarditis; repeat } \\
\text { pericardiocentesis; peri- } \\
\text { cardiectomy. }\end{array}$ \\
\hline Reuter 2006 & South Africa & $\begin{array}{l}40 \text { people with } \\
\text { pericardial effu- } \\
\text { sion }\end{array}$ & 17 to 66 & $38 \%$ & $0 \%$ & $\begin{array}{l}\text { Not report- } \\
\text { ed }\end{array}$ & $\begin{array}{l}\text { Prednisone versus no } \\
\text { prednisone }(5 \mathrm{~mL} \text { in- } \\
\text { trapericardial } 0.9 \% \\
\text { saline })^{4}\end{array}$ & $\begin{array}{l}\text { Repeat pericardiocente- } \\
\text { sis; pericardiectomy; con- } \\
\text { strictive pericarditis; infec- } \\
\text { tion. }\end{array}$ \\
\hline 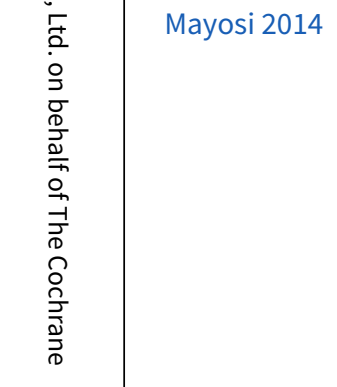 & $\begin{array}{l}\text { Kenya, } \\
\text { Malawi, } \\
\text { Mozam- } \\
\text { bique, Nige- } \\
\text { ria, Ugan- } \\
\text { da, Sier- } \\
\text { ra Leone, } \\
\text { South } \\
\text { Africa, and } \\
\text { Zimbabwe }\end{array}$ & $\begin{array}{l}1440 \text { with peri- } \\
\text { cardial effusion } \\
\text { (83\%) or constric- } \\
\text { tion }(17 \%)\end{array}$ & $\geq 18$ & $67 \%$ & $22 \%$ & $17 \%$ & $\begin{array}{l}\text { Prednisolone for } 6 \text { weeks } \\
\text { with or without } M \text {. indicus } \\
\text { pranii versus placebo } 5\end{array}$ & $\begin{array}{l}\text { All-cause deaths; deaths } \\
\text { from pericarditis; constric- } \\
\text { tive pericarditis; hospital- } \\
\text { ization; infection; cancer. }\end{array}$ \\
\hline
\end{tabular}

Abbreviations: ART: proportion of participants on antiretroviral therapy; HIV: human immunodeficiency virus; TB: tuberculosis. 
1 In the Schrire 1959 study, corticosteroid dose was given at a loading dose of $300 \mathrm{mg}$ daily followed by a maintenance dose of $100 \mathrm{mg}$ daily. At a later date, cortisone was substituted by prednisolone with a loading dose of $60 \mathrm{mg}$ daily and a maintenance dose of $20 \mathrm{mg}$ daily.

In the Strang 2004a and Strang 2004b , the trial authors stratified prednisolone dosing by age: The dose for children aged 5 to 9 years was $30 \mathrm{mg}$ daily for weeks 1 to $4 ; 15 \mathrm{mg}$ daily for weeks 5 to $8 ; 7.5 \mathrm{mg}$ daily for weeks 9 to 10 ; and $2.5 \mathrm{mg}$ daily for week 11 . For children 10 to 14 years, the dose was $45 \mathrm{mg}$ for weeks 1 to $4 ; 22.5 \mathrm{mg}$ for weeks 5 to $8 ; 7.5$ $\mathrm{mg}$ for weeks 9 to 10 ; and $2.5 \mathrm{mg}$ for week 11. The dose for adults was $60 \mathrm{mg}$ for the first 4 weeks; $30 \mathrm{mg}$ for weeks 5 to $8 ; 15 \mathrm{mg}$ for weeks 9 to 10 ; and $5 \mathrm{mg}$ for week 11 .

3 In the Hakim 2000 study, the dose of prednisolone was $60 \mathrm{mg}$ daily for the first week and was tapered thereafter by $10 \mathrm{mg}$ every week.

4In the Reuter 2006 study, the corticosteroid arm received oral prednisone plus intrapericardial placebo ( $5 \mathrm{~mL} 0.9 \%$ saline solution). Oral prednisone was started at $60 \mathrm{mg}$ per

day for 4 weeks, followed by $30 \mathrm{mg}$ per day for 4 weeks, $15 \mathrm{mg}$ per day for 2 weeks, and $5 \mathrm{mg}$ per day for 1 week. This study had 3 arms. We did not include the third trial arm, which received intrapericardial triamcinolone, in this current review.

5 Mayosi 2014 used prednisolone for six weeks at a dose of $120 \mathrm{mg}$ per day in the first week, $90 \mathrm{mg}$ per day in the second week, $60 \mathrm{mg}$ per day in the third week, $30 \mathrm{mg}$ per day in the fourth week, $15 \mathrm{mg}$ per day in the fifth week, and $5 \mathrm{mg}$ per day in the sixth week. 


\section{APPENDICES}

\section{Appendix 1. Detailed search strategy}

\begin{tabular}{|c|c|c|c|c|c|}
\hline Search set & CIDG SR ${ }^{1}$ & CENTRAL & MEDLINE2 2 & Embase $^{2}$ & LILACS 2 \\
\hline 1 & tuberculosis & Tuberculosis [MeSH] & Tuberculosis [MeSH] & Tuberculosis [MeSH] & tuberculosis \\
\hline 2 & Pericard* & Tuberculosis ti, ab & Tuberculosis ti, ab & Tuberculosis ti, ab & Pericard* ${ }^{\star}$ \\
\hline 3 & heart & 1 or 2 & 1 or 2 & 1 or 2 & heart \\
\hline 4 & 2 or 3 & $\begin{array}{l}\text { heart or cardi* or peri- } \\
\text { card }^{\star} t i, a b\end{array}$ & $\begin{array}{l}\text { heart or cardi }{ }^{\star} \text { or peri- } \\
\operatorname{card}^{\star} t i, a b\end{array}$ & $\begin{array}{l}\text { heart or cardi* or peri- } \\
\operatorname{card}^{\star} t i, a b\end{array}$ & 2 or 3 \\
\hline 5 & 1 and 4 & 3 and 4 & 3 and 4 & 3 and 4 & 1 and 4 \\
\hline 6 & - & $\begin{array}{l}\text { "Pericarditis, Tubercu- } \\
\text { lous"[Mesh] }\end{array}$ & $\begin{array}{l}\text { "Pericarditis, Tubercu- } \\
\text { lous"[Mesh] }\end{array}$ & $\begin{array}{l}\text { tuberculous pericarditis } \\
\text { [Emtree] }\end{array}$ & - \\
\hline 7 & - & 5 or 6 & 5 or 6 & 5 or 6 & - \\
\hline
\end{tabular}

${ }^{1}$ Cochrane Infectious Diseases Group Specialized Register.

2Search terms used in combination with the search strategy for retrieving trials developed by the Cochrane Collaboration (Lefebvre 2011).

\section{WHAT'S NEW}

\begin{tabular}{lll}
\hline Date & Event & Description \\
\hline 12 September 2017 & $\begin{array}{l}\text { New citation required and conclusions } \\
\text { have changed }\end{array}$ & $\begin{array}{l}\text { We updated this review, added new authors, and included new } \\
\text { trials. The conclusion of this review changed compared to the } \\
\text { previous published version. }\end{array}$ \\
\hline 12 September 2017 & New search has been performed & The author team updated this review. \\
\hline
\end{tabular}

\section{H I S T O R Y}

Protocol first published: Issue 4, 1997

Review first published: Issue 3, 1998

\begin{tabular}{lll}
\hline Date & Event & Description \\
\hline 10 November 2008 & Amended & Converted to new review format with minor editing. \\
\hline 12 January 2005 & Amended & New studies found but not yet included or excluded. \\
\hline 18 May 2003 & Amended & Minor update \\
\hline 17 June 2002 & $\begin{array}{l}\text { New citation required and conclusions } \\
\text { have changed }\end{array}$ & Substantive amendment. Issue 4, 2002: Hakim 2000 added. \\
\hline
\end{tabular}




$\begin{array}{lll}\text { Date Event Description } & \text { Den }\end{array}$

New studies found and included or excluded

\section{CONTRIBUTIONS OF AUTHORS}

Charles S Wiysonge and Bongani M Mayosi led the preparation of the current version of the review, with important intellectual inputs from all co-authors.

Charles S Wiysonge and Bongani M Mayosi were involved in all stages of the review.

Dumisani Majombozi was involved in screening of searches, study selection, data extraction, and verification of data analysis.

Freedom Gumedze provided the data on the Mayosi 2014 trial and verified the data analysis.

Mpiko Ntsekhe, Lehana Thabane, Jimmy Volmink, and Shaheen Pandie read and provided important input into successive drafts of the review.

All review authors read and approved the final version of the review.

\section{DECLARATIONSOF INTEREST}

Mpiko Ntsekhe, Lehana Thabane, Freedom Gumedze, Shaheen Pandie, and Bongani M Mayosi were investigators in an included study (Mayosi 2014). Jimmy Volmink was a member of the Data Safety and Monitoring Committee for the same study. However, two review authors (CSW and DM) who were not involved in this trial independently extracted the data for this study, which were verified by Paul Garner, David Sinclair, Hannah Ryan, and Maya Tickell-Painter.

Charles S Wiysonge, Mpiko Ntsekhe, Jimmy Volmink, and Bongani M Mayosi were co-authors of a study assessed and excluded from the review (Wiysonge 2008). A review author (DM) who was not involved in this study initially assessed the eligibility of this study.

\section{SOURCES OF SUPPORT}

\section{Internal sources}

- Cardiac Clinic Research Fund, University of Cape Town, South Africa.

- Stellenbosch University, South Africa.

- South African Medical Research Council, South Africa.

- Liverpool School of Tropical Medicine, UK.

\section{External sources}

- Department for International Development, UK.

Grant: 5242

\section{DIFFERENCES BETWEEN PROTOCOL AND REVIEW}

There are differences between the authors of the protocol and the current version of the review. The protocol had three authors (Bongani Mayosi, Jimmy Volmink, and Patrick Commerford), while this review update has eight review authors.

The protocol set out to assess the effects of only four interventions (six-month antituberculous drug regimens compared with regimens of nine months or more, corticosteroids, pericardial drainage, and pericardiectomy). However, in this review we have assessed the effects of any intervention used to treat tuberculous pericarditis.

The protocol did not report cancer as a potential outcome, but we have reported outcome data on cancer in this version of the review.

\section{IN DEX TERMS}

\section{Medical Subject Headings (MeSH)}

Adrenal Cortex Hormones [therapeutic use]; Antitubercular Agents [therapeutic use]; Cause of Death; Colchicine [therapeutic use]; Drainage; HIV Seronegativity; HIV Seropositivity [drug therapy]; Immunotherapy; Pericardiectomy; Pericarditis, Tuberculous [complications] [drug therapy] [mortality] [*surgery]; Pericardium [surgery]; Randomized Controlled Trials as Topic

\section{MeSH check words}

Humans 